\title{
Uma Ferramenta Para Avaliação Semi-Automática de Programas Exercício
}

Edson Noboru Yamada

DISSERTAÇÃO DE MESTRADO APRESENTADA AO INSTITUTO DE MATEMÁTICA E ESTATÍSTICA

DA

UNIVERSIDADE DE SÃO PAULO

Curso: Mestrado em Matemática Aplicada Área de Concentração: Ciência da Computação Orientadora: Profa. Dra. Dilma Menezes da Silva

São Paulo, 1997.

O aluno recebeu apoio do CNPq. 


\title{
Uma Ferramenta Para Avaliação Semi-Automática de Programas Exercício
}

\author{
Este exemplar corresponde à redação final \\ da dissertação devidamente corrigida e \\ defendida por Edson Noboru Yamada \\ e aprovada pela comissão julgadora.
}

São Paulo, 24 de agosto de 1997.

Banca Examinadora:

- Profa. Dra. Dilma Menezes da Silva (Presidente) - DCC-IME-USP

- Prof. Dr Markus Endler - DCC-IME-USP

- Profa. Dra. Eliane Martins - IC-Unicamp 
Pra mamãe e pra Simone. 


\section{Agradecimentos}

Á minha mãe, principal incentivadora de meus estudos.

À Dilma, pela amizade, por ter acreditado neste trabalho desde o rascunho do projeto e por todo o trabalho de orientação, que incluiu, dentre outras coisas, ter lido e relido cada linha deste texto $\Omega\left(\mathrm{n}^{2}\right)$ vezes.

Ao Arnaldo, por ter sido o meu orientador de programa e também por todos os galhos que me quebrou.

Ao Arnaldo, Markus e Reverbel, pelas sugestões.

Ao Yoshi, pelas suas brilhantes aulas de Análise de Algoritmos - não fossem elas, talvez tivesse desistido do programa em seus primeiros meses.

Ao Armando, Bira, Chiba e Humberto, que me deram coragem para tomar a decisão (difícil) de interromper a minha carreira na indústria para voltar à academia.

A todos os colegas da Opus Software, pela compreensão, interesse e apoio à realização deste trabalho.

Aos amigos que fiz no IME, que tornaram a caminhada bem mais doce e humana.

À Nami e ao Daniel Panário, por terem assinado as cartas de recomendação para o meu ingresso no mestrado.

A todo o DCC, pela privilegiadíssima formação que me deu nesses 6 anos e meio de convívio.

À Simone, por ser muito mais que minha companheira nesses anos todos.

Muito obrigado! : 


\title{
Resumo
}

Os programas exercício exercem papel fundamental no aprendizado de programação de computadores durante as disciplinas introdutorias de computação ministradas na universidade - são através deles que os alunos têm oportunidade de fixar e colocar em prática os conhecimentos teóricos e conceituais adquiridos em aula.

O processo de avaliação e correção desses programas, entretanto, normalmente têm sido feito quase que de forma totalmente manual, sendo uma atividade geralmente demorada e nem sempre agradável. Em muitos casos, o processo restringe-se a avaliar a corretude da saída dos programas, ignorando-se as questões relacionadas a qualidade de programação.

O objetivo deste trabalho é pesquisar sobre as possíveis técnicas de automação deste processo - em particular, a aplicação de algumas tecnologias disponíveis em reengenharia de software e métricas de software.

Também apresentamos o projeto e implementação de uma ferramenta que incorpora essas tecnologias, além de um estudo de caso sobre seu uso.

Concluímos que a ferramenta se mostrou muito útil na tarefa de entendimento e inspeção de programas.

\begin{abstract}
Programming assignments play a special role in the learning process present at undergrad level introductory computing courses - it is through them that the students have the opportunity to practice and consolidate the theoretical and conceptual knowledge acquired in classroom.

The grading process for these programs, however, is usually done manually, being an time consuming activity and, generally, unpleasant. In many cases, the process focuses solely on the correctness of the program output, leaving out concerns related to the quality of the solution.

The goal of this work is to explore some techniques in the automation of this process - in particular, on application of some technologies available to software reengineering and software metrics.

We also present the design and implementation of a tool that incoporates these technologies, as well as a case study of its usage.

We concluded that the tool is very effective in supporting program understanding and inspection.
\end{abstract}




\section{Índice Geral}

ÍNDICE GERAL ......................................................................................................................II

ÍNDICE DE QUADROS E FIGURAS....................................................................................... IV

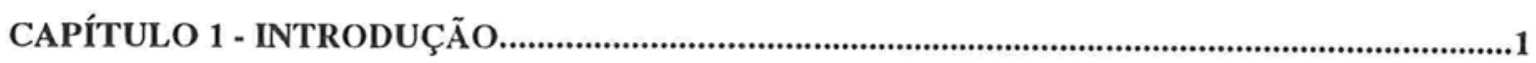

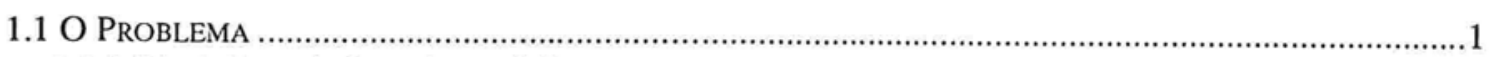

1.1.1 Disciplinas de Introdução à Programação e os Programas Exercício ..........................................

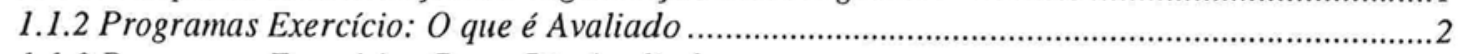

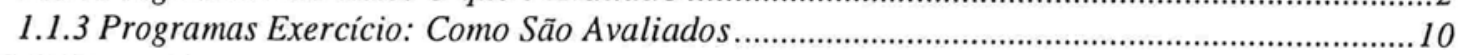

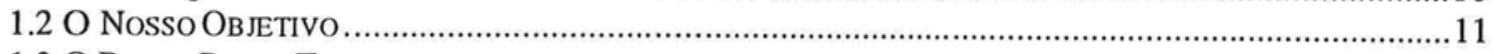

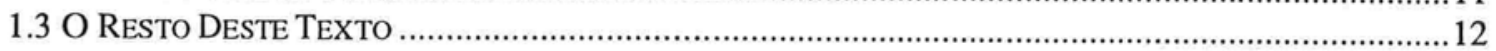

CAPÍTULO 2 - ENGENHARIA REVERSA, REESTRUTURAÇÃO E REENGENHARIA..............14

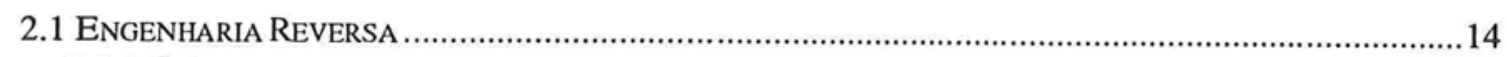

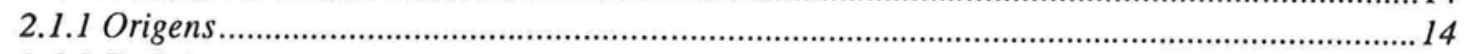

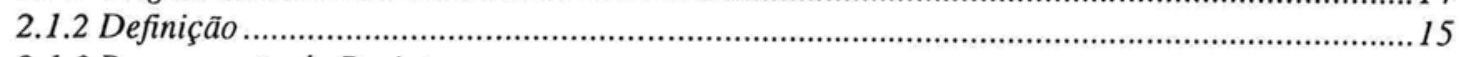

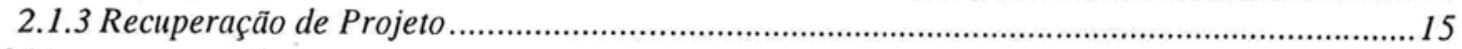

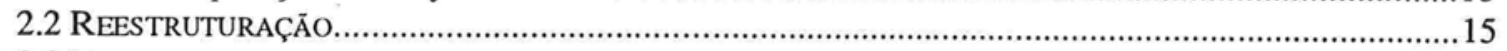

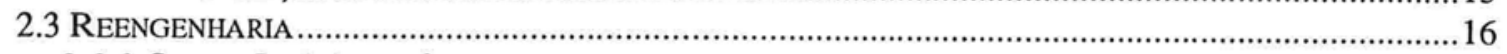

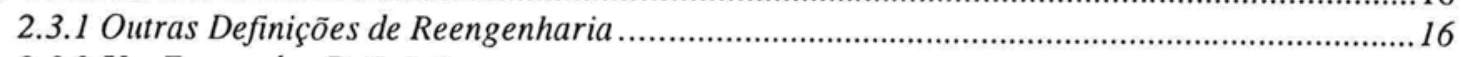

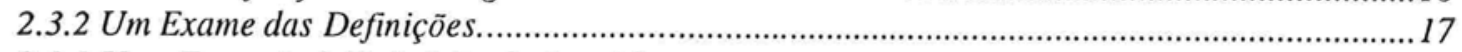

2.3.3 Uma Extensão d̀ Definição de Arnold ..................................................................................17

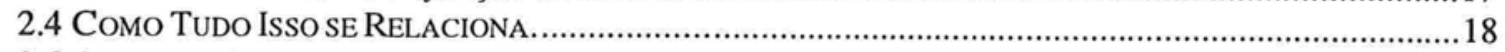

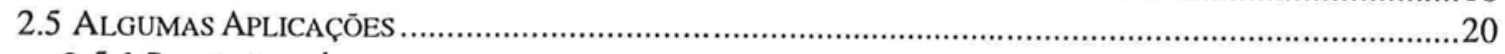

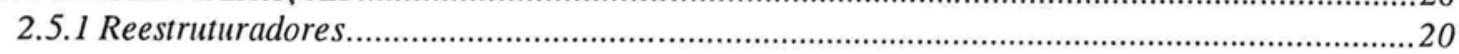

2.5.2 Atualização de Documentaçäo ...............................................................................................22

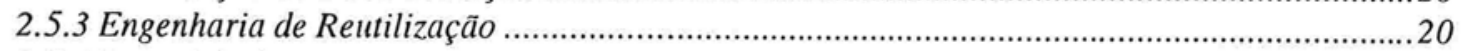

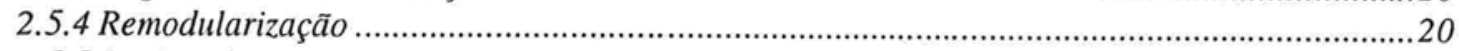

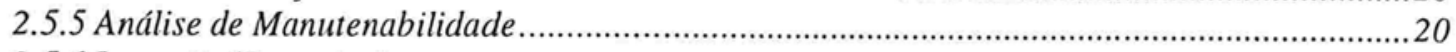

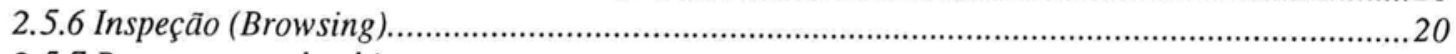

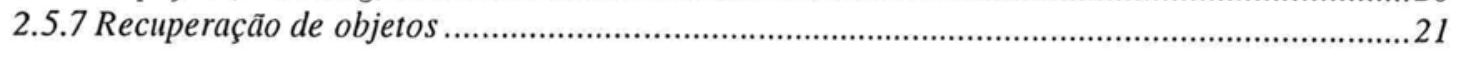

CAPÍTULO 3 - ALGUMAS FERRAMENTAS PARA REENGENHARIA DE SOFTWARE ...........22

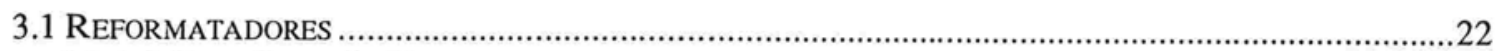

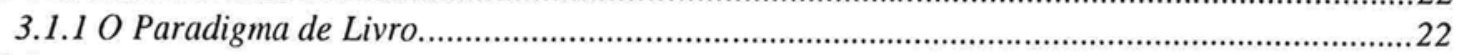

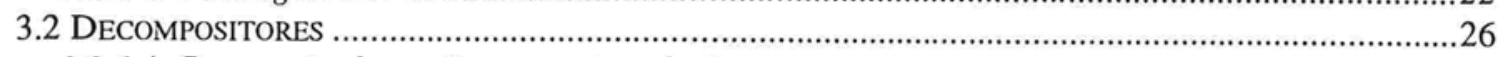

3.2.1 A Construção de um Decompositor de Programas.................................................................26

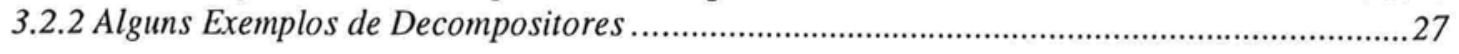

CAPÍTULO 4 - MÉTRICAS DE SOFTWARE ..........................................................................33

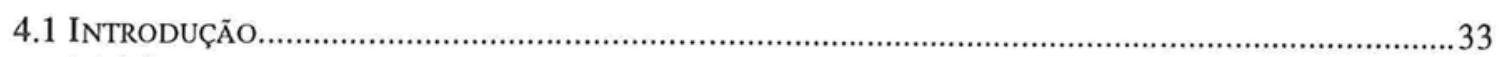

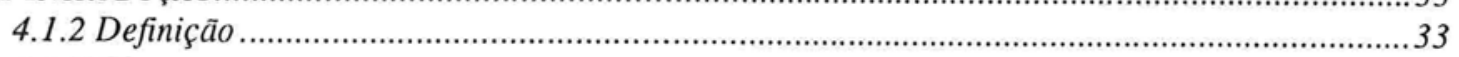

4.1.3 Classes

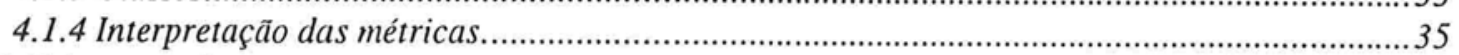

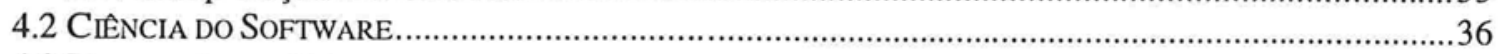

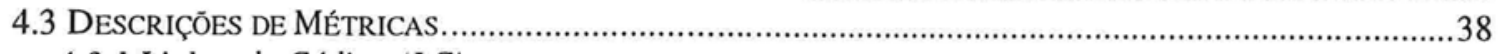

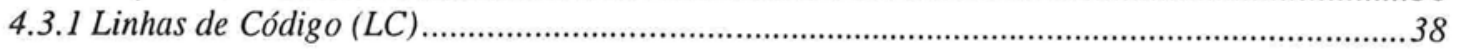




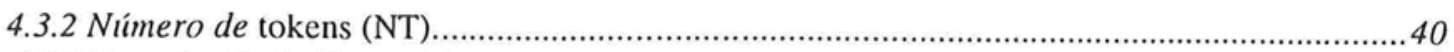

4.3.3 Complexidade Ciclomática ............................................................................................

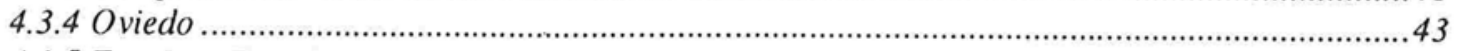

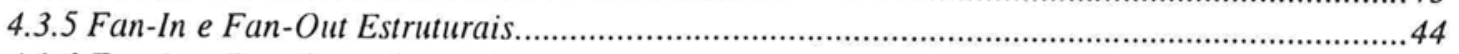

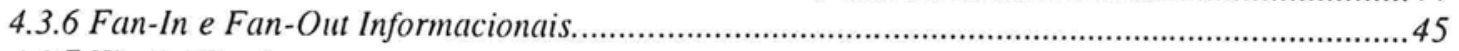

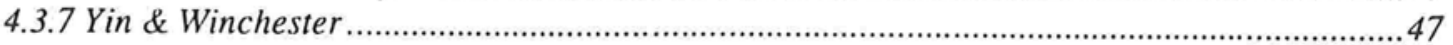

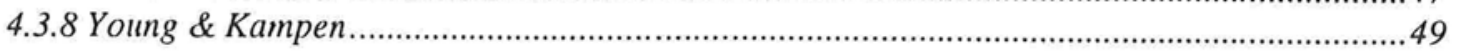

CAPÍTULO 5 - O AVASAP - AVALIADOR SEMI-AUTOMÁTICO DE PROGRAMAS ................50

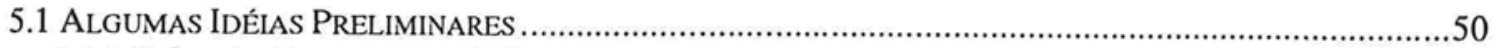

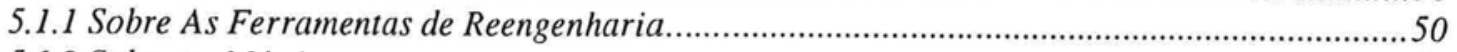

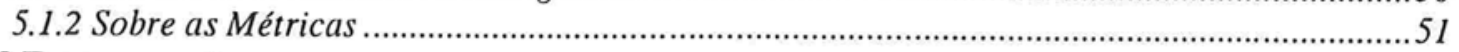

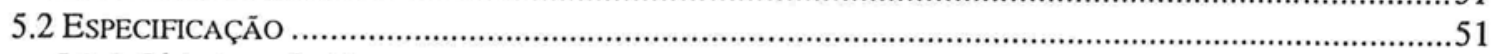

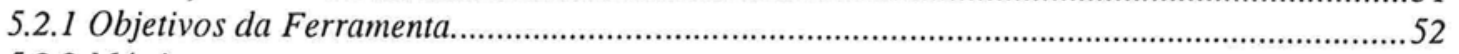

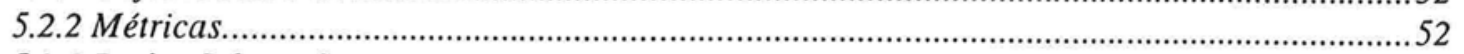

5.2.3 Dados Sobre Objetos e Estrutura do Programa....................................................................55

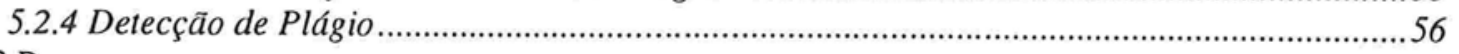

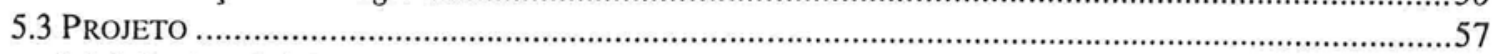

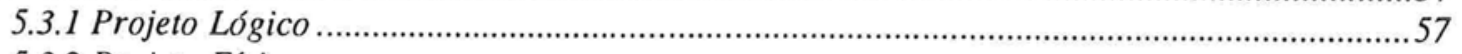

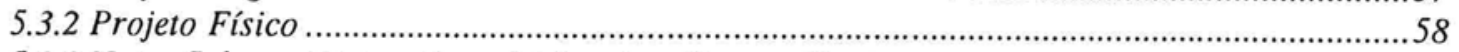

5.3.3 Notas Sobre o Dialeto Pascal Adotado e Termos Usados ............................................................61

5.3.4 O Verificador de Consistência ............................................................................................62

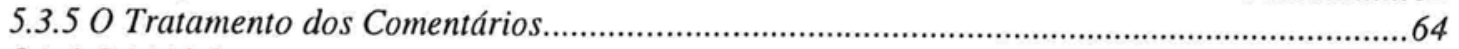

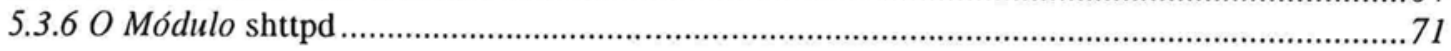

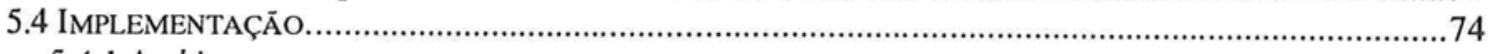

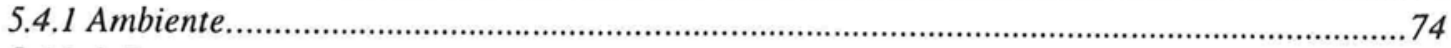

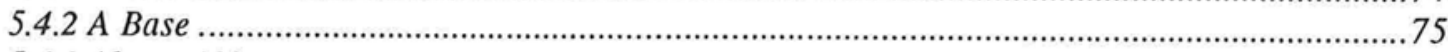

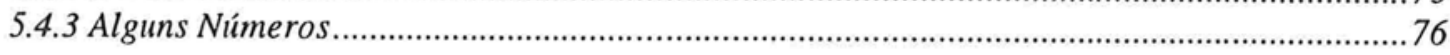

CAPÍTULO 6 6 EXPERIÊNCIAS COM O AVASAP.........................................................................77

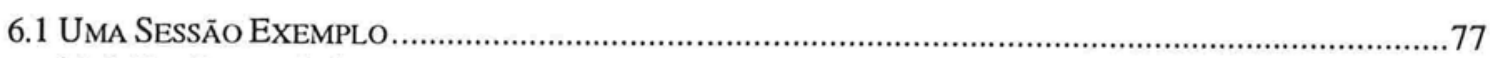

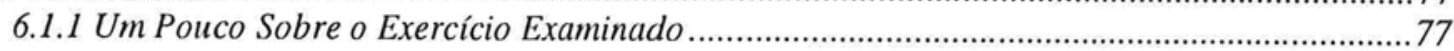

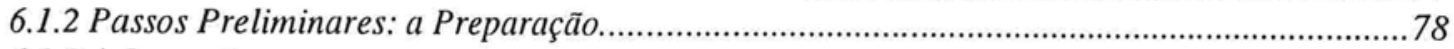

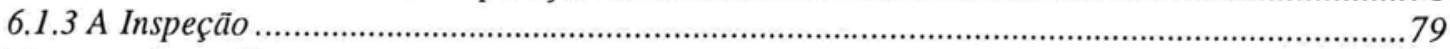

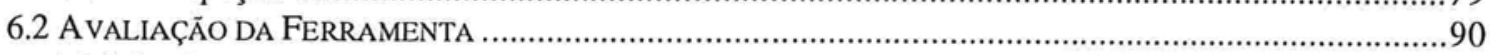

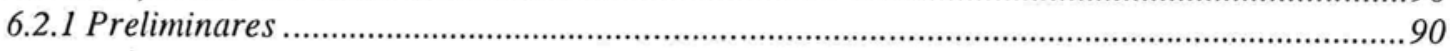

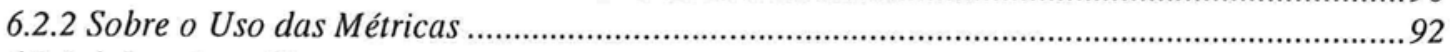

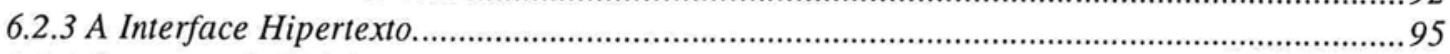

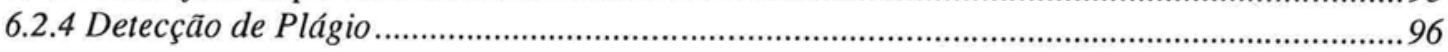

CAPÍTULO 7 - CONCLUSÕES.....................................................................................................97

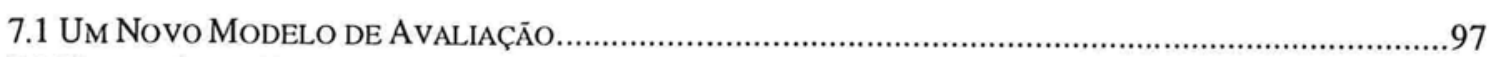

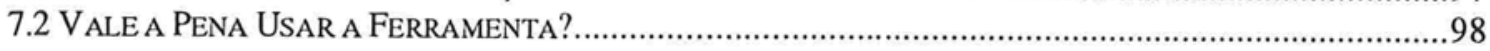

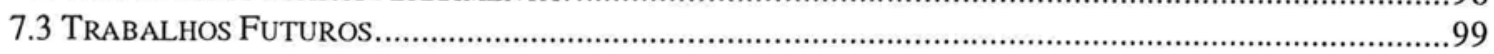

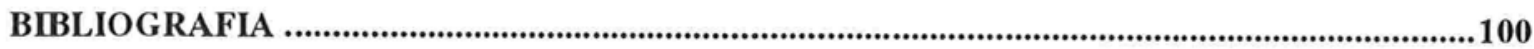




\section{Índice de Quadros e Figuras}

Quadro 1 - Características da Qualidade de SofTWARE SEGUNDo a ISO/IEC 9126 [TAR+95]...........3

QUADRo 2 - SUBCARACTERÍSTICAS DA QUALIDADE DE SOFTWARE SEGUNDO ISO/IEC 9126 [TAR+95]........4

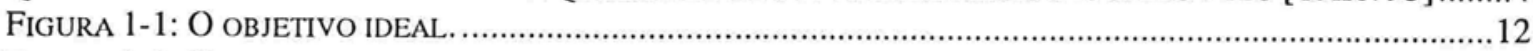

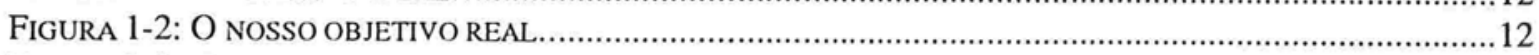

FIGURA 2-1 - RELACIONAMENTO ENTRE REENGENHARIA, REESTRUTURAÇĀO E ENGENHARIA REVERSA. ADAPTADO DE [ARN93].

FigURA 3-1: COMPARAÇĀO DE DESEMPENHO ENTRE OS PROGRAMADORES COM A LISTAGEM TRADICIONAL E A

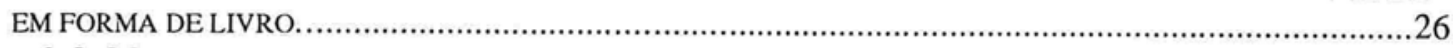

FIGURA 3-2: MODELO CONCEITUAL DE UM BANCO DE DADOS DE UM PROGRAMA C. ........................................2

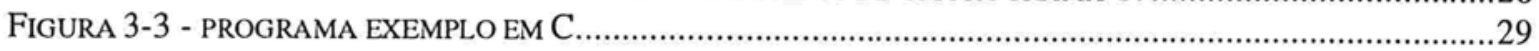

FIGURA 4-1: POSSÍvEIS RELAÇõES ENTRE CARACTERÍSTICAS INTERNAS DE UM SOFTWARE E CARACTERÍSTICAS

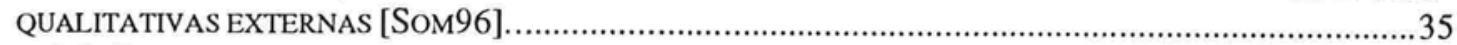

FIGURA 5-1: ESQUEMA CONCEITUAL DE FUNCIONAMENTO DO AVASAP.......................................................57

FIGURA 5-2: MODELO DE ENTIDADES E RELACIONAMENTOS DO BANCO DE DADOS GERADO.............................58

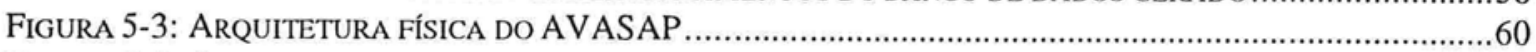

FIGURA 5-4: ALGORITMO PARA DETECÇĀO DE INCONSISTENCIAS DO TIPO 1 ……...........................................64

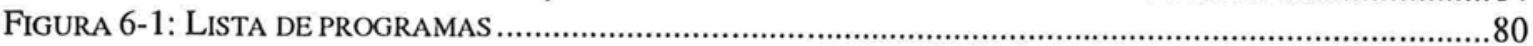

Figura 6-2: Primeira TEla Da ANÁlise Do PRograma (hTTP://LOCALHOST:9999/MFs/PAGINIC) ..............81

FIGURA 6-3: QUADRO DE DETALHES MOSTRA LISTA DE MÉTRICAS (HTTP://LOCALHOST:9999/MFS/MET)........82

FIGURA 6-4: O QUADRO DE DETALHES APRESENTA LISTA DE FUNÇŌES GLOBAIS

(HTTP://LOCALHOST:9999/MFS/LSTSIMB/FC/PROGRAMA) _..............................................................8

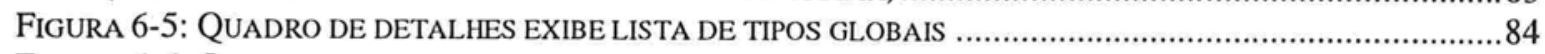

FIGURA 6-6: QUADRO DE DETALHES APRESENTA INFORMAÇŌES SOBRE O TIPO MATRIZ ....................................85

FIGURA 6-7: NO QUADRO DE DETALHES HÁ INFORMAÇōES SOBRE A FUNÇÃO RESOLVE......................................8

FIGURA 6-8: TABELA DE MÉTRICAS SOBRE O PROCEDIMENTO RESOLVE NO QUADRO DE DETALHES. ..................87

FIGURA 6-9: NO QUADRO DE DETALHES LISTA-SE AS FUNÇõES CHAMADAS POR RESOLVE...............................8

FIGURA 6-10: NO QUADRO PRINCIPAL SURGE O CÓDIGO DO PROCEDIMENTO RESOLVE......................................89

FIGURA 6-11: INFORMAÇÕES SOBRE A VARIÁVEL JOGO............................................................................90 


\section{Capítulo 1}

\section{Introdução}

Neste capítulo, abordaremos, em detalhes, vários aspectos do problema sendo tratado durante todo este texto, os nossos objetivos em relação a ele e uma breve descrição da estrutura do resto deste trabalho.

\subsection{O Problema}

\subsubsection{Disciplinas de Introdução à Programação e os Programas Exercício}

Devido ao crescente uso e importância dos computadores em praticamente todas as áreas do conhecimento humano, disciplinas de introdução à programação de computadores têm feito parte de um número cada vez maior de currículos de cursos universitários. Na Universidade de São Paulo, por exemplo, em praticamente todos os cursos de graduação de ciências exatas e tecnologia há uma disciplina desta categoria.

O nível de profundidade com o que trata a disciplina de introdução à computação varia conforme o curso. Todas elas objetivam, no mínimo, ensinar o desenvolvimento de algoritmos simples e a sua implementação em uma linguagem de programação (normalmente, Pascal ou C). Para os cursos que formarão futuros engenheiros de software (como é o caso de ciência da computação), alguns conceitos mais aprofundados já são introduzidos, como tópicos sobre estilo, modularidade etc.

\section{Os Programas Exercício Didáticos}

A prática de programação, como não poderia deixar de ser, tem papel fundamental no processo de aprendizado. Por isso mesmo, além dos exercícios feitos "no papel" durante as aulas, no decorrer do curso é exigido do aluno a implementação de 4 ou 5 programas exercício. 
Para cada um desses programas, é fornecida, em forma de enunciado, uma especificação (não formal) das funcionalidades que ele deve apresentar, além de exemplos de entradas e saídas, sugestões de algoritmos etc.

É importante notar que programas exercício didáticos possuem algumas características importantes que os diferem daqueles feitos em um ambiente de produção real:

- como toda uma turma de alunos recebe um mesmo enunciado, haverá vários programas "repetidos" que implementam uma mesma especificação. Em um ambiente de produção real, não há sentido em se fazer algo semelhante.

- os programas exercício de disciplinas introdutórias não costumam ser muito grandes: em geral, os seus textos-fonte não têm mais de 1000 linhas. Na indústria, é normal a ocorrência de programas com dezenas de milhares de linhas.

- apesar de pequenos, nem sempre os seus algoritmos e estruturas de dados são simples - muito pelo contrário, em razão do seu caráter didático, eles costumam tratar de problemas mais abstratos e complexos que os encontrados em muitos domínios do mundo real, por exemplo, os sistemas administrativos usados na indústria.

- esse tipo de programa sofre de um problema bastante peculiar: o plágio. Devido a um grande número de fatores, não é raro dois ou mais alunos submeterem um mesmo programa para avaliação (devidamente disfarçados com algumas técnicas simples de edição).

Os alunos programadores também diferem daqueles das equipes de programação do mundo real: embora seja verdade que alguns alunos cheguem à Universidade com algum conhecimento prévio de programação, pode-se afirmar que o nível de experiência é razoavelmente homogêneo, não havendo grandes diferenças em termos de conhecimento de técnicas de programação, algoritmos e estruturas de dados.

\subsubsection{Programas Exercício: O que é Avaliado}

Para a avaliação de programas em geral, a literatura existente sobre Qualidade de Software recomenda que não apenas os produtos sejam avaliados, mas também o processo pelo qual eles foram produzidos.

No nosso caso particular, por várias razões (dentre elas o grande número de alunos e as próprias dimensões reduzidas dos programas produzidos), o processo pelo qual os exercícios são desenvolvidos não é acompanhado, não sendo, portanto, avaliado.

Assim, a avaliação dos programas exercício se restringe ao produto em si.

\section{O Nosso Modelo de Qualidade Proposto}

Como base para se decidir o que deve ser avaliado ou não, tomemos a norma ISO/IEC 9126 [TAR+95], de 1991, que estabelece uma série de seis características de qualidade de produtos de software candidatas a avaliação (ver quadros 1 e 2). 
Para se ter uma idéia da importância dessa norma, ela é resultado de um esforço da ISO/IEC em agrupar a contribuição de vários modelos de qualidade de software apresentados na literatura, desde os mais antigos, como o de McCall, em 1977, e o de Boehm, de 1981, até os mais recentes, como o modelo FURPS, da Hewllet-Packard [TAR+95].

As caracterísiticas citadas são: funcionalidade, confiabilidade, usabilidade, eficiência, manutenibilidade e portabilidade.

\begin{tabular}{|l|l|}
\hline Funcionalidade: & $\begin{array}{l}\text { Evidencia que o conjunto de funções atendem às necessidades explícitas e implícitas } \\
\text { para a finalidade a que se destina o produto. }\end{array}$ \\
\hline Confiabilidade: & $\begin{array}{l}\text { Evidencia que o desempenho se mantém ao longo do tempo e em condições estabeleci- } \\
\text { das. }\end{array}$ \\
\hline Usabilidade: & Evidencia a facilidade para a utilização do software. \\
\hline Eficiência: & $\begin{array}{l}\text { Evidencia que os recursos computacionais e os tempos envolvidos são compatíveis com } \\
\text { o nível de desempenho requerido para o produto. }\end{array}$ \\
\hline Manutenibilidade & Evidencia que há facilidade para correções, atualizações e alterações. \\
\hline Portabilidade: & $\begin{array}{l}\text { Evidencia que é possível utilizar o produto em diversas plataformas com pequeno es- } \\
\text { forço de adaptação. }\end{array}$ \\
\hline
\end{tabular}

Quadro 1 - Características da Qualidade de Software segundo a ISO/IEC 9126

[TAR+95]

Mas, levando-se em conta o nosso contexto particular, é óbvio que algumas características são menos importantes que outras. A seguir, discutimos cada categoria.

Confiabilidade e Portabilidade. Não há muito sentido em se exigir um grande nível de confiabilidade e portabilidade em programas feitos em disciplinas de introdução à programação, cujos alunos estão aprendendo a programar.

Usabilidade. A usabilidade é importante, mas não muito. Sofisticadas interfaces gráficas, por exemplo, podem ser perfeitamente dispensadas - o que basta, no caso, é que a interface seja minimamente clara e não imponha dificuldades na operação do programa.

Funcionalidade. Sem dúvida alguma, a característica mais importante a ser avaliada é a funcionalidade, ou seja, checar se o programa faz realmente aquilo que o enunciado pedia. Aliás, nos primeiros exercícios, essa talvez seja a única característica realmente avaliada. 


\begin{tabular}{|c|c|c|}
\hline \multirow{5}{*}{ Funcionalidade } & Adequação & $\begin{array}{l}\text { Presença de conjunto de funções e sua apropriação para as } \\
\text { tarefas }\end{array}$ \\
\hline & Acurácia & Geração de resultados ou efeitos corretos \\
\hline & Interoperabildade & Capacidade de interagir com outros sistemas \\
\hline & Conformidade & Estar de acordo com normas, convenções, regulamentações \\
\hline & Segurança de Acesso & $\begin{array}{l}\text { Capacidade de evitar acesso não autorizado a programas e } \\
\text { dados }\end{array}$ \\
\hline \multirow{3}{*}{ Confiabilidade } & Maturidade & Frequência de falhas \\
\hline & Tolerância a Falhas & Manter nível de desempenho em caso de falha \\
\hline & Recuperabilidade & Capacidade de se restabelecer e restaurar dados após falha \\
\hline \multirow{3}{*}{ Usabilidade } & Inteligibilidade & Facilidade de entendimento dos conceitos utilizados \\
\hline & Apreensibilidade & Facilidade de aprendizado \\
\hline & Operacionalidade & Facilidade de operar e controlar a operação \\
\hline \multirow[b]{2}{*}{ Eficiência } & $\begin{array}{l}\text { Comportamento em rel. } \\
\text { Tempo }\end{array}$ & Tempo de resposta, de processamento \\
\hline & $\begin{array}{l}\text { Comportamento em rel. } \\
\text { recursos computacionais }\end{array}$ & Quantidade de recursos utilizados \\
\hline \multirow{4}{*}{ Manutenibilidade } & Analisabilidade & Facilidade de diagnosticar deficiências e causas de falhas \\
\hline & Modificabilidade & Facilidade de modificação e remoção de defeitos \\
\hline & Estabilidade & Ausência de riscos de efeitos inesperados \\
\hline & Testabilidade & Facilidade de ser testado \\
\hline \multirow{4}{*}{ Portabilidade } & Adaptabilidade & Capacidade de ser adaptado a ambientes diferentes \\
\hline & $\begin{array}{l}\text { Capacidade para ser Ins- } \\
\text { talado }\end{array}$ & Facilidade de instalação \\
\hline & Conformidade & Acordo com padrões ou convenções de portabilidade \\
\hline & Capacidade para substituir & Substituir outro software \\
\hline
\end{tabular}

Quadro 2 - Subcaracterísticas da Qualidade de Software segundo ISO/IEC 9126

[TAR+95] 
Eficiência. Eficiência (assim como manutenibilidade), dependendo do estágio em que se encontra o curso, pode ser uma característica mais ou menos importante.

Para análise de eficiência, é crucial o exame dos algoritmos e estruturas de dados utilizados.

Manutenibilidade. Lembrando que a manutenção é a fase do ciclo de desenvolvimento de software mais custosa e demorada, é importantíssimo que os alunos aprendam e façam programas o mais facilmente manuteníveis possível. Manutenibilidade está intimamente relacionada à prática de bons princípios de programação, que devem ser incentivados (ou mesmo requeridos) desde os primeiros programas.

Para a avaliação de manutenibilidade, costuma-se checar o seguinte:

Nomes dos identificadores. Sob o ponto de vista puramente funcional, os nomes de identificadores de funções, variáveis, tipos etc são completamente irrelevantes - é totalmente indiferente para o computador dar o nome a uma função que multiplica matrizes de xyz ou MultMatrizes; por outro lado, a segunda opção é significativamente mais fácil de ser compreendida sob o ponto de vista humano, devendo ser a preferida.

Apontamos alguns aspectos básicos sobre a escolha dos nomes de identificadores que devem ser observados.

1) O nome deve refletir de forma precisa e concisa o que o símbolo representa. O ideal é que um eventual leitor do texto (supondo que conheça o problema sendo tratado), ao ler um nome, tenha a melhor idéia possível sobre o papel que o símbolo desempenha na implementação.

Para isso, dentre outras coisas, é importante que eles sejam precisos, não muito genéricos e com um número de letras não exagerado.

Exemplo:

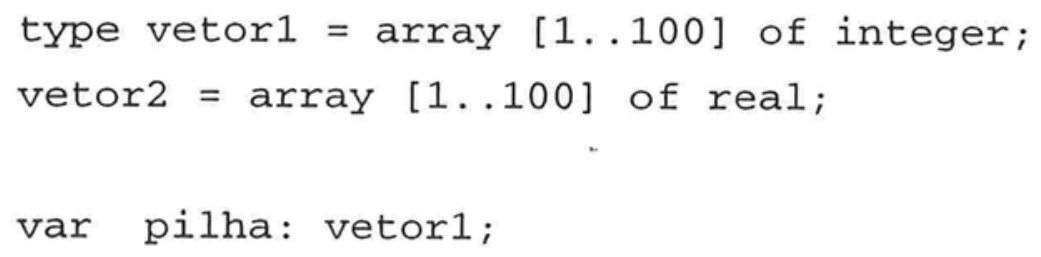

Os nomes vetor 1 e vetor2 são muito genéricos - embora nos diga que os tipos se referem a um vetor, não sabemos dizer qual a diferença entre os dois apenas a partir do nome. 
Uma alternativa melhor seria:

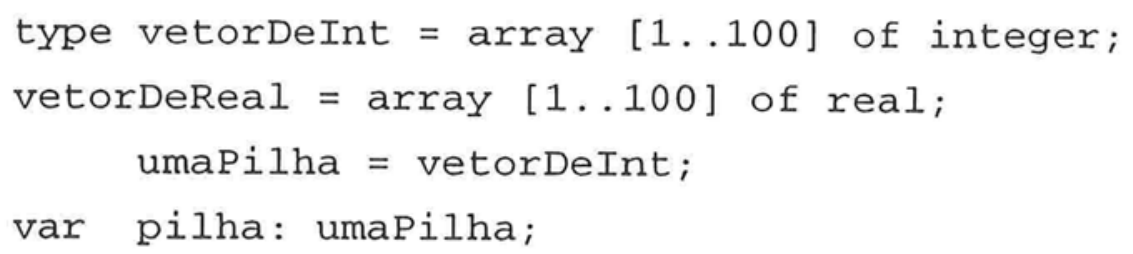

É óbvia a diferença entre vetorDeInt e vetorDeReal, e o tipo umaPilha faz uma abstração, deixando claro o seu uso para a definição de pilhas.

Atenção especial deve ser dada aos nomes das funções: um dos pontos importantes da divisão de um programa em funções é que ela promove auto-documentação, ao rotular com o próprio nome da função a funcionalidade de um trecho de código (no caso, o corpo da função) e, portanto, podendo até dispensar/diminuir comentários auxiliares, se o nome for bem escolhido.

Por exemplo, se uma função tem o nome de multiplica_matrizes e, além de multiplicar matrizes, ela as imprime na tela e guarda o resultado em um arquivo (operações que poderiam ser feitas independentemente), temos um caso onde o nome não reflete (e, portanto, não documenta eficazmente) o que a função faz.

2) Os nomes devem ser facilmente memorizáveis. Siglas, em geral, não são bem-vindas, assim como nomes crípticos como a,b,c etc (salvo casos em que elas sejam largamente empregadas no domínio do problema, como CGC, por exemplo, ou tenham uma clara relação com objetos da especificação - uma variável com nome x é perfeitmente aceitável se estivermos resolvendo um sistema linear do tipo $\mathrm{Ax}=\mathrm{b}$ ).

3) A formação dos nomes deve seguir uma regra consistente. É comum o emprego de regras para a formação de nomes - por exemplo, finalizar todos os identificadores de tipos com um _t, definir constantes em caixa alta, separar nomes compostos por '_, ou troca de caixa são regras populares.

Não consideramos que seja válido o examinador avaliar as regras empregadas em si, mas sim a forma como o aluno é consistente com as próprias regras que adotou.

Por exemplo,

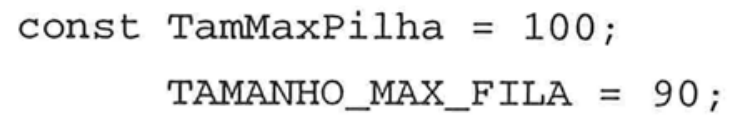


há várias inconsistências aqui:

- TamMaxpilha separa os nomes por mudança de caixa, enquanto TAMANHO_MAX_FILA, com um '_';

- a segunda constante está toda em caixa alta, enquanto a primeira, não;

- a palavra 'tamanho' está abreviada em TamMaxpilha por 'tam', enquanto em TAMANHO_MAX_FILA ela não é abreviada.

Todas essas inconsistências, embora não atrapalhem necessariamente a leitura do texto, dificultam enormemente a memorização precisa dos nomes - com uma adesão consistente à uma regra pré-definida, lembrar se o nome da constante de tamanho máximo da fila é TamMaxFila ou TAM_MAX_FILA, ou TAMANHO_MÁXIMO_FILA ou outro seria trivial, simplificando assim a tarefa de alteração ou extensão de programas.

Comentários. Os comentários, desde que bem colocados, desempenham um papel importante na hora de se entender o código.

Consideramos 2 aspectos fundamentais:

1) A Quantidade. Eles são suficientes? Teoricamente, a quantidade de comentários deve ser proporcional à dificuldade de entendimento do código e sua importância - partes complexas e fundamentais para o entendimento do resto do programa deveriam ser ricamente comentadas, ao passo que as passagens simples podem ser isentas. Entretanto,seguindo esse mesmo raciocínio, comentários demais também podem ser um mau sinal (o código pode estar excessivamente complexo).

É recomendável que pelo menos todos os símbolos globais sejam acompanhados de comentários descritivos, assim como todas as funções (em seus cabeçalhos).

Note que os comentários devem ser considerados como um complemento ao entendimento do programa - o ideal seria que o programa simplesmente não precisasse deles (se a estrutura do código fosse clara e simples o bastante, os nomes bem escolhidos etc, o próprio código se auto-documentaria) ${ }^{1}$.

\footnotetext{
${ }^{1} \mathrm{Na}$ verdade, aqui estamos excluindo os casos dos comentários que não objetivam documentar o código em si, -- por exemplo, comentários que documentem idéias importantes como as decisões de projeto (como porque se optou por usar um certo algoritmo ou estrutura de dados enquanto se podia escolher outras, quais as consequêencias da escolha etc) ; aqui, por mais claro que o código esteja, esse tipo de informação se perde completamente, não sendo válida a nossa observação. Entretanto, esse tipo de comentário é raro em programas escritos por alunos iniciantes.
} 
2) O Conteuido. O conteúdo deve ser preciso, sucinto, atual, c realmente contribuir positivamente com o entendimento do código.

Exemplos:

var pilha: umaPilha; \{a variável pilha é uma pilha\}

não é sucinto (é óbvio que pilha é uma variável, assim como pela posição em que está o comentário, é lógico que ele se refere a pilha), e de nada contribui para o entendimento (é evidente que pilha representa uma pilha - seria melhor se fosse explicada para que serve essa pilha, por exemplo).

Para o caso de variáveis vetores, geralmente comentar os elementos dele ao invés de descrevê-lo globalmente costuma trazer melhores resultados.

Por exemplo,

Indices: vetorDeInt; \{Indices das primeiras palavras de cada tamanho no dicionario\}

poderia ser reescrito de forma mais clara e precisa como

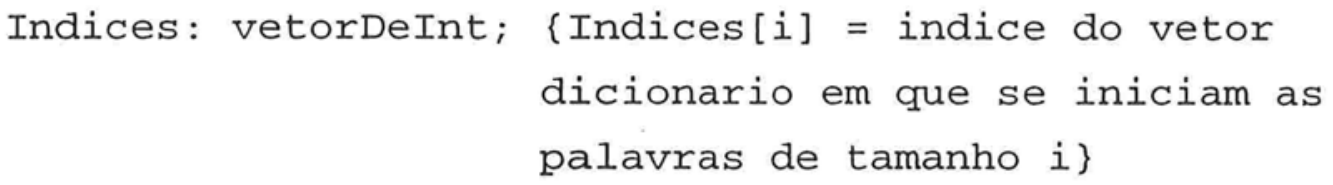

Um tipo de comentário bastante comum é como o abaixo:

$$
\begin{aligned}
& \text { \{enquanto a diferente de } 0 \text { \} } \\
& \text { while a }<0 \text { do } \ldots
\end{aligned}
$$

É desnecessário falar sobre a inutilidade deste comentário.

Apresentação. Assim como a escolha dos nomes dos identificadores, a indentação ${ }^{2}$ e formatação do texto fonte não afetam semanticamente o programa (exceto em algumas linguagens mais antigas, como o FORTRAN, onde a coluna onde se inicia uma linha é relevante). Entretanto, sob o ponto de vista humano, a forma como o texto é apresentado pode ajudar ou prejudicar significativamente a compreensão do programa - o paradigma

\footnotetext{
${ }^{2}$ Esta palavra não existe formalmente em português, embora seja de uso popular entre os técnicos de informática. O que queremos dizer com ela e suas variações é o mesmo que diz a palavra indentation em inglês, ou seja, deixar um espaço em branco (variável) antes do início de parágrafos.
} 
do livro [OC90], a ser detalhado na seção 3.1.1, é uma grande evidência disso, assim como o estudo de Miara et al [MMNB83].

Via de regra, uma linha não deve conter mais do que um único comando - mais do que isso, ש depuração torna-se mais complicada e a leitura mais cansativa.

Quanto à indentação, há vários estilos conhecidos, alguns mais populares que outros e cada um com suas vantagens e desvantagens. Para a linguagem $\mathrm{C}$, por exemplo, existem ferramentas de domínio público que indentam um programa num estilo específico.

De novo, não julgamos válido que se obrigue a adoção de um modelo específico, mas é crucial que o programador, tendo escolhido um estilo, o siga de forma consistente.

Por exemplo,

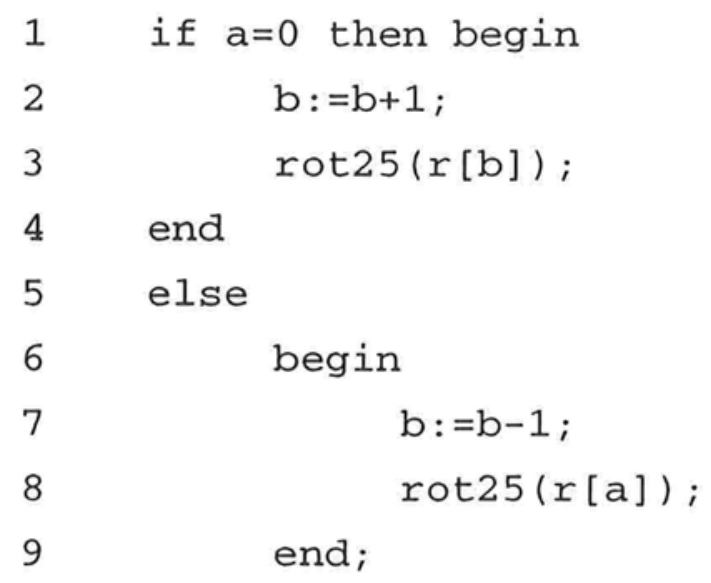

A construção acima está indentada de forma inconsistente: os comandos internos ao if estão apenas a um nível de indentação à direita em relação ao próprio if, enquanto os comandos internos da cláusula else estão a dois níveis.

Outro aspecto importante a se verificar é se a indentação reflete realmente a estrutura lógica do programa. É comum, como no exemplo abaixo, após se fazer mudanças no código, deixar a indentação desatualizada, o que pode ser uma perigosa fonte de erros.

1 if $a=0$ then

$2 \quad \mathrm{~b}:=\mathrm{b}+1$;

$3 \operatorname{rot} 25(r[b]) ;$

4 \{ A linha 3, ao contrário do que sugere a indentação, não está dentro do if.\}

Modularidade. Algumas perguntas básicas devem ser respondidas para a avaliação deste quesito: 
- Há funções excessivamente complexas? A idéia fundamental da modularização é quebrar um problema em vários problemas menores que sejam mais fáceis de serem resolvidos [YC79]. Funções excessivamente complexas podem ser sinais de má modularização, posto que poderiam ser divididas e substituídas por outras funções menores, mais simples e, portanto, mais manuteníveis.

- Há funções fazendo muitas tarefas pouco relacionadas? Funções que implementam muitas operações pouco relacionadas freqüentemente têm nomes pouco descritivos, dada a própria dificuldade de se escolher um nome que refilta todas as operações que elas façam em algumas palavras. Se a funcionalidade fosse separada em várias funções, os nomes poderiam ser melhores e o código mais simples e reutilizável.

- As funções estão muito dependentes do contexto? Funções que dependem fortemente do resto do programa (caso típico em que se faz muito uso de símbolos globais - especialmente variáveis) são pouco reutilizáveis e mais difíceis de se entender.

\subsubsection{Programas Exercício: Como São Avaliados}

\section{Modelo de Avaliação}

Aqui, apresentamos um modelo simplificado de como o examinador corrige os programas exercícios.

Para cada exercício, o aluno normalmente fornece para ser corrigido um disquete contendo o código executável acompanhado de uma listagem do código fonte.

Inicialmente, o examinador executa o programa diretamente no computador. Neste tempo, ele adquire as suas primeiras impressões sobre o programa, como a qualidade de sua interface, tempo de resposta etc. Exercita-se então o programa com algumas entradas estrategicamente escolhidas e checa-se se as saídas geradas correspondem às expectativas. Caso positivo, considera-se, pelo menos a princípio, o programa como correto em relação a funcionalidade; caso contrário, ele é considerado defeituoso.

Passa-se então à fase de leitura do código fonte, normalmente iniciada a partir de seu ponto de entrada lógico (em programas $\mathrm{C}$, a função main).

Faz-se então o entendimento do programa, onde se procura saber como o programa foi feito e porque ele funciona (ou não); em particular, aqui se identifica quais são as funções chaves (aquelas que resolvem e atacam frontalmente a maior parte do problema) e quais são as estruturas de dados principais. Levando-se em conta as dimensões dos programas considerados, é de se esperar que elas sejam em pequeno número.

Paralelamente a isso, avalia-se também aspectos qualitativos que são inerentes ao código fonte, especialmente manuteniblidade, que envolve modularidade, escolha dos nomes dos identificadores etc.

Deve-se também tentar identificar a ocorrência de plágio. 


\section{Avaliação Interna e Externa}

Da discussão do tópico anterior, note que a avaliação de programas pode ser dividida em duas fases, de acordo com a necessidade ou não de ler o código fonte:

a) Avaliação Externa: examina-se o programa como uma caixa preta, avaliando-o sob o ponto de vista de um usuário (ou seja, simplesmente executamos e usamos o programa). Aqui checamos, por exemplo, se ele tem a funcionalidade esperada, se a qualidade da interface é satisfatória, se o tempo de resposta é aceitável etc ${ }^{3}$

b) Avaliação Interna: examina-se o programa diretamente em seu código fonte, sob o ponto de vista de um outro programador (que, possivelmente, irá mantê-lo). Avalia-se aqui aspectos como escolha dos algoritmos e estruturas de dados, clareza do código, qualidade de modularização, comentários, consistência, criatividade, estilo etc.

Cabe observar que a avaliação interna é a fase, sem dúvida, mais trabalhosa e que exige mais tempo, já que a leitura atenta e cuidadosa do texto requerida é demorada.

\subsection{O Nosso Objetivo}

Atualmente, na maioria dos casos, todo o processamento de avaliação dos programas exercício é feito de forma $100 \%$ manual, sem o auxílio de qualquer tipo de ferramenta ${ }^{4}$.

O objetivo de nossa pesquisa é justamente especificar, projetar e implementar uma ferramenta que automatize ao máximo este processo. Idealmente, gostaríamos de algo como representado na figura 1-1, que recebe como entrada uma especificação do exercício a ser feito (poderia ser o seu próprio enunciado), o programa a ser avaliado (seu executável e fonte), e gera como saída comentários críticos sobre a sua qualidade, apontando os pontos fortes e fracos (exatamente como deveria fazer um corretor humano) com comentários do tipo "o prog não faz o que o item x do enunciado pede", "a função xyz não está bem modularizada", "este trecho poderia ser mais claro", "a estrutura de dados é muita complicada" etc.

\footnotetext{
${ }^{3}$ A rigor, nada impede que estas características sejam examinadas através da leitura do código fonte; entretanto, não é essa, de maneira alguma, a forma usual de se fazer isso.

${ }^{4}$ Há casos em que os examinadores usam ferramentas simples (por exemplo, para fazer comparações entre as saídas esperadas e reais, como o diff [PRL93]).
} 


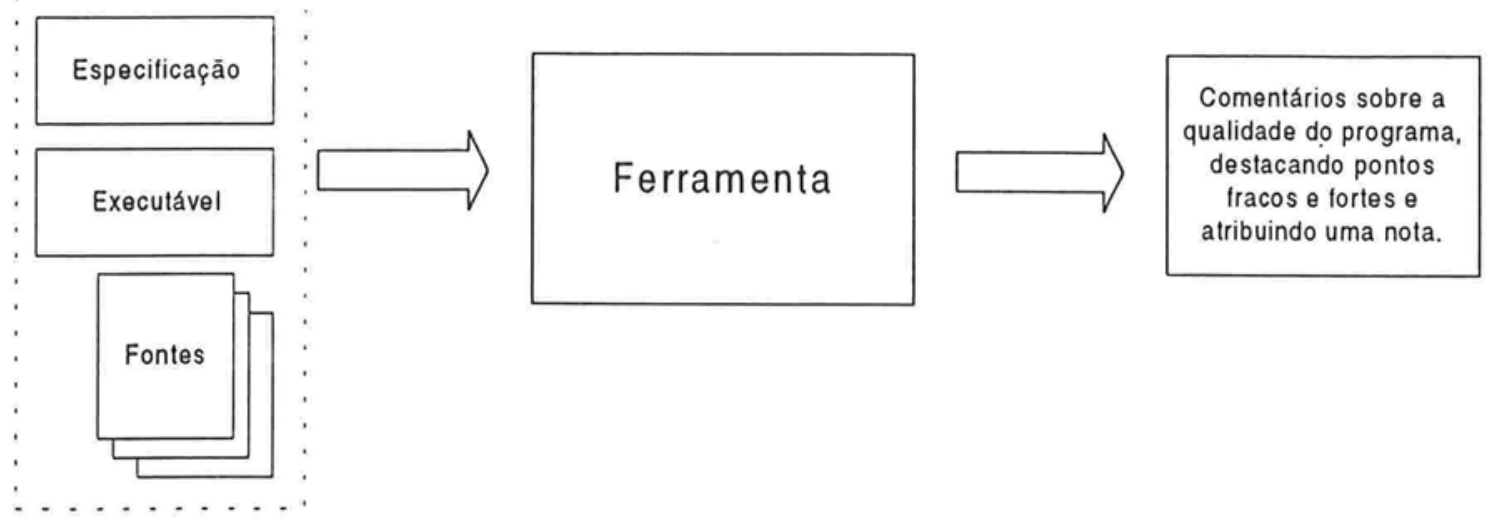

Figura 1-1: O objetivo ideal.

Obviamente, temos consciência que este objetivo é um pouco ambicioso demais (ou mesmo impossível, se considerarmos que faz parte da correção determinar se o programa pára ou não, problema sabidamente incomputável).

Além disso, sentimos que a avaliação interna, por ser a mais trabalhosa e enfadonha, é a que mais carece de automação - por isso, decidimos nos focalizar na avaliação de código fonte.

Também estaremos sendo mais realistas se nos contentarmos em obter um conjunto de informações que nos auxilie na correção ao invés dos comentários sobre a qualidade do programa, já que a obtenção deles é claramente um problema muito difícil.

Portanto, gostaríamos algo como esquematizado na figura 1-2.

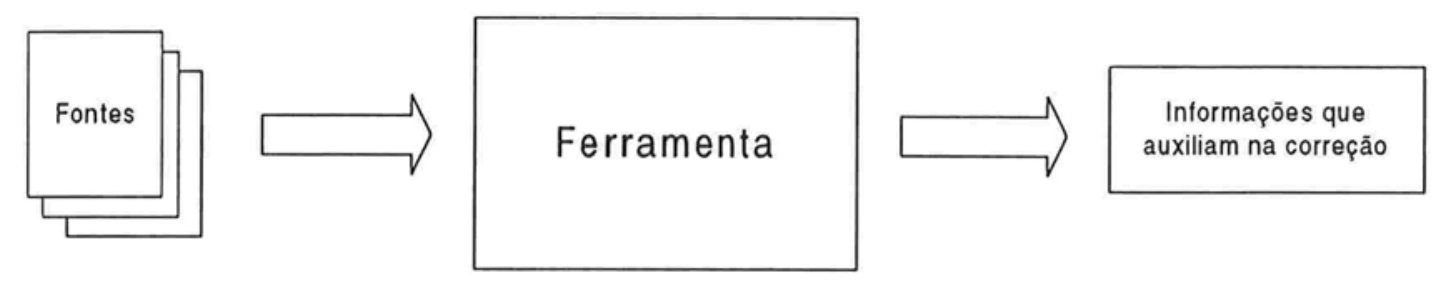

Figura 1-2: O nosso objetivo real.

\subsection{O Resto Deste Texto}

Nos próximos capítulos, fazemos uma investigação do que há na literatura que nos pode ajudar a alcançar nosso objetivo; em particular, nos focalizaremos em pesquisar reengenharia de software, sub-área da engenharia de software que nos inspirou a propor e pesquisar esse problema. 
No capítulo 2, fazemos uma breve introdução à reengenharia e conceitos relacionados, como engenharia reversa e reestruturação, abordando as definições, importância, aplicaçø̃es etc.

No capítulo 3, focalizaremos algumas ferramentas de reengenharia publicadas nos últimos anos, das quais extraímos idéias importantes.

No capítulo 4, estudaremos as métricas de software e analisaremos como elas poderiam ser aplicadas em nosso problema.

No quinto capítulo, tentaremos cumprir o nosso objetivo de especificar, projetar e descrever a implementação da ferramenta desejada.

No sexto capítulo, relataremos as experiências realizadas com a ferramenta na correção de programas exercício reais.

Finalmente, no sétimo e último capítulo, apresentamos as nossas conclusões e sugestões de continuidade do trabalho. 


\section{Capítulo 2}

\section{Engenharia Reversa, Reestruturação Reengenharia}

Neste capítulo, introduzimos os conceitos de engenharia reversa, reestruturação e reengenharia de software, como eles se relacionam, sua motivação e algumas das tecnologias disponíveis na área.

\subsection{Engenharia Reversa}

\subsubsection{Origens}

O termo "engenharia reversa", dentro do contexto de engenharia de software, tem suas origens na análise de hardware, onde a prática de se decifrar os projetos a partir dos produtos finais é algo comum. Geralmente, tem-se como objetivo analisar produtos de competidores (ou mesmo de adversários militares, em situações de segurança nacional) e tirar vantagem do conhecimento adquirido (fazendo uma cópia, ou aplicando-o no desenvolvimento ou melhoria de seus próprios produtos, por exemplo).

Rekoff define engenharia reversa como "o processo de desenvolvimento de um conjunto de especificações para um sistema de hardware por meio de um exame comum de espécimes desse sistema." [Rek85]. Ele descreve tal processo como sendo conduzido por uma pessoa que não tenha participado do desenvolvimento (sem o benefício do acesso a qualquer dos rascunhos e desenhos originais), com o objetivo de fazer uma cópia do sistema original.

Uma diferença fundamental que podemos notar é que, enquanto na análise de hardware o objetivo é tradicionalmente duplicar o sistema, em sistemas de software, na maioria dos casos, deseja-se apenas obter-se um conhecimento a respeito do projeto suficiente para ajudar na manutenção de programas. 


\subsubsection{Definição}

Existem várias definições para "engenharia reversa". A adotada pela IEEE diz que

"Engenharia reversa é o processo de análise de um sistema para:

- identificar os componentes do sistema e seus inter-relacionamentos e

- criar representações do sistema em uma outra forma ou em um nivel mais alto de abstração." [CC90]

(note que "sistema" aqui pode ser um complexo conjunto de programas comunicando-se entre si, um simples programa ou mesmo um fragmento de código, além de arquivos de dados, instruções de controle de jobs etc).

Engenharia reversa geralmente envolve a extração de artefatos de projeto ou obtenção de abstrações de nível mais alto que sejam menos dependentes de implementação de um dado sistema.

Note-se que engenharia reversa é um processo tão somente de exame, não envolvendo alteração ou replicação.

\subsubsection{Recuperação de Projeto}

Há várias sub-áreas de engenharia reversa. Uma das mais importantes é Recuperação de Projeto (Design Recovery), onde o conhecimento do domínio, informações externas e deduções formais são acrescentadas às observações do sistema para identificar abstrações de níveis superiores às que se obteriam examinando apenas o sistema. Biggerstaff ensina "Recuperação de projeto cria abstrações de projeto a partir de uma combinação de código, documentação de projeto existente (se disponível), experiência pessoal e conhecimento geral sobre o problema e a aplicação... Recuperação de projeto deve reproduzir todas as informações necessárias para uma pessoa entender totalmente $o$ que um programa faz, como ele o faz, por que ele o faz etc. Assim, ela lida com um conjunto de informações mais amplo do que se encontra em representações convencionais de engenharia de software ou código" [Big89].

\subsection{Reestruturação}

Chikofsky define reestruturação como

"uma transformação de uma forma de representação para outra no mesmo nível de abstração que preserva o comportamento externo do sistema (funcionalidade elou semântica)" [CC90].

Transformações de reestruturação geralmente são de aparência, tal como alterar o código para estruturá-lo melhor. O termo "reestruturação" se tornou popular a partir da transformação de código para código de programas não estruturados ("código espagueti") para programas estruturados (sem goto's). Entretanto, com o passar do tempo, o termo adquiriu um sentido mais amplo, onde se reconhece normalização de um modelo de dados, alterações de nomes de variáveis para algo mais significativo, transformação do código de modo a torná-lo orientado a objeto etc também como reestruturação. 
Muitos tipos de reestruturação podem ser executados apenas se conhecendo a forma estrutural, sem a necessidade de se entender o seu significado. Por exemplo, pode-se converter uma seqüência de ifs em uma estrutura do tipo case (ou vice-versa), sem se saber o propósito do programa ou qualquer coisa sobre o domínio do problema.

\subsection{Reengenharia}

A exemplo de engenharia reversa e reestruturação, pode-se encontrar várias definições de reengenharia. Uma das mais abrangentes é dada por Arnold [Arn93]:

"Reengenharia de software é qualquer atividade que

a) faz alguém entender melhor o software, ou

b) prepara ou melhora o software, geralmente para tornar mais fácil a sua manutenção, reutilização ou evolução."

Nesta definição, entenda-se por "software" não apenas código fonte, mas também documentação, figuras, análises (sobre código, projetos, especificações, dados de teste) e outros documentos que diretamente ajudem no desenvolvimento e manutenção do software.

Exemplos de atividades do tipo a) incluem: inspeção (browsing), calculo de métricas, documentação, desenho de fluxogramas do software etc.

A parte b) inclui atividades destinadas a melhorar as qualidades estáticas do software, como melhorar a escolha de nomes de identificadores, remodularização etc .

Como engenharia reversa faz "alguém entender melhor o software", podemos concluir que ela é uma atividade de reengenharia. O mesmo se pode dizer da reestruturação, desde que ela tenha como objetivo o item b) da definição (o que, em geral, é verdade).

\subsubsection{Outras Definições de Reengenharia}

Pode-se encontrar na literatura outras definições de reengenharia. Por exemplo, o grupo GUIDE de usuários da IBM define reengenharia como

"o processo de modificação de mecanismos internos ou estruturas de dados de um sistema ou programa sem mudar sua funcionalidade" [GUI89]

que, aliás, lembra muito a definição de reestruturação de Chikofsky, gerando uma certa confusão. Entretanto, ainda em [GUI89], se lê: "é raro fazer a reengenharia de uma aplicação sem que alguma funcionalidade seja acrescentada", o que evidencia a estreiteza dessa definição e a necessidade de uma mais genérica.

Chikofsky e Cross definem reengenharia como

"o exame e alteração de um sistema para reconstituí-lo em uma nova forma e subseqüente implementação dessa forma. " [CC90] 


\subsubsection{Um Exame das Definições}

Pelos motivos já explicados, preferimos desconsiderar a definição de reengenharia do GUIDE - citamo-na apenas por sua importância histórica.

Arnold e Chikofsky definem reengenharia a partir de perspectivas diferentes: enquanto o primeiro focaliza os propósitos da reengenharia, Chikofsky se concentra no processo.

Chikofsky considera qualquer exame e mudança em um sistema como reengenharia, o que nos parece aberto demais. Gostaríamos que fosse agregada ao termo "reengenharia de software" uma idéia de aperfeiçoamento, a exemplo de Arnold, que restringe a definição de reengenharia apenas às mudanças que melhorem o software.

Por outro lado, Arnold não inclui explicitamente modificações importantes de melhoramento de software, como a otimização de código e porte para outras plataformas e/ou arquiteturas, o que nos parece injusto.

\subsubsection{Uma Extensão à Definição de Arnold}

Assim, resolvemos adotar a definição dada por Arnold, porém estendida:

"Reengenharia de software é qualquer atividade que

a) faz alguém entender melhor o software, elou

b) prepara ou melhora o software, geralmente para torná-lo mais eficiente (em tempo ou espaço) ou mais fácil a sua manutenção, reutilização, evolução, ou

c) torna-o apto a ser executado em um outro contexto tecnológico diferente do original."

Dessa forma, no item b), incluímos otimização (tanto a nível de espaço como tempo) como reengenharia. Porte de código para um novo sistema operacional ou para uma arquitetura distribuída foram incluídas em c). 


\subsection{Como Tudo Isso se Relaciona}

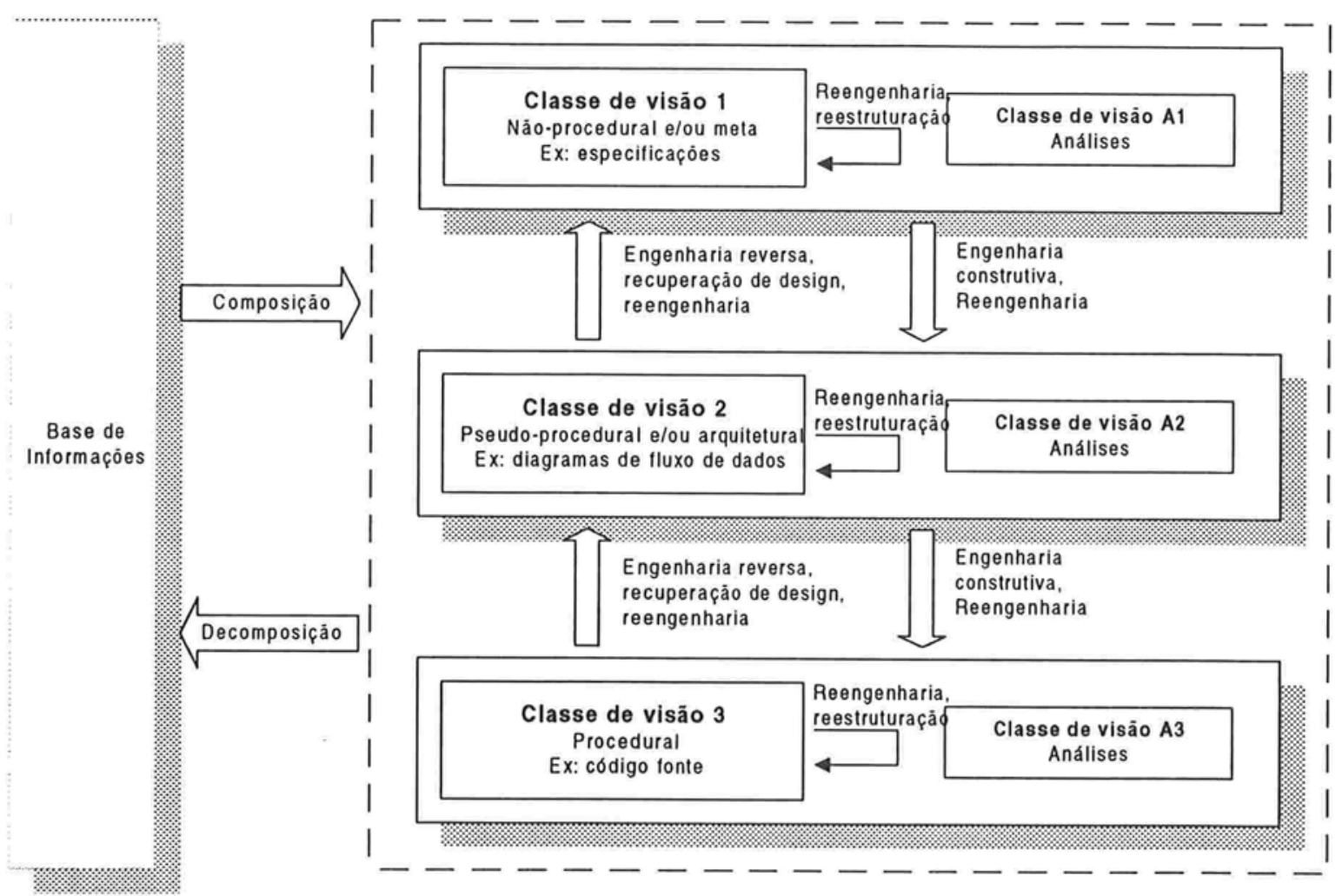

Figura 2-1 - Relacionamento entre reengenharia, reestruturação e engenharia reversa. Adaptado de [Arn93].

A figura 2-1 nos ajuda a entendermos melhor como reengenharia se relaciona com outros termos (em particular, engenharia reversa e reestruturação).

Há 5 idéias na figura 2-1:

1) visões de software,

2) base de informações,

3) decomposição,

4) composição,

5) transformação.

Uma visão de software é uma representação ou relatório sobre software, geralmente destinada a ser examinada por seres humanos (por exemplo, uma especificação, uma listagem de código fonte, métricas, dados de entrada usados como teste etc).

Visões podem ser divididas em 4 classes: 
Classe 1: Visões não-procedurais elou meta-orientadas. Exemplos: especificações, esquemas conceituais.

Classe 2: Visões pseudo-procedurais elou orientada à arquitetura. Exemplos: Projetos, diagramas de arquitetura de software, pseudo-código.

Classe 3: Visões procedurais - informações altamente procedurais ou intimamente relacionadas ou derivadas. Exemplos: Código fonte, slices, árvores sintáticas.

Classe A: Visões derivadas da análise de outras visões, podendo acompanhá-las. Exemplo: métricas de software, que são derivadas do código fonte.

A classe A, por sua vez, pode ser dividida em 3 sub-classes: classe A1, A2 ou A3, dependendo da classe da visão que a derivou (1, 2 ou 3, respectivamente). Como exemplos, da A1 citamos o índice Fog ${ }^{1}$ de um texto de especificação; da A2, níveis de acoplamento dos módulos; da A3, número de variáveis globais do código fonte.

A classificação de uma visão é um tanto quanto subjetiva, o que torna as classes 1, 2, 3 e A não disjuntas. Por exemplo, classificamos pseudo código como da classe 2, embora alguém pudesse colocá-la na classe 3 .

A base de informações é o repositório de informações sobre o software, que pode ser alimentado de três formas:

1) Decomposição do software em objetos e relacionamentos,

2) Construindo objetos ou relacionamentos incrementalmente através de ferramentas que acrescentam conhecimento à base.

3) Importando informações de outras bases.

Decomposição é o processo de transformação de uma visão em objetos e seus relacionamentos. Por exemplo, compiladores transformam código fonte em árvores sintáticas.

Composição é a geração de visões a partir de informações da base de informação. O compositor (ferramenta ou pessoa que realiza a composição) constrói uma visão encontrando os objetos e relacionamentos importantes dentro da base e, se necessário, formatando-os para sua exibição.

O conceito de transformação é representado na figura 2-1 pelas setas.

Transformações que envolvam apenas uma classe de visão podem ser consideradas reengenharia (desde que haja alguma melhoria segundo a definição) ou reestruturação. Por exemplo, de código fonte para código sem goto's (classe 3), atualização de projetos (classe 2) e correção de especificações (classe 1).

Transformações que envolvam classes diferentes podem ser entendidas como engenharia reversa, reengenharia ou engenharia construtiva. Se a classe origem for de um nível mais abstrato que a final (da classe 3 para a 2, por exemplo), temos engenharia reversa. Se ocorrer o contrário, ou seja, a classe origem for de um nível mais alto que a final, temos engenharia construtiva (forward engineering), que é o sentido natural no processo de de-

\footnotetext{
${ }^{1}$ Métrica para se avaliar a legibilidade de um texto [Som96]
} 
senvolvimento. Se qualquer dessas dessas transformações estiver inserida em um objetivo de fazer entender melhor o software ou melhorá-lo, então temos um caso de reengenharia.

\subsection{Algumas Aplicações}

\subsubsection{Reestruturadores}

São ferramentas que basicamente eliminam goto's de programas (especialmente em COBOL), substuindo-os por uma forma estruturada equivalente. Isto sempre é possível, como provaram Ashcroft e Manna [AM71] em 1971. Segundo Ulrich [Ulr90], essa foi a primeira classe de ferramentas de reengenharia a surgir (em 1975, segundo conta Yourdon [You89], já havia uma ferramenta que fazia isso).

\subsubsection{Atualização de Documentação}

Tem como objetivo, a partir de um código fonte (ou outros documentos), gerar uma documentação atualizada (ou mesmo nova), que pode ser na forma de texto (por exemplo, como comentários intra-código) ou gráfica.

Claramente, trata-se de um problema de difícil automatização.

[CHT+90], [LHG+88] e [HPL+90] são exemplos de trabalhos onde se mostram ferramentas que tentam tornar semi-automática essa tarefa.

\subsubsection{Engenharia de Reutilização}

Engenharia de reutilização é a modificação do software para torná-lo mais reutilizável, normalmente visando encontrar partes do software e reconstruí-los de modo tal que elas possam ser colocadas em uma biblioteca de reutilização [Arn93].

Há vários trabalhos descrevendo métodos para encontrar e reutilizar partes, como [BR87] e [Pri93].

\subsubsection{Remodularização}

Remodularização de software é o processo de alteração da estrutura de módulos de um sistema. Schwanke, em [Sch91], apresenta uma heurística para se fazer isso automática ou semi-automaticamente.

\subsubsection{Análise de Manutenabilidade}

Análise de manutenabilidade de software é o processo de descoberta de quais partes de um sistema mais carecem de reengenharia.

[Pee81] define uma metodologia para a determinação de manutenabilidade de um sistema.

\subsubsection{Inspeção (Browsing)}

A forma mais elementar de se obter um entendimento a respeito de um software talvez seja por meio de um editor de textos. O uso de hipertexto [Con87], que torna mais sim- 
ples a visualização de componentes e relacionamentos, vem provocando um grande impacto nesta área.

\subsubsection{Recuperação de objetos}

Consiste em se identificar objetos a partir de código fonte. Isto permite alguém enxergar um programa não orientado a objeto de uma forma orientada a objeto.

Pelo fato de programas orientados a objeto poderem oferecer maior clareza e capacidade de reutilização, a transformação de código para uma forma orientada a objeto tem recebido uma atenção especial. [BL91], [DNG89] e [Jac91] são exemplos de trabalhos nesta área. 


\section{Capítulo 3}

\section{Algumas Ferramentas Para Reengenharia de Software}

No decorrer deste capítulo, descrevemos algumas ferramentas para reengenharia de software que incorporam em si algumas idéias que, cremos, seriam úteis também em uma ferramenta de avaliação de programas.

\subsection{Reformatadores}

Reformatadores de código são ferramentas que alteram o formato do texto do código fonte sem, entretanto, modificar qualquer aspecto semântico do programa. Normalmente, sua função é melhorar a legibilidade e tornar mais fácil o entendimento do programa.

A classe de reformatadores mais comum é a dos reindentadores, que indentam um texto segundo um estilo pré-estabelecido, que podem ser usados para padronização de um dado conjunto de programas fonte.

Nesta seção examinaremos um reformatador especial: o bookmaker.

\subsubsection{O Paradigma de Livro}

Várias teorias vêm sendo desenvolvidas para tentar explicar o processo pelo qual as pessoas entendem programas. Dois dos conceitos presentes em virtualmente todas elas são chunks e beacons [OC90].

Um chunk é um grupo de instruções ao qual o programador associa uma idéia mais abstrata que identifica e descreve a funcionalidade correspondente.

Por exemplo, o trecho abaixo poderia ser agrupado mentalmente e ser reconhecido como "cálculo da soma dos elementos do vetor x". 


$$
\begin{aligned}
& \text { sum }:=0 ; \\
& \text { for } i:=1 \text { to } n \text { do } \\
& \text { sum }:=\text { sum }+x[i]
\end{aligned}
$$

Note que um chunk pode perfeitamente estar inserido dentro do contexto de um chunk mais complexo (o acima, por exemplo, poderia fazer parte de um chunk que realiza um complicado cálculo vetorial).

Já os beacons são pontos notáveis de um programa que ajudam o examinador a localizar e/ou isolar chunks - por exemplo, tokens que identificam o início da definição de uma função ou marcadores de finais de bloco.

\section{O Formato Livro}

Um livro é uma coleção de informações organizadas de modo a tornar o mais fácil e agradável possível a sua leitura. Para tanto, existem os índices e a paginação, que permitem a

o leitor acessar os dados desejados o mais diretamente possível, como também a divisão em capítulos, seções e sub-seções, que simplificam a busca e leitura.

Além disso, podemos ler um livro de várias formas: querendo-se apenas ter uma idéia geral do conteúdo, pode-se ler apenas o índice geral ou folheá-lo por cima; desejando-se ir a algum tópico específico, podemos nos localizar pelo índice remissivo; dentro de um tópico específico, podemos ainda nos concentrar nas seções e parágrafos de maior interesse.

\section{O Paradigma do Livro}

Oman e Cook [OC90], baseados nas idéias discutidas nas duas últimas seções, perceberam o seguinte:

- seria interessante que o texto de um programa fosse apresentado de uma forma tal que seções de comandos (candidatos a chunks) fossem isolados visualmente (por linhas em branco, por exemplo), e que se destacasse tipograficamente algumas palavras/comandos chave (candidatos a beacons), para orientar a leitura.

- ler um programa de várias maneiras, assim como um livro, seria uma característica bastante desejável, posto que são atividades comuns de um programador (principalmente na hora da manutenção) ter uma idéia geral do que um programa faz, localizar diretamente algum módulo e, dentro desse módulo, qual rotina ou trecho de rotina é responsável por uma certa função, etc.

Daí surgiu a idéia de formatar listagens de programas como os livros o são - a esse modelo de formatação deram o nome de paradigma de livro. 


\section{As Analogias}

O primeiro passo para se definir o paradigma é identificar as analogias existentes entre textos literários e textos de código fonte de programas.

Oman e Cook sugeriram as seguintes:

\begin{tabular}{|c|c|c|}
\hline 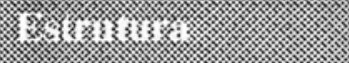 & 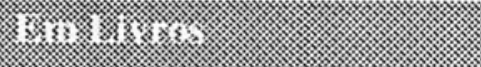 & 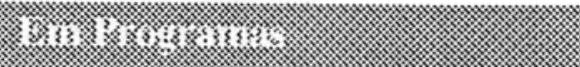 \\
\hline Prefácio & $\begin{array}{l}\text { Introdução do autor ao } \\
\text { leitor }\end{array}$ & $\begin{array}{l}\text { Comentários introdutórios nos } \\
\text { cabeçalhos }\end{array}$ \\
\hline Indice Geral & Mapa geral do conteúdo & $\begin{array}{l}\text { Diagrama de estruturas dos com- } \\
\text { ponentes }\end{array}$ \\
\hline $\begin{array}{l}\text { Indices mais deta- } \\
\text { lhados e paginação }\end{array}$ & $\begin{array}{l}\text { Mapa detalhado do con- } \\
\text { teúdo }\end{array}$ & $\begin{array}{l}\text { Mapas de referência cruzada com } \\
\text { número de linhas }\end{array}$ \\
\hline Capítulos & Divisões de alto nível & Arquivos, Módulos, Objetos \\
\hline Seções & $\begin{array}{l}\text { Divisões dentro dos } \\
\text { capítulos }\end{array}$ & $\begin{array}{l}\text { Seções de código intra-módulos } \\
\text { (em Pascal, há uma seção para } \\
\text { variáveis, outra para constantes } \\
\text { etc) }\end{array}$ \\
\hline Parágrafos & $\begin{array}{l}\text { Pedaços de informações } \\
\text { agrupados }\end{array}$ & $\begin{array}{l}\text { Comandos aninhados ou relacio- } \\
\text { nados por composição }\end{array}$ \\
\hline Sentenças & $\begin{array}{l}\text { Frases delimitadas e defini- } \\
\text { das por pontuação e estilo }\end{array}$ & Comandos e declarações \\
\hline Pontuação & $\begin{array}{l}\text { Mecanismos para delimita- } \\
\text { ção e destaque de estrutu- } \\
\text { ras }\end{array}$ & $\begin{array}{l}\text { Mecanismos para delimitação e } \\
\text { destaque de estruturas }\end{array}$ \\
\hline
\end{tabular}

\section{A Ferramenta}

Oman e Cook também desenvolveram uma ferramenta para por em prática as suas idéias, à qual deram o nome de Bookmaker. Ela recebe como entrada o código fonte (que pode estar dividido em vários arquivos) de um programa (em C ou Pascal) e gera como saída um arquivo único, paginado, com o texto reformatado segundo o paradigma. O processo não é totalmente automático - alguns aspectos precisam de orientação de um ser humano, como a divisão dos blocos de comandos em grupos candidatos a chunks.

O Bookmaker atua essencialmente de três formas sobre a entrada:

1) Geração de comentários: durante o processo, a ferramenta recolhe informações úteis que são apresentadas na saída sob a forma de comentários - por exemplo, o índice geral, que diz em quais páginas estão localizadas cada capítulo (correspondente aos arquivos que compõe o programa) ou cada tópico, como uma função ou declaração de variáveis globais. Um índice detalhado também é gerado sob forma de comentários, que além de localizar todas as funções declaradas, fornece informações sobre cada 
uma delas como quais são as funções por ela chamadas, por quais funções ela é acionada etc. Além disso, comentários da forma $/ *$ end $\mathrm{xxx}$ */ são gerados ao lado de marcadores de final de estruturas de blocos ( ) em C) para ajudar o leitor a identificar qual estrutura de controle está sendo finalizada.

2) Geração de linhas em branco: linhas em branco são geradas para delimitar e destacar seções do código - por exemplo, entre a declaração de variáveis e o início do código, entre cada definição de funções etc.

3) Reformatação: a ferramenta muda a tabulação de comandos simples colocando sob a forma de orações, posicionando-os horizontalmente. Por exemplo, a construção

$$
\text { if } \begin{aligned}
& \mathrm{x}=\mathrm{y} \text { then } \\
& \mathrm{x}:=\mathrm{z} ;
\end{aligned}
$$

se tranforma em

$$
\text { if } \mathrm{x}=\mathrm{y} \text { then } \mathrm{x}:=\mathrm{z} \text {; }
$$

Também para melhorar a legibilidade, algumas estruturas são re-indentadas e realinhadas. Alguns tipos de fontes também são alterados com o intuito de se destacar palavras importantes do texto: chamadas de funções são colocadas em itálico, os nomes das funções sendo declaradas ficam em negrito e os símbolos globais também são destacados tipograficamente ${ }^{1}$.

É importante observar que nenhuma das alterações feitas afeta a semântica do programa submetido - a saída gerada é totalmente compilável, além de ser totalmente equivalente à entrada.

\section{Um Estudo Experimental}

Para se comprovar na prática os benefícios do paradigma, vários estudos foram feitos.

Em um deles, de um editor de textos, escrito em aproximadamente 1000 linhas de Pascal, foi propositalmente retirado um procedimento (e todas as chamadas a ele no resto do programa) que tornava o tratamento de opções de linha de comando independente da ordem em que eles eram fornecidos.

Foram feitas duas versões de listagens: uma tradicional, formatada por uma ferramenta de formatação simples, e uma outra em forma de livro, segundo o paradigma proposto, ou seja, contendo índices, com divisões por capítulos, seções etc.

53 programadores sêniores foram convidados para o experimento, aos quais foram pedidos que restaurassem a funcionalidade original - ou seja, que reescrevessem o procedi-

\footnotetext{
${ }^{1} \mathrm{O}$ paper original não deixa claro sob que forma é feito esse destaque.
} 
mento retirado e colocassem chamadas nos pontos corretos (tarefa de manutenção essa que é similar a muitas que ocorrem no mundo real).

28 deles receberam a listagem tradicional e, 25, a em forma de livro, para que se pudesse estudar o efeito da formatação sobre o desempenho dos programadores.

Nenhuma explicação foi dada sobre o formato de livro usado em uma das versões de listagem - queria-se também medir qual o grau de facilidade em se compreendê-lo.

Para executar a tarefa, foi dado o tempo de uma hora. Os resultados estão ilustrados na figura 3-1.

Listagem tradicional

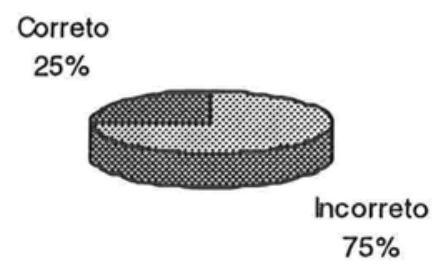

Listagem em forma de livro

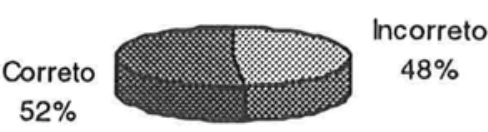

Figura 3-1: Comparação de desempenho entre os programadores com a listagem tradicional e a em forma de livro.

Dentre os que usaram a listagem tradicional, $75 \%$ não conseguiram terminar a tarefa ou a fizeram incorretamente, enquanto apenas $25 \%$ completaram a tarefa de forma desejada. Em contrapartida, dentre os que usaram a listagem em forma de livro, 52\% fizeram corretamente a manutenção, enquanto $48 \%$ não conseguiram terminar ou fizeram errado - ou seja, o índice de acertos do segundo grupo foi o dobro do índice do segundo.

\subsection{Decompositores}

Decompositores de programas (também chamados de sistemas de abstração de programas) têm como função sumarizar informações sobre a estrutura de um dado programa em um banco de dados (geralmente relacional), que pode então ser consultado para se analisar, estudar e entender vários aspectos do software.

\subsubsection{A Construção de um Decompositor de Programas}

A construção de um decompositor de programas envolve três passos [CNR90]:

1) Formação de um modelo conceitual: neste passo, definimos quais entidades e relacionamentos das estruturas dos programas a serem analisados serão alvo de futuro estudo. Em outras palavras, devemos fazer a modelagem conceitual dos dados envolvidos. 
2) Extração de visões relacionais: um analisador sintático e semântico é construído para se examinar código-fonte de programas e, a partir dos dados conseguidos, alimentar o banco de dados modelado anteriormente.

3) Construção de visões abstratas: ferramentas são projetadas para se ler o banco de dados gerado no item anterior e oferecer informações sobre algum aspecto da estrutura do programa sendo examinado dentro de um certo nível de abstração.

Esse procedimento ficará mais claro adiante.

\subsubsection{Alguns Exemplos de Decompositores}

Nesta seção, examinaremos rapidamente 3 analisadores: o FAST, para programas FORTRAN, o Omega, para programas escritos em uma linguagem semelhante a Pascal e, finalmente, o CIA, para programas em C. Esta última, devido a sua importância em nossa pesquisa (serviu de base para a nossa ferramenta), será coberta com maiores detalhes.

\section{FAST}

O FAST (FORTRAN Analysis System) [BJ77], é um analisador que a partir de programas escritos em FORTRAN, gera um banco de dados hierárquico que é então administrado por um sistema gerenciador de banco de dados (o System 2000), livrando assim o FAST dessa tarefa.

O modelo conceitual subjacente compreende as entidades módulos, comandos, nomes e seus relacionamentos. FAST então oferece uma interface a partir da qual o usuário pode obter informações sobre o programa analisado.

\section{Omega}

O Omega [Lin84] analisa programas escritos em uma linguagem parecida com Pascal chamada Model. Como o FAST, ele também gera um banco de dados (só que desta vez relacional), que é então administrado pelo sistema Ingres [SWKH76].

O modelo conceitual compreende dados mais detalhados sobre os programas, envolvendo entidades como variáveis, expressões, comandos etc a um nível tal que seja possível que os objetos do programa sendo considerado possam ser reconstruídos usando-se apenas o banco de dados formado. Obviamente, guardar tanta informação tem o seu preço: o processamento de um programa, ainda que não muito grande, leva muito tempo e exige uma quantidade de espaço considerável, além das consultas terem um tempo de resposta indesejavelmente alto.

\section{CIA}

O CIA ( $C$ Information Abstraction System), desenvolvido na Universidade da Califórnia em Berkeley [CNR90], é composto de três módulos principais: o $C$ Abstractor, que colhe informações a partir de um programa $\mathrm{C}$ e as insere em um banco de dados relacional; 0 InfoView, que oferece uma interface para consultas a esse banco; e o Software Investiga- 
tor, que consiste em um conjunto de ferramentas que fornece informações relevantes a respeito da estrutura do programa sendo examinado e que pode servir de apoio a reutilização de funções, análise de binding (a ser explicada adiante) etc.

Para evitar os problemas de eficiência e desempenho do Omega, o CIA não gera um banco de dados tão detalhado - apenas os símbolos globais e seus relacionamentos é que são guardados. A perda de informações não é grande, considerando-se que os objetos locais são relevantes, por definição, apenas dentro de um contexto limitado.

O Modelo Conceitual. Na figura 3-2 temos o diagrama de entidades e relacionamentos do modelo conceitual usado pelo CIA.

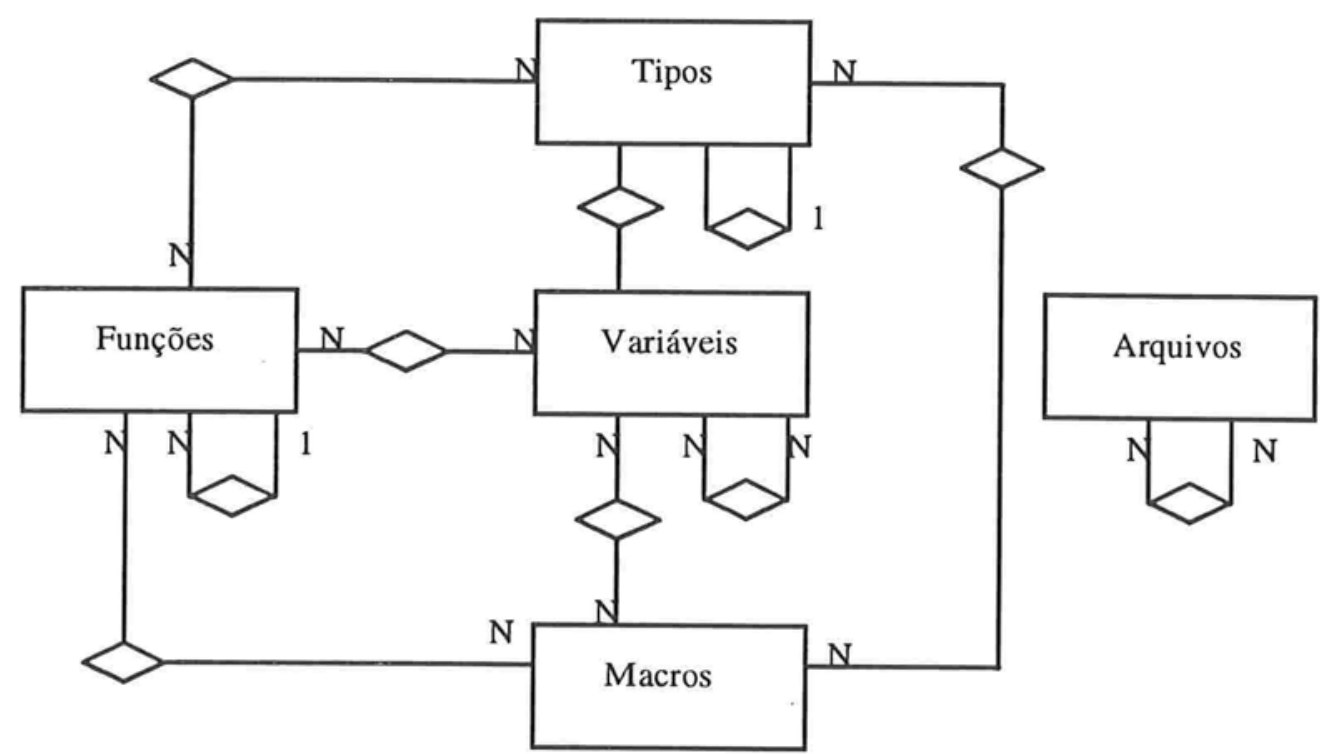

Figura 3-2: Modelo conceitual de um banco de dados de um programa C.

Um programa em $\mathrm{C}$ é visto como um conjunto de entidades (ou objetos) globais interrelacionados. Temos cinco tipos distintos de entidades: arquivos, macros, variáveis, tipos de dados e funções.

Cada entidade possui um conjunto de atributos. Por exemplo, a função main, não estática, da figura 3-3 é declarada no arquivo main. c entre as linhas 6 e 9, e retorna um valor do tipo int.

$<\operatorname{main} . \mathrm{c}>$

1 \#include "complex.h"

2 \#define TAM_MAX_STR 5

3 


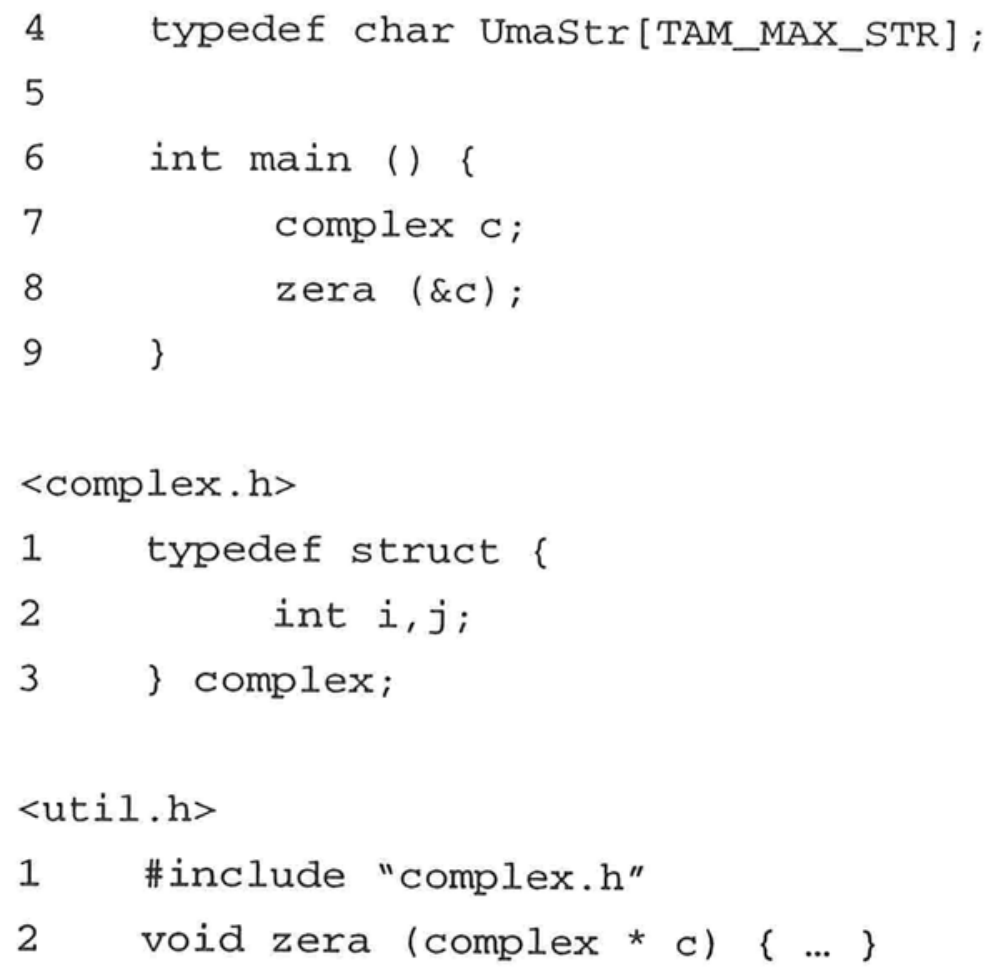

Figura 3-3 - programa exemplo em C

A lista de atributos de main ficaria como:

$\begin{array}{ll}\text { file (arquivo) } & \text { main.c } \\ \text { datatype (tipo de dados) } & \text { int } \\ \text { name (nome) } & \text { main } \\ \text { staric (estática) } & \text { no } \\ \text { bline (linha inicial) } & 6 \\ \text { eline (linha final) } & 9\end{array}$

Da mesma forma, há também um conjunto de atributos para cada um dos outros conjuntos de entidades.

Os relacionamentos. Dizemos que há um relacionamento de referência entre duas entidades A e B se a definição de A faz referência a B (em outras palavras, se A não puder ser compilado sem a definição de B). 
Por exemplo, na figura 3-3, o arquivo main. c tem um relacionamento de referência com $\mathrm{o}$ arquivo complex.h, assim como entre as funções main e zera.

Recuperando Informações. O banco de dados criado pelo CIA a partir de um programa C é gerenciado pelo sistema Ingres. Para consultá-lo, há duas alternativas básicas: usar a ferramenta InfoView ou diretamente junto ao gerenciador, usando a sua linguagem de consulta QUEL ${ }^{2}$. Abaixo, daremos exemplos de consultas através das duas formas.

Informações sobre entidades. O InfoView apresenta três comandos básicos: info, rel e view.

Info fornece informações sobre os atributos de uma dada entidade. Por exemplo, a seguinte instrução mostra os atributos da função main:

$\$$ info function main

file type function static bline eline

main. $\mathrm{C}$ int main no $\quad 6 \quad 9$

Usando diretamente uma linguagem de consulta, informações mais detalhadas podem ser obtidas sobre as entidades, como:

- qual o tamanho médio das funções?

- qual o número de funções estáticas no programa?

- qual o arquivo que tem o maior número de funções?

- quais funções no arquivo main.c retornam um valor int?

Em QUEL, a última consulta poderia ser expressa como

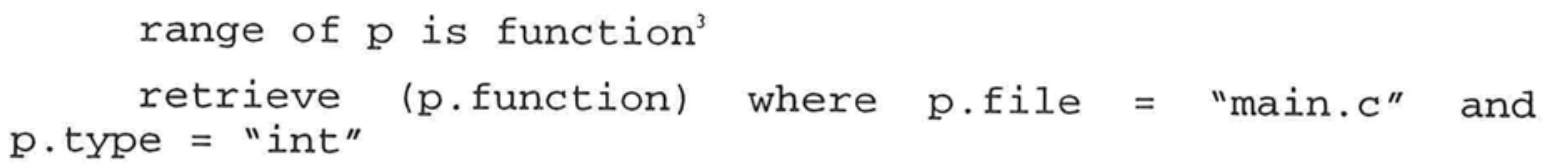

\footnotetext{
${ }^{2}$ Os autores do projeto optaram por usar o Ingres como seu gerenciador de banco de dados, mas poderiam perfeitamente ter usado um outro qualquer que aceitasse a linguagem SQL.

${ }^{3}$ Tabela que contém as funções
} 
O comando view mostra como uma certa entidade foi definida no texto do programa.

Por exemplo, para se obter a definição do tipo UmaStr, usamos

\$ view type Umastr

typedef char UmaStr[TAM_MAX_STR]

Neste caso, a definição da macro TAM_MAX_STR pode ser de interesse:

\$ view macro TAM_MAX_STR

\#define TAM_MAX_STR 5

Informações sobre os relacionamentos. O comando rel fornece informações sobre o relacionamento de duas entidades. Conforme veremos adiante, este comando é bastante útil especialmente para a construção de visões gráficas e estudo das estruturas dos programas.

A sintaxe básica é

rel classe-entidade1 classe-entidade2 nome-entidade1 nome-entidade2

Os dois primeiros argumentos especificam o tipo do relacionamento, e os dois últimos (opcionais), a entidade pai (a que faz uma referência) e a filha (a referenciada).

Por exemplo, para saber quais as funções chamadas por main,

\$ rel function function main -

$\begin{array}{llll}\text { file1 } & \text { function1 } & \text { file2 } & \text { function2 } \\ - & -- & - & --1 . c \\ \text { main.c } & \text { main } & \text { util.c } & \text { zera }\end{array}$

$\mathrm{O}$ '-' simboliza um coringa que indica que qualquer nome de entidade serve, e pode ser usado tanto para se especificar o pai como o filho, ou mesmo ambos.

De novo, usando diretamente a linguagem de consulta do gerenciador de banco de dados, poderíamos obter informações mais flexíveis sobre os relacionamentos, tais como:

- quais as funções definidas em util.c que são referenciadas por alguma função de main.c?

- quais as funções mais chamadas? 
- quais as funções estáticas que referenciam o tipo de dados complex?

Por exemplo, em QUEL, a última consulta pode ser obtida com

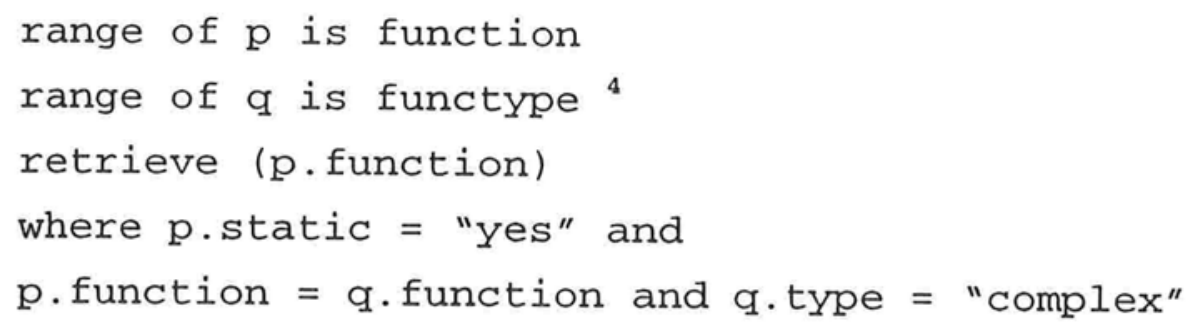

O Software Investigator. Dentro do CIA, há ainda um conjunto de ferramentas (denominado genericamente de Software Investigator) que utiliza as informações armazenadas no banco de dados para a geração de gráficos e análises de estruturas dos programas.

Por exemplo, a partir dos dados dos relacionamentos entre as entidades, pode-se desenhar grafos de chamadas entre funções, hierarquia de dependência de arquivos etc de forma razoavelmente simples: através de várias chamadas ao comando rel, visto anteriormente, consegue-se todas as informações desejadas (por exemplo, quais são as funções chamadas por cada rotina); os vários resultados, devidamente formatados, servem então de entrada a uma outra ferramenta, a DAG (que desenha grafos) [GNV88], que finalmente desenha o grafo desejado. Todo esse processo é devidamente encapsulado em um programa ou shell script.

Outra operação importante (também facilmente implementável usando o rel) é a extração de sub-sistemas induzidos por uma função $\mathrm{f}$, que é o conjunto de todas as entidades das quais $f$ depende, direta ou indiretamente, para que possa ser compilada. Operações desse tipo são importantes quando se deseja reutilizar uma dada função do programa.

O software investigator ainda oferece o que Hutchens e Basili [HB85] chamam de análise de bindings, que examina o quão forte duas funções estão acopladas - isto pode ser medido, segundo esses cientistas, calculando-se o número de objetos comuns referenciados por elas. A análise de binding é útil para a modularização do sistema, de modo que o acoplamento inter-módulos seja o mínimo possível.

${ }^{4}$ functype é a tabela que contém o relacionamento entre funções e tipos 


\section{Capítulo 4}

\section{Métricas de Software}

Neste capítulo, dissertamos sobre métricas de software - o que são, para que servem e qual o seu grau de confiabilidade. Em especial, nos concentramos naquelas métricas que poderão nos ser úteis ao nosso objetivo (avaliação de código).

\subsection{Introdução}

\subsubsection{Definição}

Métrica de software podem ser definida como sendo qualquer tipo de medida relacionada a um sistema de software, processo ou sua documentação. Exemplos triviais: número de linhas de código de um sistema, número de erros detectados, quantidade de programadores exigidos para a codificação etc.

\subsubsection{Classes}

Podemos dividir as métricas em duas classes:

- métricas de controle: são as que assistem o controle ou administração do processo de desenvolvimento

- métricas de previsão: são aquelas que podem ser usadas para se prever algum aspecto da qualidade do produto ou de uma métrica de controle.

Outra classificação comumente usada é a seguinte: 
- métricas de produto: são as que quantificam algum aspecto de um produto (final ou intermediário) dentro do ciclo de desenvolvimento, como documentos, especificações, código, relatórios de teste etc. Por exemplo, número de linhas de código.

- métricas de processo: são as que quantificam atributos do processo de desenvolvimento e seu ambiente (por exemplo, tempo gasto na codificação de um sistema).

Observe que as métricas de controle não são específicas a software - qualquer ambiente de produção industrial pode ser administrado e controlado por métricas similares.

Kitchenham, em [Kitch90b], cita três categorias de métricas de controle: as de recursos, que podem medir esforço, tempo, uso de máquina etc; as usadas para se estimar quanto trabalho ainda resta a ser feito para se concluir um projeto, como percentual do número de módulos previstos que foram codificados, e as de controle de defeitos.

Métricas de previsão são medidas de um atributo de um produto que pode ser usado para se prever uma qualidade associada a ele. Por exemplo, sugere-se que tendo em mãos o número de decisões que existem em um programa, supostamente pode-se estimar o quão difícil será mantê-lo (se essas previsões são realmente válidas ou não, permanece uma questão em aberto - nas seções seguintes discutiremos a questão em mais detalhe).

Idealmente, gostaríamos de poder avaliar uma certa qualidade externa de um programa (como confiabilidade, por exemplo) medindo um atributo interno (como número de decisões) - isto porque um atributo externo é algo que só conseguiríamos conhecer com exatidão depois de um tempo (nem sempre curto) de uso do software.

A figura 4-1 mostra alguns relacionamentos entre características qualitativas de um software e seus atributos internos que, acredita-se, podem ser verdadeiros. 


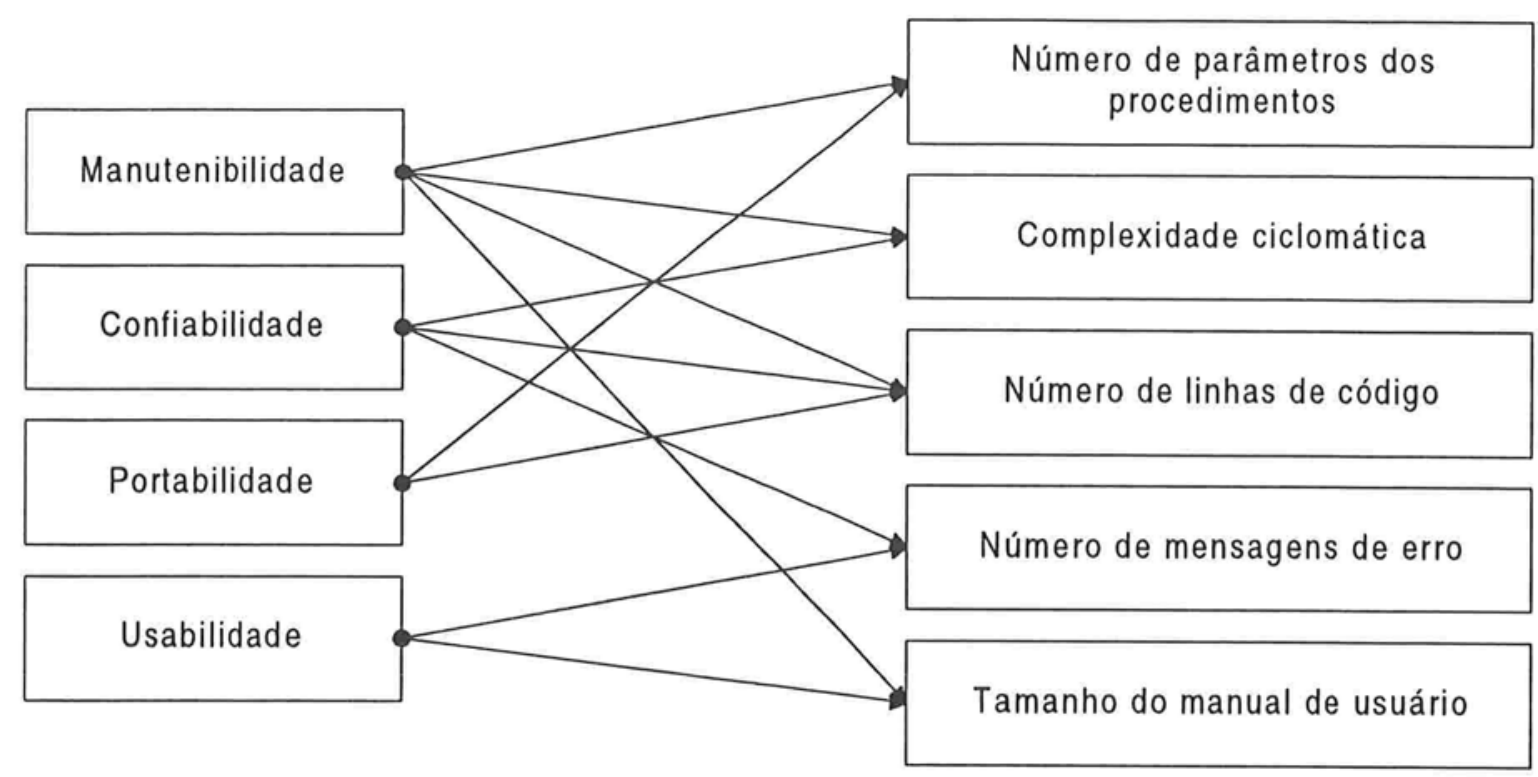

Figura 4-1: Possíveis relações entre características internas de um software e características qualitativas externas [Som96].

\subsubsection{Interpretação das métricas}

As métricas de software, em geral, não possuem uma escala de interpretação como tem, digamos, as medidas de temperatura - ou seja, não há como interpretar um valor de 100 linhas de código da mesma maneira como um valor de $100^{\circ} \mathrm{C}$ (ou seja, de forma absoluta). Normalmente, as métricas são interpretadas de forma relativa.

Kitchenham [Kicth90b] sugere três formas:

- Comparações com valores planejados ou esperados: compara-se os valores das métricas obtidos com aqueles que foram inicialmente planejados ou estimados.

- Comparações com outros projetos similares: um valor de uma métrica é julgado normal ou anormal pela comparação com outros valores obtidos em projetos similares caso, por exemplo, de um conjunto de projetos realizados como exercício por alunos de uma mesma turma.

- Comparações com outros componentes dentro de um projeto: semelhante ao item anterior, só que aqui comparamos métricas de módulos/procedimentos dentro de um mesmo projeto; dessa forma, podemos identificar, por exemplo, módulos críticos com taxas de erros grandes demais se comparados com a média. 


\subsection{Ciência do Software}

A teoria de ciência do software foi formalizada por Halstead em sua monografia Elements of Software Science, publicada em 1977 [Hal77]. Nesta teoria, todo programa de computador é visto como uma série de tokens. Cada token, por sua vez, pode ser classificado em apenas duas maneiras: ou ele é um operador ou é um operando (esta idéia vem do fato que todos os programas podem ser reduzidos a uma seqüência de instruções em liguagem de máquina que são compostos por um operador e um número de operandos).

Assim, definem-se 4 métricas básicas que servirão de base para as demais:

$\eta_{1}=$ número de operadores únicos

$\eta_{2}=$ número de operandos únicos

$N_{l}=$ número total de ocorrências de operadores

$N_{2}=$ número total de ocorrências de operandos

O tamanho do vocabulário de um programa, que consiste do número de tokens únicos usados para a construção de um programa, é definido como

$$
\eta=\eta_{1}+\eta_{2}
$$

Define-se o comprimento da implementação como

$$
N=N_{1}+N_{2} \text {. }
$$

Volume é uma outra medida para o tamanho do programa, que é definido como

$$
V=N \cdot \log _{2} \eta \text {. }
$$

$V$ pode ser interpretado de duas maneiras:

a) como o tamanho real (em bits) de um programa em um computador, assumindo-se que uma codificação binária do vocabulário foi utilizada, ou

b) como o número máximo de comparações mentais necessárias para se escrever um programa de tamanho $N$, levando-se em consideração que para cada um dos $N$ tokens do programa, uma busca binária foi usada para selecionar o operando/operador correto do vocabulário de tamanho $\eta^{l}$.

\footnotetext{
${ }^{1}$ Essa idéia de que o ser humano faz "buscas" pela sua memória fazendo uma pesquisa binária nunca foi confirmada por experimentos psicológicos, servindo inclusive de argumento para severas críticas contra a teoria como um todo, como em [Coul83].
} 
Um algoritmo pode ser implementado de várias maneiras por programas equivalentes. Dentre esses programas, o de tamanho mínimo, por definição, é dito ter um volume $V^{*}$.

Qualquer programa com um volume $V$ está implementado em um nível $L$, que é definido como

$$
L=V^{*} / V .
$$

A dificuldade de um programa é definida como sendo o inverso de $L$, ou seja,

$$
D=1 / L \text {. }
$$

O esforço requerido para implementar um programa aumenta conforme o tamanho também aumenta. Também exige-se mais esforço implementar um programa em um nível mais baixo quando comparado com outro programa equivalente em um nível superior.

Assim, a teoria define esforço como

$$
E=V / L=D \times L
$$

(a unidade de E é "discriminações mentais elementares").

A teoria tenta ainda caracterizar outros atributos de programas, como o nível da linguagem $\lambda$, que expressa o poder da linguagem sendo usada para implementar o programa; $T$, que é o tempo necessário para se codificar o programa; $B$, que é número de erros restantes em um programa ao fim de alguma fase do processo de desenvolvimento etc.

\section{Fórmulas}

$L$ não é diretamente mensurável; em seu lugar, usa-se o estimador $L_{\text {est }}$ :

$$
L_{\text {est }}=\left(2 / \eta_{1}\right)\left(\eta_{2} / N_{2}\right)
$$

O nível da linguagem é dado por

$$
\lambda=L_{\text {est }}^{2} V
$$

O esforço E é dado por

$$
E=V / L_{\text {est }}
$$

Enquanto $B$ e $T$ são estimados por

$$
T_{\text {est }}=E / 18 \quad B_{\text {est }}=E^{2 / 3} / 3000=V / 3000
$$




\section{Críticas}

Halstead não define de forma precisa como classificar um token como operador ou operando - apenas cita que um símbolo ou palavra-chave que especifica uma ação é um operador, e os que representam dados, operadores.

Entretanto, em algumas linguagens, isto gera algumas ambigüidades: em $\mathrm{C}$, por exemplo, um ponteiro para uma função pode se encaixar em ambas as categorias.

A teoria também diz que as seções de declarações devem ser ignoradas. Entretanto, em linguagens como COBOL, essas seções representam boa parte do esforço de codificação, volume etc.

Existem ainda outros vários problemas - ao leitor interessado, citamos [SCD83] e [HF81].

\section{Estudos}

Um grande volume de estudos foi feito a respeito da teoria, chegando inclusive a merecer um número completo dedicado ao assunto da respeitada IEEE Transactions on Software Engineering (edição de março de 1979).

Entretanto, [Kitch90] diz que a maioria desses estudos confundiram identificação de correlações, que indicam a existência de um relacionamento, com estudos de regressões, que indicam a natureza de um relacionamento. Além disso, em muitos casos não se testou estatisticamente qualquer das hipóteses consideradas.

Hamer e Frewin [HF81] fizeram uma completa reavaliação dos estudos e concluíram que os resultados obtidos, em sua maioria, foram totalmente ilusorios.

\section{Conclusões}

A importância da ciência do software é muito mais histórica do que prática. Descartamos a aplicação das métricas desenvoldidas pela teoria.

\subsection{Descrições de Métricas}

\subsubsection{Linhas de Código (LC)}

O número de linhas de código é, sem dúvida alguma, a métrica mais usada e estudada até hoje [Nick94, PCM91], provavelmente devido a sua grande simplicidade e facilidade com que é calculada. Ela se baseia essencialmente na idéia de que programas com um maior número de linhas são mais complexos e mais difíceis de serem elaborados e mantidos.

LC é, basicamente, uma medida do tamanho físico do código fonte de um programa ou componente dele. 
Essa métrica admite um grande número de variantes e antes de ser usada, deve-se especificar com exatidão qual delas é a adotada - por exemplo, se deve-se contar as linhas de comentários, as linhas em branco, as linhas de declarações, as linhas usadas para depuração do programa etc.

\section{Usos}

Normalmente, LC é usada como métrica para estimação de esforço e tempo requerido para se terminar um produto, assim também como uma métrica de complexidade, servindo para identificação de componentes críticos de um software. Pode também ser usada como uma métrica de controle para se quantificar que porcentagem de um projeto está pronta.

\section{Críticas}

As grandes falhas dessa métrica são frutos de sua ingenuidade (visão simplista para uma limha de código).

Por exemplo, enquanto métrica de complexidade, a heurística de LC assume que todas as linhas de um programa contribuem de forma uniforme. Assim, tanto a linha

$$
\mathrm{x}=1
$$

como

$$
\mathrm{x}=(\mathrm{y}<(\mathrm{x} \& \mathrm{w}) ? \mathrm{~h} * \mathrm{~d}: \mathrm{k} * \mathrm{~m}) ;
$$

supostamente são igualmente complexas, o que, intuitivamente, não nos parece correto e poderia comprometer a acurácia da métrica.

Igualmente, LC também assume que dois programas com o mesmo número de linhas são, no mínimo, semelhantemente complexos, ignorando assim aspectos importantes que afetam a complexidade de um programa como o domínio da aplicação, por exemplo (30 linhas do núcleo de um sistema operacional são, em geral, mais complexas que 30 linhas de um programa de controle de folha de pagamento).

Como métrica de produtividade, LC peca por desconsiderar que programadores com diferentes estilos e níveis de experiência podem resolver um mesmo problema com um número de linhas bastante diferente (assim, um programador que codifica 300 linhas por dia não é, necessariamente, mais produtivo que um que escreve apenas 200, considerandose que o estilo do último seja mais enxuto). A situação se agrava se compararmos programas escritos em linguagens diferentes (a implementação de soluções em linguagens como a linguagem de máquina tendem a ter um maior número de linhas que as equivalentes em Pascal, por exemplo).

\section{Estudos}

Kitchenham e Shepherd, em [KPL90, Shep90], compararam LC como estimadora de complexidade com outras métricas mais sofisticadas (a de fan-in e fan-out informacionais, 
por exemplo, descritas na seção 4.4.4) e concluíram que todas apresentam eficiência semelhante (ambas tiveram boa concordância com os examinadores humanos com respeito a complexidade dos programas examinados).

Outros estudos, como [KC85] ou [Kitch86], relatam que existe uma associação entre o tamanho de um componente e o número de erros achados nele.

\section{Conclusões}

LC pode ser recomendada como métrica de controle ou como estimadora de complexidade, contanto que seja usada e interpretada com cuidado.

Antes de tudo, é necessário se definir de forma precisa o que deve ser contado ou não. Deve-se também tomar o cuidado de fazer comparações dentro de um contexto onde os programas estejam escritos em uma mesma linguagem e a diferença de estilos e experiência dos programadores não seja grande o suficiente a ponto de comprometer os resultados.

Tomadas as devidas precauções, devido a sua simplicidade e facilidade com que é calculada, LC pode ser uma boa métrica.

\subsubsection{Número de tokens (NT)}

Assim como LC, o número de tokens ${ }^{2}$ [Nick94] é uma métrica bastante simples, embora não seja tão intuitiva e facilmente computável. A sua heurística se baseia na suposição que um programa com mais tokens seja mais complexo do que um com menos.

Esta métrica elimina alguma das ambigüidades intrínsecas de LC (por exemplo, linhas em branco nunca serão levadas em consideração, assim como comentários), mas introduz algumas novas: pares de delimitadores (como ( e l) devem ser contados como apenas 1 token ou 2 ?

\section{Críticas}

NT, assim como LC, também paga o seu preço devido à sua ingenuidade, de modo que críticas análogas aplicadas à LC também valem aqui.

A contagem de tokens separadores também pode levantar alguns problemas: o fato de uma vírgula ser contada como uma ocorrência, ao passo que um espaço em branco não, faz com que programas escritos em Lisp tenham o valor de NT diferenciados - por exemplo, foo $(\mathrm{a}, \mathrm{b})$ terá $\mathrm{NT}=5$, mas em Lisp, a expressão equivalente ( $f \circ \circ \mathrm{a} \mathrm{b}$ ) teria $\mathrm{NT}=4$.

\section{Estudos}

Não temos conhecimento de estudos sobre o assunto.

\footnotetext{
${ }^{2}$ Tokens são os menores itens (também chamados de itens léxicos) de um texto efetivamente tratados por um compilador (por exemplo, símbolos especiais, identificadores, números etc).
} 


\section{Conclusões}

Devido a maior importância da métrica LC (no sentido em que ela foi muito mais pesquisada e estudada), consideramos melhor a aplicação dela do que NT.

\subsubsection{Complexidade Ciclomática}

A complexidade ciclomática foi introduzida por McCabe em [McCab76] e é uma métrica que modela programas usando teoria dos grafos.

Dado um programa, considere o seu grafo $G$ de fluxo de controle ${ }^{3}$. A complexidade ciclomática (ou número ciclomático), denotada por $v(G)$, é igual ao número de caminhos de execução linearmente independentes de $\mathrm{G}$.

Pode-se provar [McCab76] que, em programas estruturados, v(G) pode ser calculado facilmente a partir do texto do código fonte: basta somar 1 ao número de condições em comandos de decisão do programa (note que condições compostas com n predicados devem ser contadas como $\mathrm{n}$ ).

\section{Usos}

Pela própria definição de $\mathrm{v}(\mathrm{G})$, o número ciclomático pode ser usado como uma medida de testabilidade, servindo para estimar o esforço necessário para testes estruturais - para se exercitar todos os caminhos independentes de um programa, pelo menos $\mathrm{v}(\mathrm{G})$ casos de teste precisam ser elaborados e testados.

Além disso, McCabe também sugere o uso dessa métrica para identificação de módulos de difícil manutenção e entendimento (que seriam exatamente aqueles que tivessem v(G) superior a um certo limite - ele sugere 10 para programas FORTRAN).

\section{Críticas}

Em seu cálculo, v(G) leva apenas em conta a complexidade da estrutura de controle do programa, ignorando a complexidade de suas estruturas de dados. Entretanto, é possível simplificar a estrutura de controle de um programa sacrificando os seus dados, como mostra o seguinte exemplo:

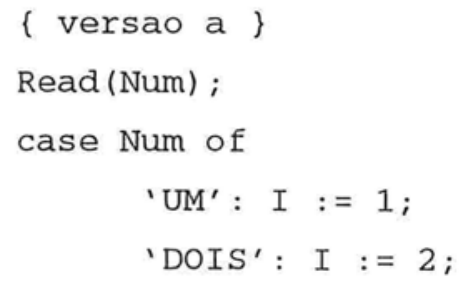

${ }^{3}$ Grafo de fluxo de controle de um programa é um grafo onde cada vértice representả ưm bloco do programa [seção 4.3.4] e dois vértices $a$ e $b$ são adjacentes se, $\bullet$ sonkente se, a execurqãa do bloco correspondente a $a$ pode ser seguida pela de $b$. 
end;

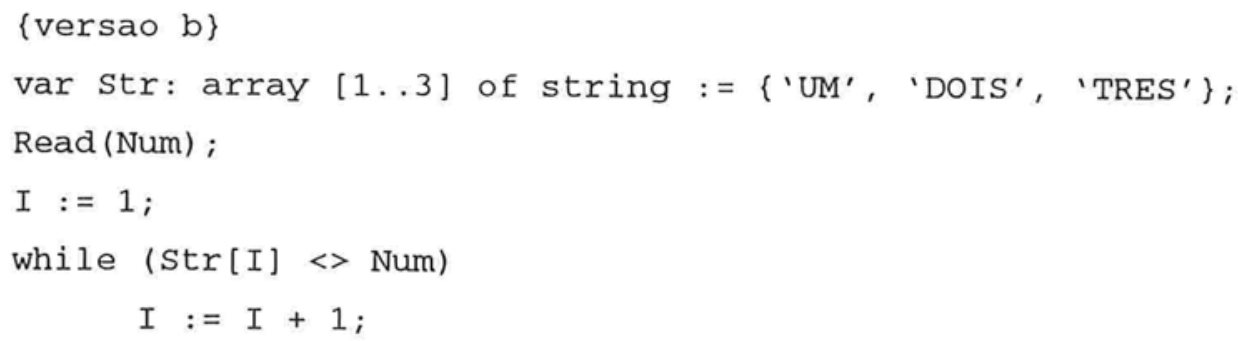

$\mathrm{v}(\mathrm{G})$ na versão b é menor do que na versão a, mas introduziu uma estrutura de dados a mais (que neste exemplo não é muito complicada, mas poderia ser arbitrariamente complexa).

Outro ponto freqüentemente criticado no número ciclomático é o fato de não diferenciar comandos de decisão aninhados ou não-aninhados, embora os do primeiro tipo, pelo menos intuitivamente, colaboram mais para a complexidade de um programa (principalmente quando a profundidade do aninhamento não é pequena).

\section{Estudos}

Schneidewind, em [Schn79], em um estudo feito sobre um programa escrito em Algol de 31 módulos, descobriu que dentre os 64 erros encontrados, 40 deles estavam em módulos cujo $\mathrm{v}(\mathrm{G})$ era maior do que 4 .

Walsh, em [Wal79], em um estudo semelhante, concluiu que os módulos (dentre o total de 276) de um grande sistema que apresentavam $v(G)>=10$ tinham maior incidência de erros do que os outros.

Henry, Kafura e Harris, em [HKH81], coletaram o histórico de erros do sistema Unix e chegaram a uma correlação entre $v(G)$ e o número de erros superior a 0,9.

Grady, em [Gra94], reporta ainda que na Hewlett-Packard, onde essa métrica vem sendo usada com aprovação, estudos mostraram que o número de atualizações efetuadas sobre um módulo é proporcional ao valor de $\mathrm{v}(\mathrm{G})$.

Por outro lado, Shepherd [Shep88] critica a métrica devido à falta de um modelo teórico explícito na qual se baseie e, pelos resultados dos experimentos feitos por ele, pelo seu fraco desempenho experimental. 


\section{Conclusões}

Os estudos encorajadores realizados sobre a métrica aliada a sua simplicidade, faz de v(G) uma boa sugestão de métrica a ser calculada.

\subsubsection{Oviedo}

Oviedo, em [Ov80], desenvolveu uma métrica para identificação de módulos excessivamente complexos dentro de um programa que requerem cuidados especiais. Ao contrário da métrica de McCabe, a métrica proposta por Oviedo procura levar em conta não apenas a complexidade do fluxo de controle mas também a do fluxo de dados.

Antes, porém, cabem aqui algumas definições preliminares: um bloco de um programa é uma seqüência maximal linear de instruções ordenadas que tem as seguintes propriedades:

a) sempre que a primeira instrução é executada, todas as outras estão programadas para também o serem;

b) a primeira instrução é a única que pode ser executada diretamente depois da execução de um outro bloco

Ocorre uma definição de uma variável $v$ sempre que uma instrução qualquer modifica o valor de v. Uma referência à variável $v$ acontece quando v é usada em alguma expressão sem, entretanto, afetar o seu valor (no lado direito de uma atribuição ou em uma instrução de saída, por exemplo).

Para a definição da métrica, Oviedo fez duas suposições básicas:

a) Variáveis que são referenciadas em um bloco e que não foram definidas nesse mesmo bloco colaboram para tornar mais difícil o seu entendimento.

b) Quanto maior o número de blocos, mais complexo é o programa.

Oviedo então sugere que a complexidade de um programa pode ser estimada pela fórmula

$$
C=p \cdot F C+q \cdot F D
$$

onde

$F C=$ complexidade do fluxo de controle, que é igual ao número total de arestas do grafo de fluxo de controle.

$F D=$ complexidade do fluxo de dados, que é igual a soma da complexidade do fluxo de dados de todos os blocos do programa. A complexidade de dados de um bloco $b$ é igual o número de variáveis referenciadas mas não definidas em $b$.

$p$ e $q=$ pesos para cada uma das complexidades, que podem ser ambas iguais a 1. 


\section{Críticas}

Kitchenham [Kitch90] faz uma crítica interessante a essa métrica: a fórmula sintetiza duas quantidades cujas unidades de medida são distintas.

Isto traz dois problemas:

a) A unidade de medida da métrica não é clara.

b) A forma sintética torna mais difícil a interpretação dos valores fornecidos pela métrica, já que se perde a informação de quanto cada uma das duas quantidades somadas contribui para o valor final. Na prática, isso pode ser importante no momento em que se deseja reprojetar módulos cujas complexidades estão muito altas donde surge a questão: o módulo está muito complexo por causa dos dados ou por causa do controle?

\section{Estudos}

Não se tem conhecimento de nenhum estudo de validação dessa métrica.

\section{Conclusões}

A inexistência de estudos anteriores desencoraja a sua implementação.

\subsubsection{Fan-In e Fan-Out Estruturais}

Fan-In e Fan-Out estruturais são duas métricas sugeridas por Yourdon e Constantine [YC79] que tentam quantificar o grau de acoplamento entre módulos de um sistema a partir de sua representação em um diagrama de estruturas (structure chart).

O fan-in de um componente é dado pelo número de linhas que entram em sua caixa no diagrama de estruturas (em outras palavras, é o número de módulos que o invocam). O fan-out corresponde ao número de linhas que saem (ou seja, é o número de módulos que ele chama).

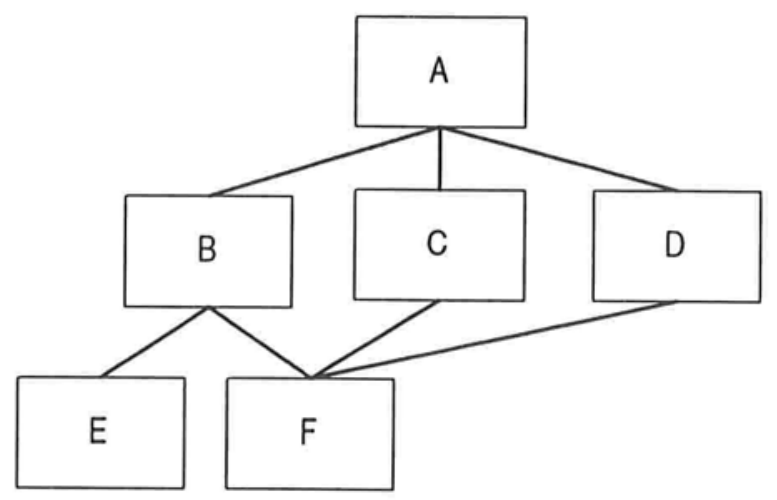


No exemplo acima, fan-in $(B)=1$ e fan-out $(B)=2$, enquanto fan-in $(F)=3$ e fan-out $(F)$ $=0$.

Um fan-in alto pode chamar a atenção a módulos críticos de alta responsabilidade, cujo mau funcionamento pode comprometer a funcionalidade dos vários outros módulos que utilizam os seus serviços e, portanto, devem ser alvos de um cuidadoso exame e checagem de erros (ou mesmo remodularização).

Um fan-out elevado, por sua vez, pode sugerir que a dificuldade em se entender o módulo é grande, devido a complexidade da lógica de controle exigida para coordenar todos os componentes subordinados.

\section{Estudos}

Troy e Zweben [TZ81] estudaram as métricas e observaram que o valor de fan-out de um módulo é correlacionado com a sua probabilidade de ocorrência de erros. $\mathrm{O}$ valor do fanin, pelo contrário, não demonstrou esta tendência. Estudos de Kitchenham et al [KPL90] confirmaram esses dados.

\section{Conclusões}

Dada a simplicidade das duas métricas e os resultados de estudos anteriores, os dois valores podem ser calculados, embora apenas fan-out tenha se mostrado promissora.

\subsubsection{Fan-In e Fan-Out Informacionais}

Henry e Kafura, em [HK81], fizeram uma espécie de generalização dos conceitos de fan-in e fan-out estruturais à qual deram o nome de fan-in e fan-out informacionais.

As métricas de fan-in/fan-out informacionais são baseadas no fluxo de informação entre procedimentos, que inclui não apenas o fluxo baseado no fato de um procedimento chamar o outro, mas também nas informações passadas por meio de valores de retorno e naquelas que são passadas entre procedimentos via estruturas de dados globais.

Antes de definir a métrica, precisamos estabelecer alguns conceitos básicos.

Há uma ocorrência de um fluxo local de informação que sai de um módulo A e entra em um módulo B quando pelo menos uma das seguintes condições valem:

a) A chama B

b) B chama A e A retorna um valor que B subseqüentemente utiliza

c) um terceiro módulo $\mathrm{C}$ chama $\mathrm{A}$ e depois $\mathrm{B}$, passando um valor de saída de $\mathrm{A}$ como entrada para B.

O fan-in informacional de um procedimento A é o número de fluxos locais que entram em A mais o número de estruturas de dados globais dos quais A recupera informações. 
O fan-out informacional de um procedimento A é o número de fluxos locais que saem dele somado ao número de estruturas de dados globais que ele atualiza.

Cabe aqui observar que como em toda chamada de procedimento há um fluxo local de informação, a contagem de fan-in/fan-out informacional engloba a estrutural.

Henry e Kafura então definem a seguinte fórmula para indicar a complexidade de um procedimento:

$$
C=\text { tam } \mathrm{x}(\text { fan-in informacional } \mathrm{x} \text { fan-out informacional })^{2}
$$

onde tam pode ser dado por qualquer métrica de tamanho (como, por exemplo, o número de linhas de código).

\section{Usos}

Os autores sugerem pelo menos três usos para a métrica:

1) Identificação de procedimentos pouco coesos: valores altos de fan-in e fan-out de um procedimento revelam um grande número de conexões com o resto do programa, o que pode indicar que o procedimento executa mais de uma função (devendo, portanto, ser remodularizado).

2) Identificação de pontos de estresse: procedimentos com alta complexidade podem ser pontos de estresse (procedimentos com um grande volume de informações atravessando por ele), que são de baixa manutenibilidade - qualquer mudança em um procedimento desse tipo potencialmente gera um grande número de efeitos colaterais no resto do programa.

3) Deteç̧ão de um refinamento inadequado: por exemplo, um procedimento com um valor muito alto de fan-in ou fan-out pode revelar uma falha no projeto original, onde deveria haver um nível de abstração extra.

\section{Críticas}

Ao contrário do fan-in/fan-out estrutural, esta métrica procura levar em conta a interação de um procedimento com as suas estruturas de dados, o que é algo bom.

A exemplo do que ocorre na métrica de Oviedo, a fórmula de Henry e Kafura multiplica fatores de unidades diferentes, de modo que as mesmas críticas aplicadas à primeira também valem aqui.

Outro problema é que a métrica pode nos fornecer valores nulos para procedimentos arbitrariamente complexos, contanto que o seu fan-in ou fan-out seja igual a zero. Este pode ser o caso, por exemplo, de um procedimento que está na camada mais baixa de um sistema (eventualmente até contendo operações que lidam diretamente com o hardware) e com fan-out nulo. 


\section{Estudos}

Henry e Kafura, em [HK81], aplicaram as métricas a um programa (o sistema operacional Unix), e concluíram que o valor da métrica de um procedimento é correlacionado com o número de mudanças que ele viria a sofrer posteriormente.

Entretanto, Kitchenham e Shepherd, em [KPL90, Shep90], comparam essa métrica com outras mais simples (linhas de código e número ciclomático), e concluíram (surpreendentemente) que ambas são igualmente (razoavelmente) eficazes como estimadoras de complexidade de um procedimento.

\section{Conclusões}

Embora aparentemente seja promissora e bem elaborada, ao levar em consideração vários fatores que influenciam a complexidade de um programa, estudos demonstraram que ela não é mais eficaz que outras métricas mais simples.

Assim, talvez não valha a pena a sua implementação, claramente não trivial.

\subsubsection{Yin \& Winchester}

Yin \& Winchester desenvolveram um conjunto de métricas para avaliação de complexidade de um sistema de software baseando-se no número de módulos do seu desenho e a topologia das conexões entre eles [Kitch90].

A idéia básica é comparar a estrutura de projeto do sistema a ser avaliado com a estrutura que Yin \& Winchester consideram ideal, que é a estrutura de árvore - quanto mais semelhante a estrutura for a de uma árvore, melhor ela é.

As métricas podem ser aplicadas a sistemas ou sub-sistemas.

\section{Usos}

As métricas são usadas para indicar quais pontos de um desenho são de má qualidade.

\section{Fórmulas}

As quantidades básicas, que podem ser calculadas a partir do diagrama de estruturas do sistema, são:

- $A_{i}$, que é o número total de arcos que ligam os módulos (considerando-se todos os níveis entre 0 e i) do desenho sendo examinado

- $\quad N_{i}$, que o número total de módulos entre os níveis 0 e i 
O número de arcos em uma estrutura ideal (a de árvore, ou seja, onde cada módulo é chamado apenas por um outro) é igual ao número total de módulos menos 1, i.e.,

- $T_{i}=N_{i}-1$

A partir desses valores, as 3 medidas de qualidade de desenho podem ser calculadas:

- $C_{i}=A_{i}-T_{i}$, que tenta medir a complexidade absoluta do nível i do desenho

- $R_{i}=C_{i} / A_{i}$, que tenta medir a complexidade relativa do i-ésimo nível (também chamado de impureza relativa)

- $D_{i}=\left(C_{i}-C_{i-1}\right) /\left(A_{i}-A_{i-1}\right)$, que supostamente mede a complexidade relativa de um nível da hierarquia (também chamado de impureza diferencial)

\section{Críticas}

O maior problema dessa métrica é, sem dúvida, a sua fundamentação sobre a hipótese de que o formato 'ideal' de um diagrama de estruturas é a de árvore. Esta idéia não é compartilhada, por exemplo, por Constantine \& Yourdon, os proponentes do método de projeto que leva ao uso desses diagramas - eles recomendam [YC79] que sejam projetados módulos de uso genérico (para executar tarefas freqüentemente requisitadas) e que sejam postos nos níveis mais inferiores do desenho (de modo que possam ser chamados) e que, portanto, fazem com que vários arcos incidam sobre esses módulos, afastando o formato do desenho de uma árvore.

Além disso, a existência de módulos chamados por mais de um outro não torna o sistema, necessariamente, menos claro - pelo contrário, considerando que isso pode reduzir duplicações. Estruturas não-árvores também podem servir para a identificação de módulos candidatos a reutilização, o que é algo positivo.

\section{Estudos}

[Kitch90] cita estudos sobre dois sistemas que indicaram a existência de uma associação entre $C_{i}$ e $R_{i}$ com a taxa de erros encontrados. Desconhece-se a validação das métricas como avaliadoras de clareza e manutenibilidade.

\section{Conclusões}

Pelo que foi discutido na seção de críticas, não vemos motivos para se empregar essa métrica. 


\subsubsection{Young \& Kampen}

Young e Kampen, em [YK79], publicaram uma métrica para se estimar a legibilidade de programas de tamanho médio, escritos em linguagem estruturada, a partir de características de seu código e sua estrutura.

Em seu estudo, foi analisado um conjunto de programas e, a partir de uma análise de regressão linear, chegou-se a formula

$$
L=0,295 \text { VAR - 0,499 NLC + 0,13NC }
$$

onde $\quad \mathrm{VAR}=$ tamanho médio normalizado dos nomes das variáveis

NLC = número de linhas contendo comandos

$\mathrm{NC}=$ número ciclomático

\section{Uso}

Uma métrica de legibilidade pode ser usada para se avaliar o nível de dificuldade para se entender, manter e estender um programa.

\section{Críticas}

Pelo fato da fórmula ter sido obtida por estudos de regressão, é bem provável que ela seja dependente de ambiente. Assim, mesmo supondo que realmente exista uma associação entre a legibilidade de um programa com, por exemplo, o número ciclomático, é bastante improvável que os coeficientes sejam iguais para todos os programas.

De qualquer forma, é bastante estranho que o coeficiente de $N C$ na fórmula seja positivo, o que implica que quanto maior a complexidade ciclomática, mais legível é o programa.

\section{Conclusões}

Como os coeficientes da fórmula provavelmente são dependentes do ambiente, é necessário, antes de se aplicá-la, que se faça uma recalibração, o que pode ser um estudo bastante oneroso e mesmo arriscado, considerando-se a ausência na literatura de estudos independentes que confirmem a associação entre número de linhas com comandos, número ciclomático e tamanho de variáveis com legibilidade.

Sendo assim, não nos parece recommendável o seu uso. 


\section{Capítulo 5}

\section{O AVASAP - Avaliador Semi-Automático de Programas}

Neste capítulo, apresentamos a especificação, projeto e descrição da ferramenta que propomos para auxiliar na tarefa de correção de programas, ao qual demos o nome de AVASAP (Avaliador Semi-automático de Programas).

\subsection{Algumas Idéias Preliminares}

Antes de partirmos para a descrição da ferramenta, gostaríamos de discutir alguns pontos importantes que pudemos aprender a partir da discussão feita nos capítulos anteriores.

\subsubsection{Sobre As Ferramentas de Reengenharia}

Do capítulo 3, onde fizemos um estudo sobre algumas ferramentas disponíveis de reengenharia, destacamos o seguinte:

- Um abstrador de programas pode ser uma ferramenta bastante útil também na correção de programas. Ferramentas como o CIA, originalmente pensadas para o estudo de estruturas de programas, pelo simples fato de gerar dados que ajudam no entendimento deles (atividade fundamental na sua correção), como quais funções chamam uma certa rotina, já podem ser consideradas bastante úteis. Além disso, elas podem também fornecer algumas métricas interessantes, assim como informações derivadas, como detecção de funções mortas (não chamadas por nenhuma outra), dados sobre o uso de símbolos, que poderiam sugerir ao avaliador, por exemplo, qual o grau de acomplamento entre as funções (através da quantidade de variáveis globais acessadas), quais as estruturas de dados mais importantes, partindo-se da idéia (não necessaria- 
mente correta, que precisaria ser checada) que as variáveis mais usadas são as mais importantes etc.

- Um mecanismo para rápida localização de símbolos e trechos de programas seria bem-vindo em uma ferramenta de avaliação. A exemplo do que ocorre com os abstradores de programas, algumas propriedades dos reformatadores de código (a exemplo do bookmaker, examinado no capítulo 3) também seriam interessantes em uma ferramenta de avaliação, como a de facilitar a localização de pontos importantes de um texto de programa e melhora de legibilidade.

Pensando em unir essas duas características, chegamos à idéia de que oferecer uma interface hipertexto [Con87] seria uma boa saída. A forma como usamos essa tecnologia ficará mais clara nas seções seguintes.

\subsubsection{Sobre as Métricas}

Do capítulo sobre métricas, observamos o seguinte:

- A aplicação de métricas pode ser útil. Estudos sugerem que o uso de algumas métricas (em contextos diferentes do nosso) produziram resultados satisfatórios [Wal79, Gra94, KC85].

- Podemos tirar vantagem do nosso contexto particular. Conforme discutido no capítulo 1, os programas exercício didáticos têm algumas propriedades peculiares que os distinguem daqueles feitos no mundo real e que tornam mais propícias a aplicação de algumas métricas. Destacamos os seguintes aspectos:

- pelo fato de sempre termos vários programas "iguais" (que implementam uma mesma especificação), verificar a normalidade (ou anormalidade) de algumas métricas é mais simples, por termos várias outras bases de comparação (lembre-se que a interpretação de métricas se faz principalmente por comparações com situações similares [seção 4.1.4]);

- os programas são sempre escritos na mesma linguagem e por programadores com níveis de conhecimento e estilo similares, o que fortalece a idéia de que as métricas podem ser comparadas.

\subsection{Especificação}

No que se segue, descreveremos (não muito detalhadamente, para não sobrecarregar o leitor) aquilo que, a princípio, esperamos da ferramenta. 


\subsubsection{Objetivos da Ferramenta}

O objetivo maior da ferramenta é ajudar um ser humano na correção de exercícios programa didáticos.

Observando o nosso modelo de qualidade descrito no capítulo 1, verificamos que a maioria dos fatores examinados, claramente, são de difícil automação. As métricas podem até ser empregadas para se avaliar alguns aspectos importantes (como complexidade, por exemplo), assim como algumas heurísticas que tentem apontar inconsistências léxicas na formação de nomes de identificadores podem ser elaboradas - mas, de qualquer forma, há a exigência de um ser humano supervisionando o processo.

Sendo assim, a estratégia para atingir o nosso objetivo de se conseguir uma ferramenta que auxilie na avaliação de programas consiste em atacar em 3 frentes distintas: o uso de métricas e dados sobre objetos do programa, um verificador de consistências e uma interface que permita uma leitura rápida, objetiva e confortável de modo a poder conferir o que os dados fornecidos indiciam.

- métricas: para verificação de complexidade e modularidade do código, o uso de algumas métricas de qualidade pode ser interessante, na medida em que elas podem destacar de modo objetivo quais funções, módulos ou programas que tenham problemas nesse aspecto.

- dados sobre objetos e estrutura do programa: a exemplo do que ocorre nos abstradores de programa, gostaríamos que nossa ferramenta pudesse nos fornecer dados sobre objetos (variáveis, tipos, constantes etc) e a organização estrutural do programa sendo examinado como, por exemplo, quantas e quais funções chamam uma dada rotina, quais funções usam um certo símbolo etc.

- um mecanismo de verificação automática de consistência: seria interessante se a ferramenta dispusesse de um mecanismo que checasse a consistência da formação dos nomes dos identificadores e indentação. Claramente, nenhum dos dois problemas é de fácil resolução - eventualmente, uma interferência humana pode vir a ser necessária.

- uma interface hipertexto para o exame do texto fonte: com o hipertexto, pode-se ter um fácil acesso a trechos importantes do programa (por exemplo, definição de uma variável ou tipo) além de informações mais detalhadas sobre um certo símbolo (como as estatísticas e métricas).

\subsubsection{Métricas}

\section{Métricas Sobre a Ocorrência de Símbolos Globais}

As seguintes quantidades devem ser calculadas em relação à ocorrência de símbolos globais:

- número de variáveis globais

- número de tipos globais 
- número de constantes globais

- número de funções globais

Hipótese a verificar ${ }^{I}$ : calculamos essas métricas para se verificar a hipótese que a ocorrência de símbolos globais (especialmente variáveis, como sugere [YC79]) afeta a modularidade do programa.

\section{Métricas Sobre Ocorrência de Módulos e Funções}

- número de módulos

- número de funções globais

Motivação: dar uma idéia da tamanho do programa

- tamanho médio das funções (em linhas)

- número de funções que usam símbolos globais

Hipótese a verificar: essas métricas medem essencialmente o grau de interdependência entre as funções do programa através de símbolos não locais e o quão dividido está o programa em funções.

\section{Métricas Sobre a Ocorrência de Comentários}

- número de linhas de comentários

- proporção de comentários em relação ao número de linhas de código

Hipótese a verificar: a quantidade de comentários melhora a clareza de um programa

\section{Métrica Sobre o Tamanho dos Símbolos}

- tamanho médio dos símbolos

Hipótese a verificar: o tamanho médio dos símbolos tem relação com legibilidade do código.

\section{Métricas de Complexidade}

Conforme vimos no capítulo anterior, existem várias métricas para complexidade de código. Dentre elas, elegemos as três abaixo pelos seguintes critérios: simplicidade, facilidade de implementação e resultados obtidos em estudos anteriores.

- número ciclomático

\footnotetext{
${ }^{1}$ Pretende-se fazer a verificação dessa e das outras hipóteses listadas a seguir por meio de um confronto com opiniões subjetivas de seres humanos.
} 
- número de linhas de código (está se contando todas as linhas exceto as em branco ou as que contenham apenas comentários)

- fan-in/fan-out estruturais (porém, por fan-out, estamos considerando apenas as chamadas às funções definidas no programa - em Pascal, por exemplo, estamos deixando de contar as chamadas à função pré-definida writeln).

Hipótese a ser verificada: essas métricas avaliam o quão complexo está o código.

\section{Outras Métricas}

- profundidade máxima de aninhamento $^{2}$

Hipótese a ser verificada: a profundidade máxima de aninhamento de um módulo ou função está relacionada com a sua complexidade.

Profundidade Máxima de Aninhamento. A seguir, passamos a definir formalmente o conceito de profundidade de uma instrução.

Uma instrução I está aninhada numa estrutura $E$ se e somente se ela estiver dentro de um bloco de instruções de uma estrutura $E$ de condição (como no caso da estrutura if-thenelse) ou num bloco de uma estrutura E de repetição (em Pascal, como no caso de while, repeat e for).

Uma estrutura E está aninhada numa estrutura $E^{\prime}$ se e somente se o bloco de instruções da primeira fizer parte do bloco da segunda.

Uma instrução I está aninhada imediatamente numa estrutura E se e somente se I está aninhada em E e não existe uma outra estrutura E' aninhada em E que também aninhe I.

Uma estrutura $E$ está aninhada imediatamente numa estrutura $E^{\prime}$ se e somente se E está aninhada em E' e não existe uma outra estrutura E'' (diferente de E') aninhada em E' que também aninhe $\mathrm{E}$.

A profundidade de uma estrutura E é 1 se ela não estiver aninhada em nenhuma outra estrutura de repetição ou condição; se ela estiver aninhada, a sua profundidade será $\mathrm{p}+1$, onde p é a profundidade da estrutura E' que a aninha imediatamente.

Finalmente, a profundidade de uma instrução I será 0 se ela não estiver aninhada em nenhuma estrutura de repetição ou condição E; caso contrário, ela terá a mesma profundidade da estrutura que a aninha de forma imediata.

A profundidade máxima de uma função é a maior profundidade de todas as suas instruções. A profundidade máxima de um módulo é a maior profundidade máxima de todas as suas funções.

\footnotetext{
${ }^{2}$ Esta métrica foi sugerida pela banca do exame de qualificação deste texto (composta por A. Mandel, D. M. Silva, F. C. R. Reverbel e M. Endler).
} 


\subsubsection{Dados Sobre Objetos e Estrutura do Programa}

Abaixo, enumeramos os dados sobre objetos (não locais) e a estrutura do programa que gostaríamos que fossem acessíveis da forma mais simples e rápida possível ao usuário.

Note que não abordamos informações sobre os objetos locais (a exemplo do que o CIA faz [seção 3.2.2]). Isto foi feito por duas razões básicas: economia de espaço (guardar informações sobre todos os objetos, indiscrimadamente, demandaria uma grande quantidade de memória) e sua relativa pouca importância, já que, pelo fato dos objetos serem locais, pela própria definição, eles sర́ são interessantes dentro de um escopo limitado - havendo interesse em algum dado sobre eles, o usuário poderia, em tese, obtê-lo manualmente com facilidade.

\section{Informações Sobre Funções}

- declaração da função (com os parâmetros e seus tipos esperados)

- os comentários descritivos da função e de cada um dos parâmetros (ver nota abaixo)

- número de variáveis/tipos/constantes não locais que a função usa

- lista de variáveis/tipos/constantes não locais que a função usa

- número de funções que ela acessa (fan-out)

- lista de funções que ela acessa

- número de funções que a usam (fan-in)

- lista de funções que a usam

- código fonte que define a função

\section{Informações Sobre Variáveis, Tipos e Constantes Globais}

- a forma como o símbolo foi declararado, que informa qual o seu tipo

- comentário descritivo

- módulo que exporta a variável

- número de funções que usam o símbolo

- número de módulos que acessam o símbolo

Hipótese a ser verificada: o uso de um símbolo pelas funções e módulos refletem a sua importância dentro da implementação.

\section{O Comentário Descritivo}

Para enriquecer a fase de inspeção do programa, tomaremos por hipótese que os alunos possam ser inquiridos a formatar os comentários intra-código que descrevam declarações de símbolos dentro de um formato especial: por exemplo, poderíamos estabelecer que 
logo após a abertura de um comentário (que, em Pascal, se faz com um ( * ou \{ ), deverá vir um sinal de $\langle$ ou $>$, indicando, respectivamente, se o comentário se refere ao último símbolo declarado antes do comentário ou o primeiro depois.

Por exemplo, considere o seguinte trecho:

const

$$
\mathrm{XYZ}=100 ;\{<\text { Número máximo de linhas possível }\}
$$

Aqui, seria entendido que o comentário Número máximo de linhas possível se refere à constante XYZ.

Há ainda uma forma alternativa de se fazer isso: adotar-se que comentários em uma certa posição relativa a uma declaração de um símbolo se referirá a ele.

Por exemplo, para variáveis, poderíamos estabelecer que comentários iniciados na mesma linha, à direita, se referem à tais variáveis.

Assim, em

$\operatorname{var}$

$$
\mathrm{x} \text { : integer; \{ numero de linhas \} }
$$

AVASAP interpretaria que número de 1 inhas se refere a $\mathrm{x}$.

Note que esta segunda maneira seria mais natural e, mesmo de programas feitos sem o AVASAP em mente, poderiam ser extraídos os comentários descritivos de cada símbolo de forma correta com uma razoável probabilidade.

O estilo e formatação exata dos comentários é deixada como uma futura decisão de projeto.

\subsubsection{Detecção de Plágio}

A tarefa de detecção de plágio de forma manual geralmente não é simples, principalmente quando o número de programas examinados cresce.

Seria interessante portanto que a ferramenta dispusesse de um mecanismo que ajude o examinador a identificar os casos de plágio.

Os algoritmos a serem utilizados deixamos como uma decisão de projeto. 


\subsection{Projeto}

Nesta seção, descrevemos, em linhas gerais, alguns aspectos do projeto da ferramenta.

\subsubsection{Projeto Lógico}

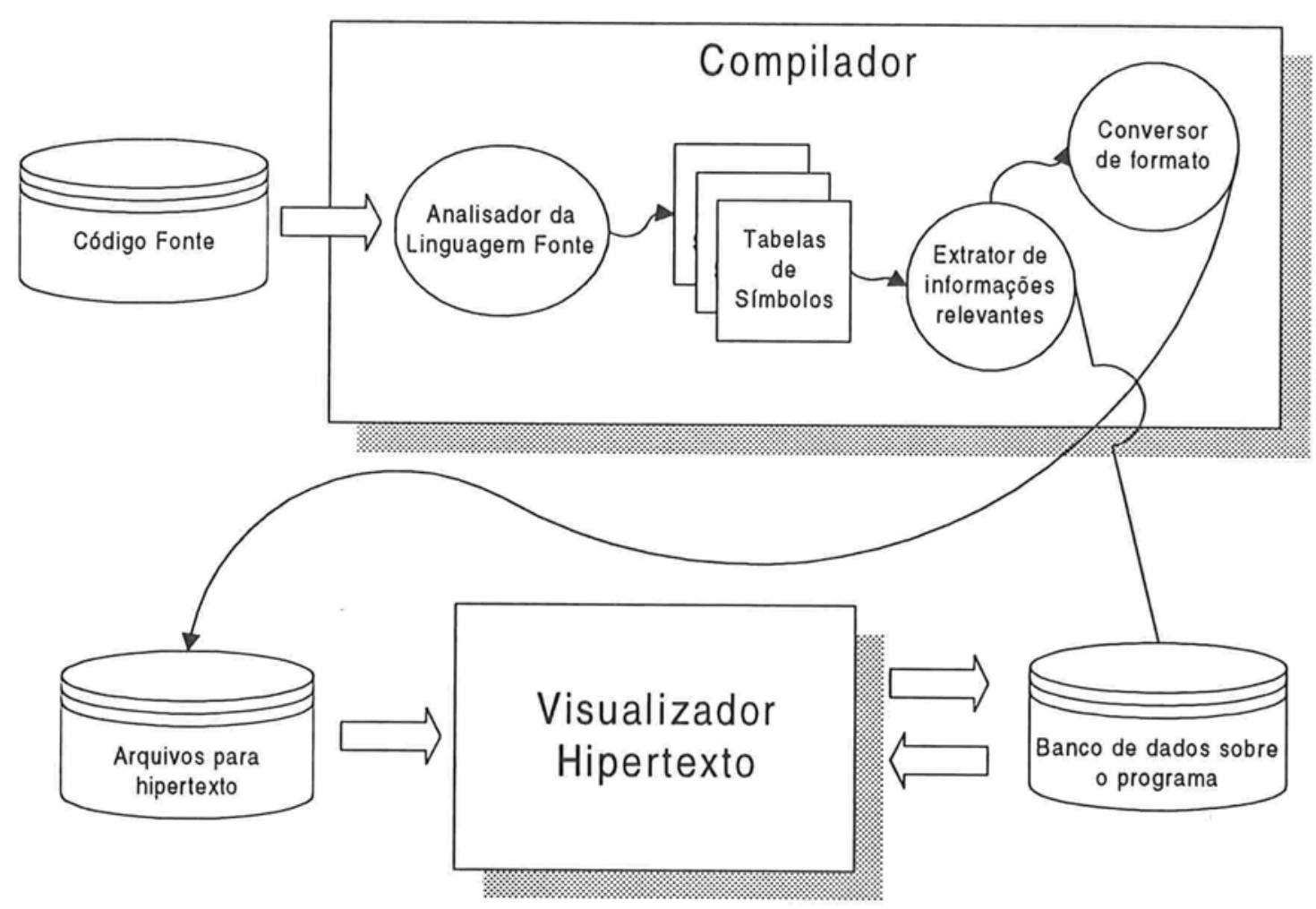

Figura 5-1: Esquema conceitual de funcionamento do AVASAP

Na figura 5-1 podemos ver o esquema conceitual básico de funcionamento do AVASAP.

Como entrada, temos um conjunto de arquivos contendo o código fonte do programa a ser avaliado. Essa entrada será analisada sintaticamente por um dos macro componentes da ferramenta (como em um processo normal de compilação), que então alimentará um grupo de tabelas de símbolos internas.

Essas tabelas de símbolos, por sua vez, serão analisadas por um outro módulo, que delas extrairá as informações consideradas importantes para a análise.

Parte dessas informações será gravada em arquivos que deverão estar em um formato aceitável por uma outra ferramenta visualizadora de hipertextos. Outra parte dará origem a um banco de dados (cujo modelo de entidades e relacionamentos está na figura 5-2), que guardará informações sobre os programas examinados. A forma de como esse banco de dados será usado ficará mais claro adiante. 


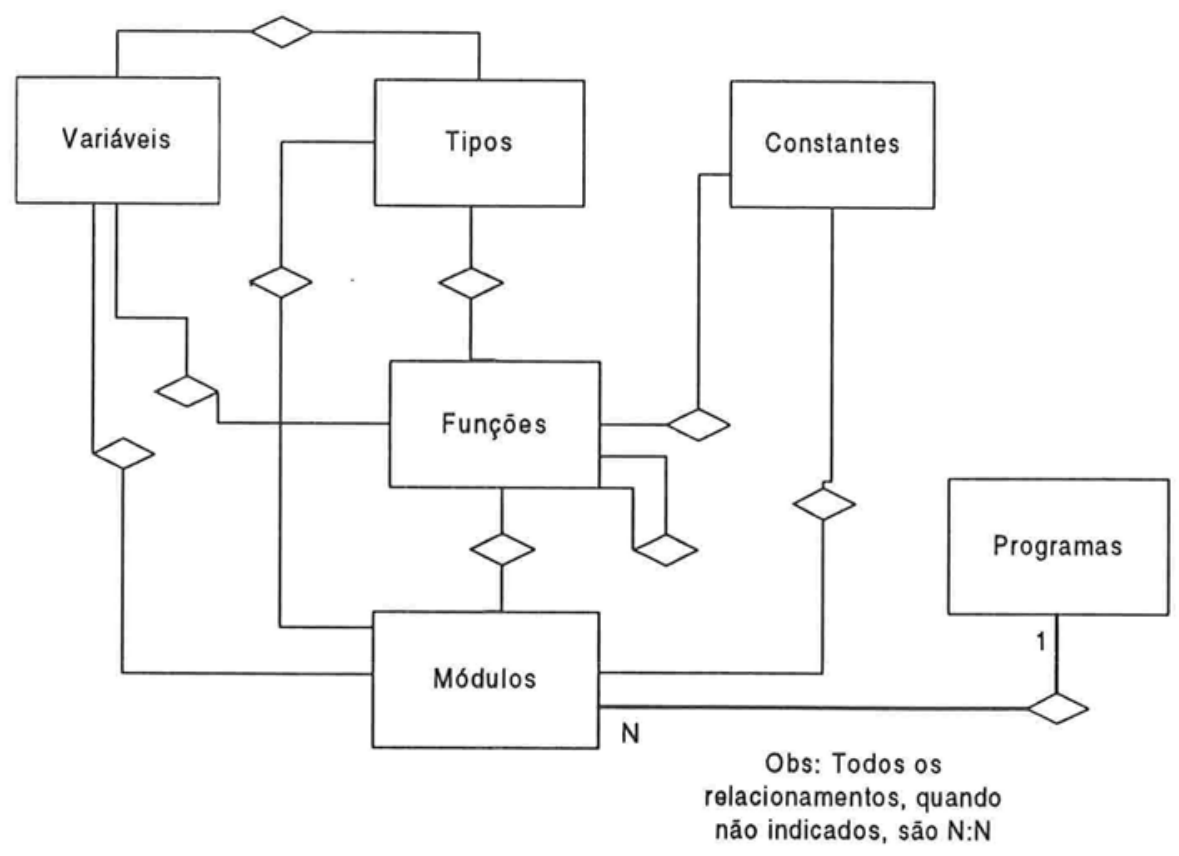

Figura 5-2: Modelo de entidades e relacionamentos do banco de dados gerado

\subsubsection{Projeto Físico}

\section{Algumas Decisões de Projeto}

Por ainda ser a linguagem mais escolhida nas universidades para as disciplinas de introdução à programação (tanto nos EUA [Lev95] como no Brasil ${ }^{3}$ ), decidimos que a primeira versão de nossa ferramenta aceitaria apenas programas cujo código fonte fosse escrito em Pascal [JW74]. Entretanto, AVASAP está estruturado de uma forma tal que se possa trocar a linguagem a ser analisada com pouco impacto no código (de preferência, restrita aos módulos de análise sintática e construção de tabelas de símbolos) ${ }^{4}$.

Da mesma forma, devido a grande e crescente popularidade do padrão HTML [MK96], decidimos que AVASAP irá gerar saída neste formato, podendo assim ser lido por uma variedade de visualizadores WWW (por exemplo, Netscape Navigator e Microsoft Internet Explorer).

\footnotetext{
${ }^{3}$ Dado conseguido através de uma pesquisa informal realizada em 1996 via correio eletrônico junto aos principais departamentos de ciência da computação brasileiros.

${ }^{4} \mathrm{O}$ impacto, na verdade, dependerá fortemente do paradigma da linguagem: se como a Pascal ela for procedimental (C, por exemplo), as mudanças não seriam tão grandes como se fosse uma linguagem orientada a objetos ( $\mathrm{C}++$, por exemplo), onde haveria necessidade até de alterar o modelo conceitual dos dados da figura 5-2.
} 


\section{Deteç̧ão de Plágio}

Whale [Wha90] pesquisou quais são as técnicas de plágio mais comuns; dentre elas, destacou:

- troca de nomes de identificadores

- mudança de comentários

- reformatação/reindentação

- isolar um trecho de código in-line em uma função (ou vice-versa)

Há ainda outras formas mais sofisticadas, mas essas respondem pela grande maioria dos casos dentro do contexto sendo considerado (mesmo porque o uso de técnicas mais complexas talvez simplesmente não compensasse - seria mais fácil para o aluno realmente fazer o programa).

Para a identificação de plágio, testaremos o uso de um par de métricas: o número ciclomático e o número de linhas de código (excluindo linhas em branco ou apenas de comentários).

Note que o número ciclomático $\mathrm{v}(\mathrm{G})$ claramente permanece invariante em relação às 3 primeiras técnicas listadas acima.

Quanto a isolar um trecho de código in-line em uma função, contanto que essa função não seja chamada mais do que uma única vez e o seu código não seja alterado (em especial, nenhuma decisão seja acrescentada ou retirada), v(G) não se altera.

Transformar uma função em código in-line também deixa $\mathrm{v}(\mathrm{G})$ intacto, contanto também que a função não fosse chamada em mais de um lugar e o seu código não fosse alterado.

Por acreditarmos que essas hipóteses são realistas, o uso das duas métricas nos parece promissor na tentativa de selecionar os programas possivelmente plagiados.

\section{Os visualizadores HTML, o Problema da Leitura de Páginas e o shttpd}

A decisão de optar por visualizadores HTML traz algumas vantagens: dispensa-se a necessidade de codificar um visualizador hipertexto (tarefa, aliás, não trivial) e aproveita-se do poder e padronização da HTML e mesmo da linguagem Java.

Por outro lado, deparamo-nos com um novo problema: de onde o visualizador HTML irá obter as páginas hipertexto?

Uma alternativa simples seria o AVASAP gerar de antemão todas as páginas possivelmente acessáveis pelo usuário e guardá-las no disco local - o visualizador, no caso, iria procurar as páginas em file://<path-do-arquivo>. Entretanto, essa solução sofre de um sério problema de escalabilidade - é evidente que a quantidade de páginas poderia se tornar muito grande, mesmo para programas não muito extensos.

Outra possível solução seria usar scripts CGI em um servidor WWW real [Dow96], mas essa opção nos parece algo altamente indesejável por questões de segurança e flexibilidade 
(exigir que o usuário disponha de um servidor WWW real e no qual tenha permissão para a gravação de arquivos nos parece ser algo pouco realista).

Surgiu então a seguinte idéia: construir uma espécie de simulador de um httpd (daemon responsável pelo atendimento a requisições http [Dow96]) que rode localmente e que responda às requisições de páginas do visualizador de uma forma diferente: ao invés de buscar as páginas no disco do servidor, elas seriam geradas on the fly, de acordo com a demanda, a partir de consultas ao banco de dados gerado pelo AVASAP. Por essas razões, demos a esse módulo o nome de shttpd (simplified httpd).

\section{O Banco de Dados}

O gerenciamento da base de dados não será feito diretamente pelo shttpd. Preferimos deixar esta tarefa a cargo de um servidor SQL específico e, por uma questão de disponibilidade, usaremos o Mini $S Q L$, da Hughes Technologies, shareware disponível para a plataforma Unix (apesar de sua qualidade altamente discutível).

\section{O Resultado}

Assim, fisicamente, a arquitetura do sistema é a desenhada na figura 5-3.

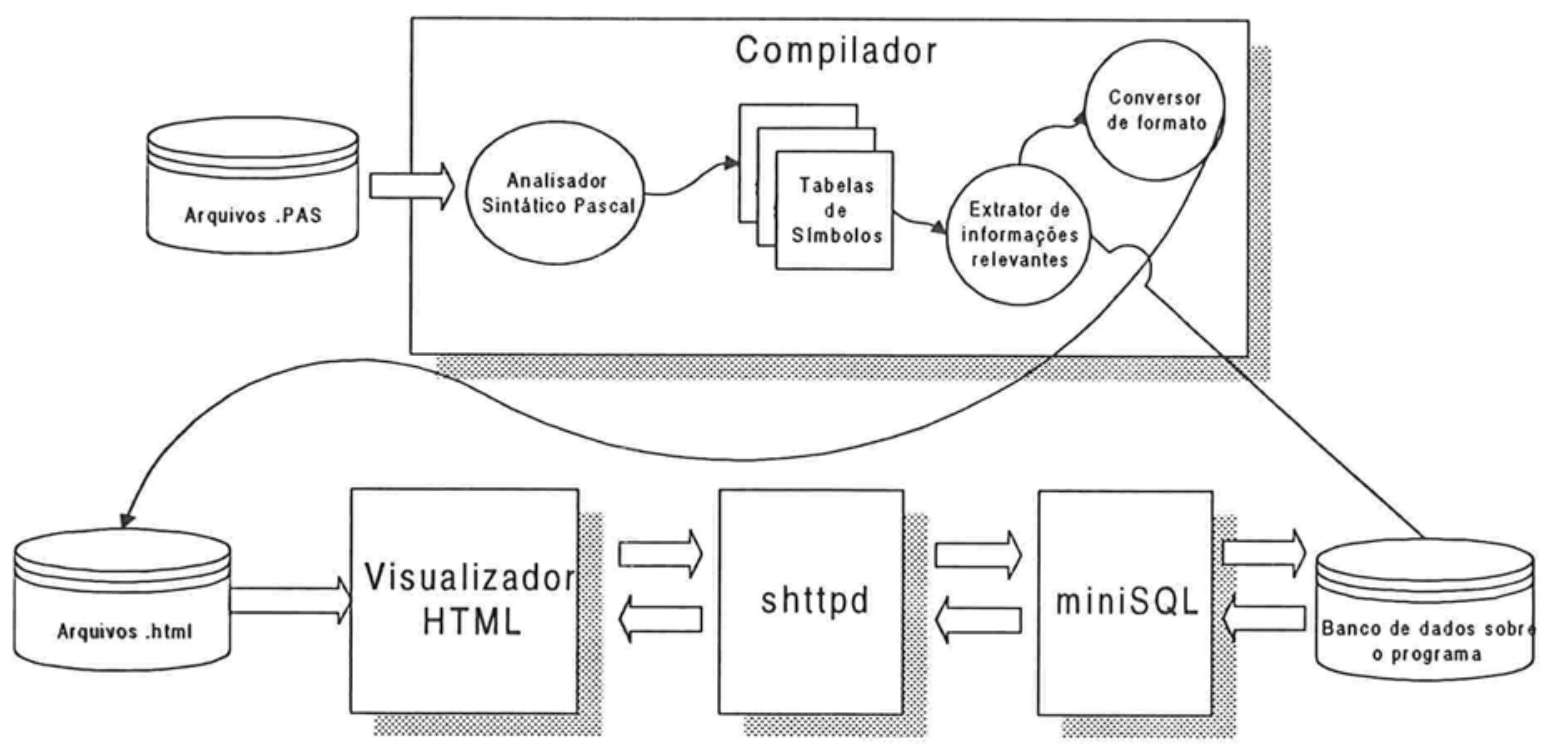

Figura 5-3: Arquitetura física do AVASAP 


\subsubsection{Notas Sobre o Dialeto Pascal Adotado e Termos Usados}

\section{Extensões à Linguagem}

A versão da linguagem Pascal que iremos considerar é a implementada pela Borland no seu compilador Turbo Pascal versão 5.0. A escolha foi feita baseada na sua popularidade no meio acadêmico brasileiro.

Várias extensões à linguagem originalmente proposta por Wirth foram feitas. A mais importante é o conceito de Unit, que permite ao programador fazer a "compilação em separado", onde se divide o programa em vários arquivos que podem ser compilados de forma independente. Assim, um programa Pascal pode ser composto de vários arquivos, onde todos eles definem uma unit (exceto um: o que contém o programa principal, o qual chamaremos de arquivo principal).

Cada unit possui duas partes: a de interface e a de implementação. Na primeira parte, o programador declara quais símbolos (funções, procedimentos, variáveis, tipos, constantes) serão exportados, ou seja, poderão ser visíveis e usados por outras units; além disso, aqui também se declara de quais outras units deseja-se importar símbolos. Na segunda parte, faz-se a efetiva implementação de procedimentos e funções exportados, além de outras rotinas auxiliares que não serão visíveis pelo mundo exterior à unit.

Note que o arquivo principal pode apenas importar símbolos - exportá-los é privilégio das units.

\section{Termos Utilizados}

Chamaremos de função principal o trecho de código a partir do qual se inicia a execução do programa 5 .

No que se segue, o termo módulo corresponderá a uma unit ou ao arquivo principal. Função referir-se-á genericamente tanto a uma função como a um procedimento Pascal. Símbolos semi-globais serão os símbolos globais a um módulo em particular (declarados na seção de implementação) mas não potencialmente visíveis pelas funções do arquivo principal - em particular, nenhum símbolo declarado no arquivo principal é semi-global.

Símbolos globais serão aqueles que são exportados por algum módulo (podendo, portanto, serem usados por qualquer outro) ou os declarados no arquivo principal e visíveis por todas as suas funções. Ou, simplificadamente, símbolo global é todo aquele potencialmente visível pela função principal.

Símbolo não local é um símbolo global ou semi-global.

\footnotetext{
${ }^{5}$ A bem da verdade, essa denominação é, a rigor, imprópria para programas Pascal, já que o ponto onde se inicia a execução não pertence a uma função ou procedimento; entretanto, por uma questão de conveniência, que ficará mais claro no decorrer do texto, preferimos tratar esse trecho como se fosse uma função.
} 


\subsubsection{O Verificador de Consistência}

\section{Consistência de Formação de Nomes de Identificadores}

Aqui descrevemos, em linhas gerais, o algoritmo para a verificação da consistência na formação dos nomes dos identificadores (o problema é descrito com detalhes na seção 1.1.2).

Casos Considerados. Claramente, trata-se de um problema de difícil automação - o número de tipos de inconsistências é muito grande, e checá-los todos exigiria um algoritmo bastante extenso e trabalhoso. Alguns casos, em particular, exigiriam uma interpretação semântica dos identificadores (como em NumPtos e Vidas - número de pontos e número de vidas; entretanto, no 10 símbolo se abreviou número com Num, enquanto no segundo, não), o que demandaria algoritmos mais complexos.

Sendo assim, decidimos atacar apenas dois tipos, identificáveis lexicamente, os quais consideramos bastante relevantes devido a sua freqüente ocorrência, conforme pudemos observar em uma amostra de programas:

1) Uso das Palavras e Suas Abreviaturas: Para nomear um identificador, nada mais natural que escolher um nome que reflita o papel do objeto dentro do contexto da implementação (conforme recomendamos em 1.1.2). Por exemplo, para uma variável que guarde o número total de pontos feitos em um jogo, uma escolha razoável seria Totalptos. Entretanto, se para uma outra variável que guarda o número de faltas escolhermos o nome TotFaltas, apesar dele refletir o seu objetivo, estaremos sendo inconsistentes: no primeiro caso, não abreviamos a palavra "total", enquanto no segundo caso usamos "tot".

2) Separação de Identificadores Compostos: Freqüentemente, o nome de um identificador é formado por mais de uma palavra (ou abreviatura), como Totalptos. Para fazer a separação entre essas palavras, 2 estilos são bastante populares: uso de troca de caixa (como o exemplo), e separação usando o símbolo underscore (como em total_vagas) ${ }^{6}$. O uso desses dois estilos em um mesmo programa consideramos inconsistente?

No que se segue, chamaremos de inconsistência do tipo 1 a descrita no item 1 , e inconsistência do tipo 2, a descrita no segundo item.

\footnotetext{
${ }^{6}$ Obviamente, há ainda quem simplesmente não separe as palavras, como em totalvagas. Por ser pouco legível, não consideramos esse estilo recomendável e também será desconsiderado em nosso algoritmo.

${ }^{7}$ Uma exceção deveria ser aberta para o caso dos nomes de constantes: é bastante popular o estilo em que se grafam os nomes desses identificadores totalmente em caixa alta (como TAM_MAX_PILHA). Neste caso, é claro que a única forma que resta para se separar as palavras é por meio de um ' ', - assim , ainda que no resto do programa tenha se separado palavras por troca de caixa, seria injusto qualificar como inconsistente essa formação. Entretanto, por ora, deixamos de tratar esse caso.
} 
Os algoritmos. Para a detecção de inconsistências do tipo 2, a tarefa é mais fácil: para o primeiro identificador composto recolhido do texto do programa, determina-se qual o estilo usado para a separação (trivial); se em algum outro identificador composto do texto foi usado um outro estilo, detecta-se a inconsistência; caso contrário, conclui-se que não houve inconsistências do tipo 2.

Para a detecção de inconsitências do tipo 1, há a necessidade de algo mais elaborado.

O nosso algoritmo exige como entrada uma lista contendo n palavras; para cada uma dessas n palavras, haverá um conjunto associado (de tamanho variável porém finito) contendo a própria palavra e suas possíveis abreviações ${ }^{8}$.

Por exemplo,

Palavra

Tamanho

Maximo

Minimo

Quanto maior for essa lista de palavras, mais precisamente serão identificadas as abreviações. Por outro lado, alimentá-la exaustivamente pode ser um problema considerável, além de afetar o desempenho de nosso algoritmo descrito abaixo.

Recomendamos, portanto, que para cada conjunto de programas exercícios, seja feita uma análise do problema e que se construa uma lista contendo pelo menos as palavras esperadas dentro dos textos 9 . Por exemplo, se o exercício for um jogo de batalha naval, termos como navio, tabela, coordenada etc serão certamente usados.

Posto isso, o algoritmo é simples (figura 5-4)

\footnotetext{
${ }^{8}$ Evidentemente, o número de todas as possíveis abreviações é muito grande - estamos considerando apenas as abreviações comuns (para tamanho, por exemplo, tnh seria uma possível abreviação, porém pouco usual).

${ }^{9}$ Uma ferramenta poderia ser projetada para ajudar na construção dessa lista. Por exemplo, ela poderia ler a especificação do exercício ou os comentários de um conjunto de textos-fonte e selecionar as palavras mais freqüentes (que seriam ou não confirmadas pelo usuário).
} 
\{ Entrada: $\mathrm{CJ}(\mathrm{i}), \mathrm{i}=1 . . \mathrm{n}$, contém as abreviações \}

\{ Saída: pares (j, Escolha ) que indicam que mais de uma abreviação diferente (descrita no conjunto Escolhaj) foi usada do conjunto $\mathrm{CJ}(\mathrm{j})$ \}

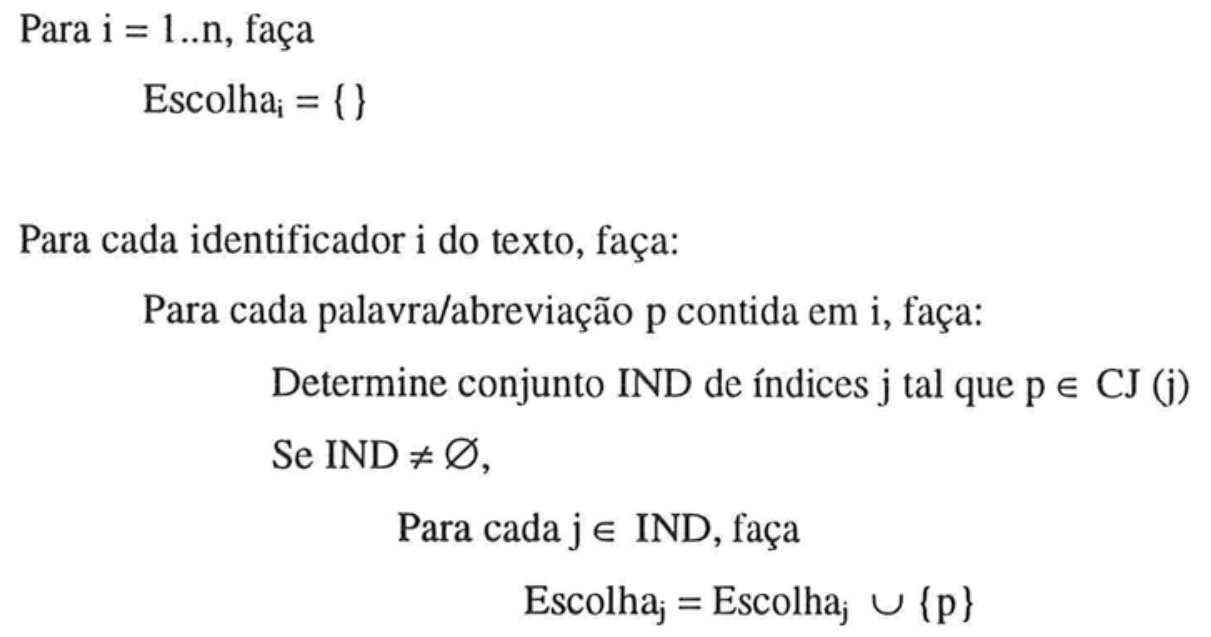

Para cada $\mathrm{j}$ tal que $\mid$ Escolha $\mathrm{j}_{\mathrm{j}} \mid>=2$, faça

Retorne (j, Escolha $a_{\mathrm{j}}$

Figura 5-4: Algoritmo para detecção de inconsistências do tipo 1

Note que o algoritmo admite a possibilidade de uma mesma abreviação corresponder a mais de uma palavra.

Após o término do algoritmo, os conjuntos Escolha $a_{j}$ conterão as ocorrências da palavra $\mathrm{j}$ e/ou suas abreviações dentro do texto. Se o conjunto Escolhak tiver mais de um elemento, então no texto possivelmente há um uso inconsistente da palavra $\mathrm{k}$.

\subsubsection{O Tratamento dos Comentários}

Uma das extensões que o AVASAP faz aos abstradores de programas tradicionais é o tratamento que faz dos comentários: ao contrário do CIA, por exemplo, onde eles são completamente ignorados, no AVASAP alguns comentários (os que descrevem símbolos não locais) são recolhidos e exibidos como atributos sob solicitação do usuário.

\section{O Estilo Esperado}

Conforme discutido na seção 5.2.3, para se fazer um tratamento adequado dos comentários, é necessário antes estabelecer um estilo ou formatação padrão para eles. Discuti- 
mos também que quanto mais natural e simples fosse esse estilo, melhor seria - eventualmente, até programas feitos sem o AVASAP em mente poderiam ter seus comentários validados.

Seguindo esse critério, e analisando uma amostra de vários programas exercício reais, chegamos ao seguinte estilo:

- Comentários de variáveis, tipos e constantes: comentários desse tipo devem começar na mesma linha em que se declara os símbolos, à sua direita.

\author{
Exemplo: \\ var \\ pontos, \\ vidas: integer; \\ \{ número de pontos \} \\ \{ número de vidas \} \\ $i, j:$ integer; \\ $\{$ uso geral \} \\ faltas: integer; \\ \{ número total de faltas \} \\ \{ sempre é positivo, \\ e maior que vidas \} \\ \{ comentário solto \}
}

Na listagem acima, o comentário número de pontos será associado a variável pontos, assim como número de vidas a vidas.

Um mesmo comentário pode se referir a mais de uma mesma variável, como no caso de i e j, ambas com o comentário uso geral.

Uma seqüência de comentários descritivos de um mesmo símbolo (ou conjunto deles) pode se estender por mais de uma linha, contanto que não seja interrompido por um identificador qualquer (provavelmente um outro símbolo sendo declarado) ou uma linha em branco. Para faltas, todo o comentário número total de faltas, sempre é positivo e maior que vidas será atribuído, mas comentário solto, não (por ter uma linha em branco separando).

- Comentários de funções, procedimentos e seus parâmetros: os comentários de procedimentos e funções devem anteceder imediatamente o início da definição das mesmas.

Exemplo: 


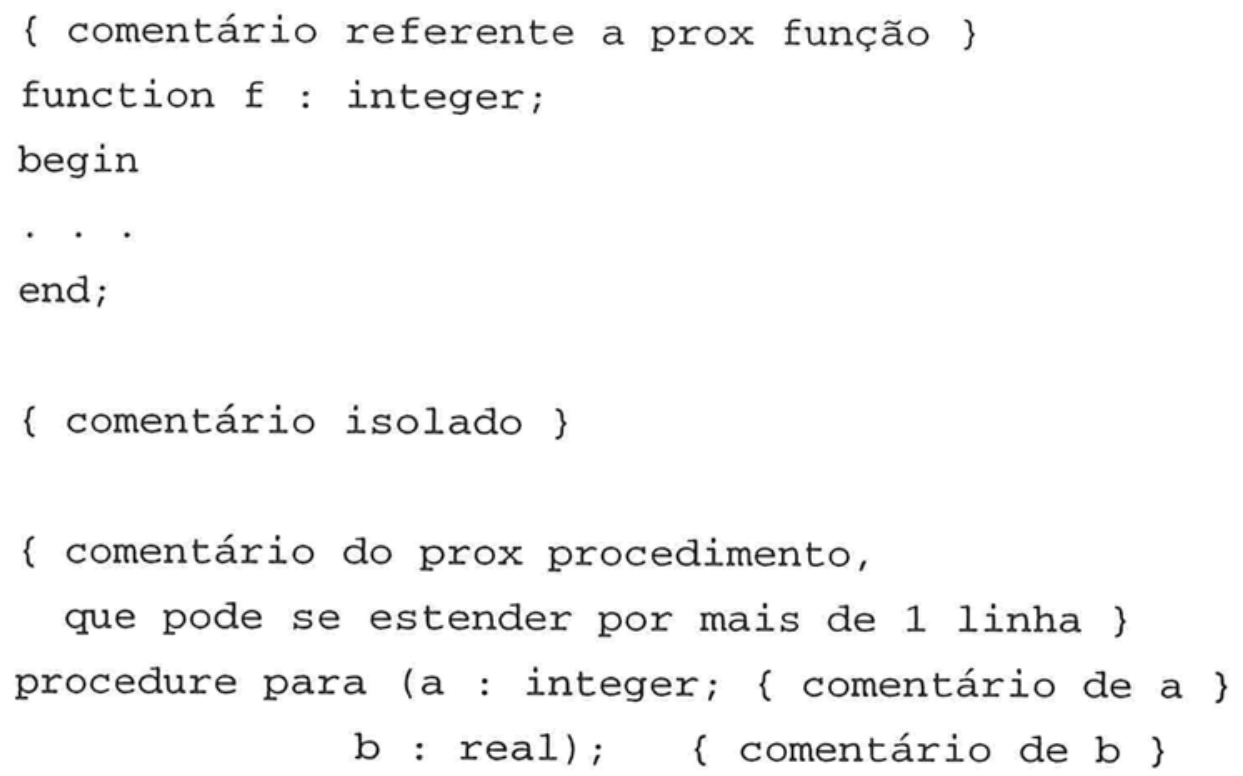

Aqui, f será associado ao comentário comentário referente a prox função. O comentário comentário isolado não será atribuído ao próximo procedimento por ter uma linha em branco isolando-o do resto do texto.

Obviamente, comentários que se referem à uma mesma função podem se estender por mais de uma linha, contanto que não sejam intercalados por um identificador qualquer ou uma linha em branco. Assim, comentário do prox procedimento, que pode se estender por mais de 1 linha será atribuido ao procedimento para.

Para os comentários de parâmetros, as mesmas regras para variáveis valem.

Como o programador pode não seguir estas diretrizes para comentários, é claro que existe a possibilidade de que eles sejam recolhidos de forma errônea (ou seja, comentários que não pertençam a um símbolo sejam atribuídos como seus, ou nem todos os comentários de um símbolo sejam de fato atribuídos).

Sendo assim, é conveniente que haja a possibilidade do usuário desabilitar essa funcionalidade, se assim o desejar (caso em que todos os comentários serão ignorados, como em um processo de compilação normal).

\section{O algoritmo}

Descrevemos aqui um algoritmo para o recolhimento dos comentários.

Antes, porém, precisamos discutir algumas mudanças necessárias no analisador léxico e introduzir um novo objeto em nosso compilador: a pilha de comentários. 
Mudanças no Analisador Léxico. Dentro de um compilador típico, o módulo de análise léxica, em cada chamada, devolve o próximo token do texto de entrada, sua classificação (que pode ser um identificador, um número, um símbolo especial etc) e, dependendo do tipo do token, alguma informação extra (como o valor de um token número). Comentários são simplesmente ignorados, assim como marcadores de final de linha (sob o ponto de vista do resto do compilador, o texto é um fluxo contínuo de palavras sem quaisquer comentários).

Duas mudanças pequenas são requeridas no analisador léxico:

- ele deve considerar relevantes os comentários, considerando-os tokens da mesma forma que um identificador ou símbolo reservado.

- ele deve também considerar quebras de linhas como tokens.

Entretanto, se esses tokens especiais simplesmente fossem repassados para o analisador sintático para serem reconhecidos, uma série de modificações seriam necessárias na gramática da linguagem.

Para resolver esse problema, introduzimos um filtro entre os dois analisadores, de modo que estes tokens sejam filtrados e o analisador sintático nem sequer chegue a tomar conhecimento deles.

Pilha de comentários. A pilha de comentários a estrutura de dados central que nos ajudará a resolver o problema descrito acima.

Para cada chamada do nosso novo analisador léxico, sempre que o token devolvido for um comentário, um identificador sendo declarado (como $\mathrm{x}$ em var $\mathrm{x}$ : integer) ou um marcador de final de linha, o empilharemos na pilha de comentários.

Para simplificar, no que se segue, C representa um comentário, I representa um identificador (que esteja sendo declarado) e $\mathrm{NL}^{10}$, um fim de linha. Para representar o conteúdo da pilha, usamos a notação $\left(X_{1} X_{2} \ldots X_{n}\right)$, onde $X_{1}$ representa o fundo da pilha, $X_{n}$ o topo e $\mathrm{X}_{\mathrm{i}+1}$ está empilhado sobre $\mathrm{X}_{\mathrm{i}}$.

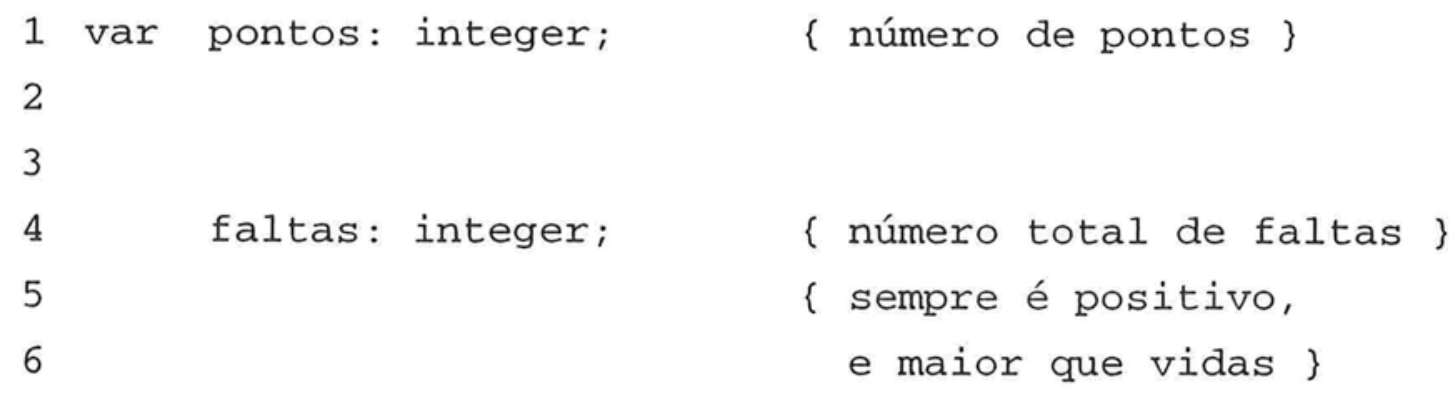

\footnotetext{
${ }^{10}$ De "new line"
} 
Por exemplo, no trecho acima, os seguintes elementos seriam empilhados: I (pontos), C (número de pontos), NL (fim da linha 1), NL (fim da linha 2), NL (fim da linha 3), I (faltas), C (número total de faltas), NL (fim da linha 4), C (sempre é positivo, e maior que vidas), NL (fim da linha 6), NL (fim da linha 7), C (comentário inútil) e NL (fim da linha 8).

Observe que o empilhamento seguido de 2 NLs caracteriza uma linha em branco no texto.

Operações na Pilha. A pilha de comentários, além da operação de empilhamento, admite também mais dois comandos: esvaziar (equivalente ao desempilhamento de todos os elementos) e resolver.

Antes de definir a operação resolver, porém, especificamos que ela só é aplicável se:

- dentro da pilha houver pelo menos um C e um I

- todos os Is estão empilhados consecutivamente, assim como os Cs

Satisfeitas essas condições, a operação resolver concatena todas as strings correspondentes aos comentários empilhados em uma única string (preservando a ordem em que foram empilhados), que então é interpretada como o comentário descritivo de todos os identificadores presentes na pilha (como efeito prático, todas as tabelas de símbolos são preenchidas apropriadamente).

Regras de Transformação. Quando algum elemento é empilhado, eventualmente alguma transformação é operada sobre a pilha e mesmo sobre a tabela de símbolos, preenchendo automaticamente 0 atributo de comentário descritivo correspondente a um símbolo.

As seguintes regras ditam o comportamento da pilha:

1) Antes de se empilhar um NL, verifica-se:

a) Se o topo da pilha contém um NL e apenas comentários no resto (C C C . . C NL): esvazia-se a pilha e o empilhamento é cancelado. Razão: bloco de comentários isolados por uma linha em branco (caracterizada por 2 NLs seguidos - um no topo e outro a empilhar) se tornam orfãos.

b) Se o topo da pilha contém um NL e no seu interior há pelo menos um I e um C: resolva a pilha, esvazie-a e cancele o empilhamento. Razão: detectou-se uma declaração de identificador seguida, na mesma linha (e eventualmente nas imediatamente seguintes), de comentários descritivos isolados por uma linha em branco. 
c) Se o topo da pilha contém um I (. . I): esvazie a pilha e cancele o empilhamento. Razão: declaração de identificador(es) não foi seguida, na mesma linha, de um comentário - portanto, ele(s) não tem comentários associados.

d) Se a pilha estiver vazia: cancele o empilhamento.

e) Caso contrário: simplesmente empilhe.

2) Antes de se empilhar um I, se o topo for um NL, desempilha-se o NL e então se verifica:

a) Se o identificador corresponder ao nome de uma função ou procedimento e o topo tiver um I: esvazia-se a pilha e cancele o empilhamento. Razão: nem o último identificador (o I do topo) nem a função sendo empilhada têm comentários associados.

b) Se o identificador corresponder ao nome de uma função e a pilha só tiver Cs: empilhe I, resolva a pilha e a esvazie. Razão: bloco de comentários da pilha correspondem à função sendo empilhada.

c) Se o identificador não corresponder ao nome de uma função e a pilha só tiver Cs: esvazie a pilha e empilhe I. Razão: foi detectada uma seqüência de comentários seguida de uma declaração de identificador que não é função, portanto, os comentários estão órfãos - os comentários da pilha poderiam ser apenas de uma função que eventualmente os seguisse.

d) Se no fundo da pilha houver uma seqüência de 1 ou mais Is seguida de uma outra sequiência de 1 ou mais Cs: resolva a pilha, esvazie-a e empilhe I. Razão: foi detectada uma seqüência de identificadores sendo declarados seguida de uma outra sequiência de comentários correspondentes, terminados pela declaração de um novo identificador.

e) Caso contrário: simplesmente empilhe.

3) Antes de se empilhar um C, se o topo for um NL, desempilhamo-no e então empilhamos C. Caso contrário, simplesmente empilhamos C.

Provaremos, a seguir, que em todas as situações onde a operação de resolução é chamada (regras $1 b$ e $2 b$ ) ela é válida.

Fatos Sobre o Estado da Pilha. Podemos provar algumas propriedades interessantes sobre o estado da pilha no decorrer do processamento, supondo que inicialmente ela esteja vazia. 
- Fato 1: Nunca a pilha terá apenas Is com um NL no topo.

Prova: Suponha que há um NL no topo com o resto da pilha contendo apenas Is. Pela regra 1c, quando NL foi empilhado, havendo apenas Is na pilha, teria de haver um esvaziamento e o empilhamento, cancelado, o que é absurdo.

- Fato 2: Nunca há 2 NLs (ou mais) empilhados consecutivamente.

Prova: Suponha que há pelo menos 2 NLs seguidos na pilha. Considere a seqüência de 2 NLs seguidos mais ao fundo. Quando o 2o NL foi empilhado, a pilha tinha o 1o NL no topo e, no seu interior, havia só Cs, só Is, ou Cs e Is.

A segunda alternativa, pelo fato 1, é impossível.

Na 1a alternativa, pela regra 1a, haveria esvaziamento, o que é absurdo.

$\mathrm{Na} 3 \mathrm{a}$ alternativa, pela regra $1 \mathrm{~b}$, também.

Portanto, tal seqüência não poderia existir.

- Fato 3: Se há algum NL na pilha, certamente ele está no topo.

Prova: pelas regras 1a e 1b e pelo fato 1, ao se empilhar um NL com um NL já no topo, a pilha sempre é esvaziada.

- Fato 4: Se há Cs e Is na pilha, com certeza todos os Cs estarão agrupados consecutivamente em um bloco, assim como os Is. Além disso, o bloco de Is estará no fundo da pilha.

Prova: Se a tese não fosse verdadeira, então haveria no interior da pilha pelo menos um I empilhado sobre um C. Seja I' o I que está nesta condição que esteja mais ao fundo da pilha:

$$
\text { (... C I' ... ) }
$$

Quando se empilhou I', se houvesse só Cs na pilha, com certeza teria havido um esvaziamento (regras 2b e 2c) - portanto, já havia pelo menos um I na pilha, que está mais ao fundo de I'. Seja I" o I nessa condição que estava mais ao topo da pilha no momento em que I' foi empilhado:

$$
\left(\ldots I^{\prime \prime} \ldots\right. \text { C I' ...) }
$$

Com certeza, não há Cs mais ao fundo de I"' (se houvesse, haveria um outro I empilhado sobre um C mais ao fundo de I', o que contraria a nossa escolha de I' - lembre-se que pelo fato 3 , não há NLs fora do topo na pilha). Logo, só há Is mais ao fundo de I' (ou I" já está no fundo):

$$
\text { ( I I . . I I'” ... C I' . . ) }
$$

Entre I" e I' só há Cs (senão, isso iria contra a nossa escolha de I'):

$$
\text { ( I I...I I' 'C...C I' ... ) }
$$


Portanto, quando se empilhou I', havia na pilha uma seção de Is ao fundo empilhada sob uma de Cs - quando se empilhou I', teria de haver um desempilhamento (regra 2d), ou seja, a pilha não poderia estar do jeito que está - absurdo.

Tendo esses fatos em mente, os comentários descritos junto a algumas regras explicando a sua razão podem ser entendidos mais claramente. Note também que pelo fato 4 , a operação de resolução, em todas as situações onde ela é invocada, ela é válida.

\subsubsection{O Módulo shttpd}

A Comunicação httpd/browser. No processo de navegação pela WWW, podemos identificar duas entidades essenciais: um cliente (o browser, como o Netscape Navigator) e um servidor que atende às requisições (o httpd, um daemon que normalmente roda em uma máquina remota).

Simplificadamente falando, a comunicação entre esses dois entes se estabelece quando o usuário especifica uma URL no browser: ao fornecer um endereço do tipo httpd://www.xxx.yyy:p/a/b/c.html, está se especificando qual máquina em que está o servidor (www.xxx.yyy), em qual porta dessa máquina ele está escutando (p, que pode ser omitido, caso em que o valor default é 80) e qual o arquivo desejado (a/b/c.html).

De posse dessas informações, o browser envia ao httpd especificado uma mensagem do tipo $G E T$ a/b/c, que então é respondida transmitindo-se o arquivo apropriado. O browser, finalmente, ao recebê-lo, interpreta-o e o exibe ao usuário.

O shttpd. O nosso simulador de httpd (chamado de shttpd) difere de um real em 3 aspectos principais:

- Simplicidade: ao contrário de um httpd real, o nosso reconhece apenas um único comando: o GET (um real aceita vários outros, como HEAD, POST etc).

- Geração dos Arquivos on the fly: ao receber um comando GET x/y/z, o arquivo solicitado não é buscado em um sistema de arquivos - ao invés disso, $\mathrm{x} / \mathrm{y} / \mathrm{z}$ é interpretado como um código (que indica a informação que se deseja), que então é traduzido em uma consulta SQL, submetida ao servidor de banco de dados. A resposta é então devidamente traduzida para HTML e transmitida como resposta.

- Leveza: por oferecer uma funcionalidade específica, o shttpd exige poucos recursos, podendo ser rodado localmente e disparado pelo próprio usuário.

Os Códigos Aceitos Pelo shttpd. Para o browser se comunicar com o shttpd, deve-se fazê-lo apontar para a URL 
O nome-host é o nome (ou endereço IP) da máquina em que está rodando o shttpd, enquanto $p$ é o número da porta em que o daemon está escutando os pedidos.

Id-do-programa é um código alfanumérico que identifica unicamente o programa sobre o qual se deseja obter informações. Uma sugestão seria usar o número do exercício concatenado com o número de matrícula do autor.

Finalmente, escreve-se o código da informação que se deseja obter. Porém, antes de passarmos à sua descrição, é importante observar que o usuário não precisa, necessariamente, conhecer esses códigos - na verdade, eles estão embutidos nos apontadores dos links, que são gerados automaticamente pela própria ferramenta.

O código deve ser um dos seguintes:

- Info: fornece informações sobre um símbolo (global ou semi-global) específico. A sintaxe do comando é

\section{Info/categ/nomeMod/nomeSimb}

onde:

categ = categoria do símbolo sobre o qual se deseja informações. Uma categoria pode ser expressa pelos códigos var, tp, cte ou $f c$ (variável, tipo, constante ou função, respectivamente).

nomeMod = nome do módulo em que está declarado o símbolo em questão

nomeSimb = nome do símbolo sobre o qual se deseja informações

Exemplo: http://catatau:9999/epl-738/info/var/pilhas/topo requisita (para o shttpd escutando na porta 9999 da máquina catatau) informações sobre a variável topo declarada no módulo pilhas do programa identificado por epl-738.

- LstAtiv: Lista de módulos ou funções que usam um determinado símbolo (global ou semi-global). A sintaxe é

\section{LstAtiv/fcOuMod/categ/nomeMod/nomeSimb}

onde:

$f c O u M o d=f c$ ou mod, indicando, respectivamente, se se deseja uma lista de módulos ou de funções

categ = categoria do símbolo sobre o qual se deseja informações sobre o seu uso nomeMod $=$ nome do módulo do símbolo em questão

nomeSimb = nome do símbolo em questão 
Exemplo: http://catatau:9999/ep1-738/LstAtiv/fc/pilhas/empilha devolve uma página contendo todas as funções que chamam a função empilha definida no módulo pilhas.

- LstPassiv: lista de símbolos (não locais) de uma certa categoria usados por uma determinada função. A sintaxe é

\section{LstPassiv/categ/nomeMod/nomeFc}

onde:

categ $=$ categoria dos símbolos que se deseja listar

nomeMod $=$ nome do módulo onde está definida a função cujos símbolos usados se deseja listar

nomeFc $=$ nome da função cujos símbolos usados se deseja listar

Exemplo: http://catatau:9999/ep1-738/LstPassiv/var/pilhas/empilha devolve uma página contendo todas as variáveis globais ou semi-globais usadas pela função $\mathrm{em}$ pilha, definida no módulo pilhas.

- LstSimb: lista de símbolos (globais ou semi-globais) de uma certa categoria declaradas no programa ou em um módulo específico. Sintaxe:

\section{LstSimb/categ/escopo/nomeMod}

onde:

categ $=$ categoria dos símbolos que se deseja listar

escopo $=$ prog ou mod, que indica, respectivamente, se se deseja listas os símbolos declarados no programa inteiro ou apenas em um módulo específico.

nomeMod (opcional) = se escopo for igual a mod, indica o nome do módulo cuja lista de símbolos se deseja imprimir.

Exemplo: http://catatau:9999/ep1-738/LstSimb/var/mod/pilhas devolve uma página contendo todas as variáveis (globais ou semi-globais) declaradas no módulo pilhas, enquanto http://catatau:9999/ep1-738/LstSimb/var/prog lista todas as variáveis (globais ou semi-globais) do programa.

- Met: Métricas de um programa ou módulo. Sintaxe:

Met/escopo/nomeMod 
onde:

escopo $=$ prog ou mod , conforme se deseje listar as métricas do programa ou de um módulo específico

nomeMod $($ opcional $)=$ nome do módulo sobre o qual se deseja listar as métricas, se for o caso

Exemplo: http://catatau:9999/ep1-738/Met/Prog devolve uma página contendo as métricas sobre o programa como um todo, enquanto http://catatau:9999/epl738/Met/Mod/pilhas fornece uma página contendo as métricas relativas ao módulo pilhas.

- LstProg: lista os identificadores de todos os programas guardados no banco de dados. Sintaxe:

$$
\text { LstProg }
$$

Obs: para esse comando, não se precisa (nem se deve) indicar um identificador de programa.

- InfoProg: devolve página que contém hiperlinks para as métricas e lista de módulos do programa. Sintaxe:

$$
\text { InfoProg }
$$

- PargInic: devolve página que contém dois quadros (frames): um apontando para uma página do tipo InfoProg e outra para o código do programa (inicialmente, na função principal).

\subsection{Implementação}

Nestta seção, discutiremos alguns aspectos a respeito da implementação.

\subsubsection{Ambiente}

Todo o projeto foi implementado sob o sistema operacional Linux 2.0 (excelente implementaç̧ăo Unix para plataforma Intel) [WK95].

O compilador (módulo que analisa os fontes, calcula as métricas e gera saídas HTML e scripts SQL) foi desenvolvido em C++, usando o compilador da GNU g++ [WK95]. O módwlo que simula um httpd local (shttpd) foi escrito em Java, usando o JDK (Java De- 
velopment Kit) próprio para o Linux. A administração do banco de dados de dados fica por conta do MiniSQL, disponível para várias plataformas Unix, inclusive Linux [Hug96]. A comunicação entre o shttpd e o MiniSQL é feito via uma API Java também disponibilizada pela Hughes.

\subsubsection{A Base}

O módulo compilador não foi desenvolvido a partir do zero: devido à semelhança de funcionalidade entre um compilador Pascal real e o módulo em questão, preferimos reutilizar o código de um compilador da linguagem Pascal (em seu dialeto original, conforme descrito por Wirth e Jensen [JW74]) escrito em C++ como exercício didático para a disciplina de Introdução à Compilação (ministrada no curso de graduação em Ciência da Computação do IME-USP).

\section{Sobre os Analisadores}

Os módulos de análise léxica e sintática do compilador estão descritos em [SHM86]. Poderíamos ter utilizado as ferramentas Lex e Yacc [Don92] mas, por uma questão de conveniência, decidimos preservar a forma original.

\section{Sobre as Mudanças}

Transformar o compilador Pascal original no módulo de compilação do AVASAP implicou uma série de mudanças no código. A seguir, descrevemos sucintamente as principais delas.

Analisador Léxico. Para o tratamento de comentários descritivos, as mudanças no analisador léxico descritas na seção 5.3 .4 foram realizadas.

Gramática. Ao contrário do que ocorria com o compilador original, a linguagem a compilar é a versão Pascal implementada pela Borland no seu produto Turbo Pascal 5.0, que introduziu algumas novas palavras chaves (unit, implementation, interface, uses, string etc), permite a declaração dos símbolos de forma mais flexível (no Pascal original, por exemplo, em cada bloco, as variáveis só podem ser declaradas após a declaração de todas as constantes) que implicaram algumas mudanças na gramática da linguagem reconhecida pelo analisador sintático.

Compilação de Units. Talvez a mudança mais significativa introduzida pela Borland na linguagem Pascal foi o conceito de units (já descrito na seção 5.3.3). A adaptação do compilador original não se resumiu, nesse caso, à gramática: houve a necessidade de dotar a ferramenta da capacidade de compilar programas compostos de vários arquivos.

Ao contrário do que ocorre em outras linguagens, como $\mathrm{C}$, nessa versão Pascal não existe uma lista explícita dos arquivos que compõem o programa - ao invés disso, no início do texto de cada arquivo há uma declaração uses que diz quais outros arquivos são necessários para a sua compilação. Para compilar um arquivo qualquer, portanto, deve-se 
ter compilado antes todos os arquivos listados na declaração uses. Para compilar o programa inteiro, simplesmente deve-se compilar o arquivo principal (e aqueles dos quais ele depende).

Assim, o seguinte algoritmo deve ser aplicado na compilação dos arquivos:

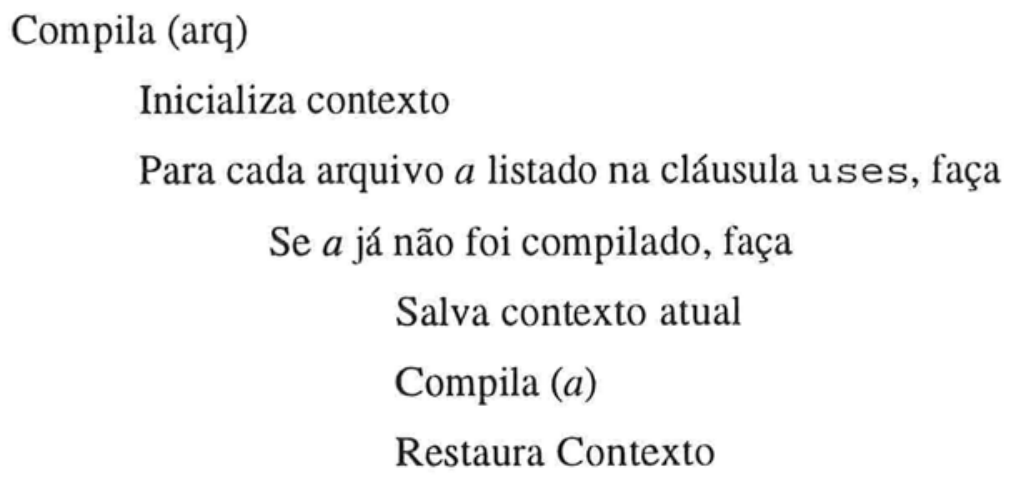

Faz análise léxica/sintática e compila os dados do texto de arq

Obs: o contexto citado acima corresponde ao conjunto de variáveis globais implementadas para guardar o estado do compilador.

\subsubsection{Alguns Números}

No momento em que este texto está sendo escrito, o compilador está implementado em um sistema de 37 módulos em $\mathrm{C}++$, consumindo ao todo aproximadamente 7000 linhas de código.

O shhtpd está escrito em Java, implementado em 8 classes públicas codificadas em 1600 linhas.

O tempo de processamento de programa de 500 linhas é bastante aceitável: não se demora mais do que 5 segundos para se compilá-lo no Linux 2.0 e inserir os dados na base de dados (em um Pentium $100 \mathrm{MHz}$ ). 


\section{Capítulo 6}

\section{Experiências com o AVASAP}

Neste capítulo, apresentamos informações sobre as nossas experiências com o uso do AVASAP na correção de programas exercício reais.

\subsection{Uma Sessão Exemplo}

A título de ilustração, mostraremos aqui, passo a passo, uma sessão de uso da ferramenta para a análise de um programa.

\subsubsection{Um Pouco Sobre o Exercício Examinado}

No que se segue, faremos a análise de um programa feito como exercício cujo enunciado, resumidamente, dizia o seguinte:

O programa é um resolvedor de palavras cruzadas. Ele recebe como entrada um arquivo contendo uma matriz descrevendo quais são as posições brancas (onde pode ser colocada uma letra) e as pretas (onde não se pode preencher) das cruzadas, $e$ um outro arquivo contendo uma lista de palavras. O programa deve encaixar essas palavras nas cruzadas, quando possivel, ou indicar a impossibilidade de se fazer isso, se for o caso. Deve-se também fornecer o tempo, em segundos, usado para a resolução do problema (para isso, foi fornecida uma função de uso obrigatório).

Como se pode perceber, não se trata de um exercício simples. Espera-se que o aluno empregue técnicas de backtracking [Wir76] para encontrar uma solução para o problema, elabore estruturas de dados simples e que se adaptem bem aos algoritmos, assim como siga as recomendações do nosso modelo de qualidade (descrito no capítulo 1). 


\subsubsection{Passos Preliminares: a Preparação}

Antes de passar a fase de inspeção/correção de um programa dos alunos, precisamos antes compilar as informações sobre o seu texto e colocar esses dados em um banco de dados.

\section{A Compilação do Programa}

Inicialmente, devemos submeter o texto do programa (escrito no dialeto Pascal do Turbo Pascal 5.0) a ser examinado ao módulo compilador do AVASAP, assim como fornecer um arquivo contendo a lista de palavras a ser usada pelo verificador de consistências na formação de identificadores (descrito na seção 5.3.4).

Para tal, comandamos:

\# comp mfs mfs.pas cruzadas.voc

onde

comp nome do compilador AVASAP.

$\mathrm{mfs} \quad$ código que identifica unicamente o programa sendo compilado (neste exemplo, estamos simplesmente usando as iniciais do autor).

mfs.pas nome do arquivo que contém o módulo principal do programa a ser examinado (os nomes dos outros módulos são obtidos automaticamente).

cruzadas.voc nome do arquivo que contém a lista de algumas palavras (e suas abreviações equivalentes) esperadas na implementação da solução.

Não havendo erros, vários arquivos são gerados: mfs.sql (lista de comandos SQL que servirá de entrada para o nosso servidor de banco de dados) e, para cada arquivo .pas do programa sendo examinado, é gerado uma versão .htm - no caso, como há apenas um (mfs.pas), é gerado apenas o mfs.htm.

\section{A Alimentação do Banco de Dados}

Feita a compilação, é hora de alimentar o banco de dados com as informações recolhidas a partir do texto do programa. Isto é feito através da instrução

\# msql cruzadas < mfs.sql

onde

msql

nosso servidor SQL

cruzadas nome do banco de dados em que as informações de entrada devem ser armazenadas - no caso, cruzadas é o nome do banco de dados que guardará todos os programas feitos para resolver o problema das palavras cruzadas. 
mfs.sql arquivo gerado no passo anterior, que contém um script SQL para a entrada dos dados compilados

Pronto - com o banco de dados carregado, já podemos partir para a fase de inspeção do programa e seus dados.

\subsubsection{A Inspeção}

Para fazer a inspeção, precisamos ter disparado antes dois processos: o nosso simulador de httpd (o shttpd) e o browser html (no caso, o netscape).

No primeiro caso, instruímos

$$
\text { \# shttpd cruzadas } 9999
$$

onde shttpd é o nome do nosso daemon, cruzadas é o nome do banco de dados sendo consultado e 9999 é o número da porta em que ele ficará escutando requisições.

Para disparar o browser, fazemos

$$
\text { \# netscape http://localhost:9999/LstProg }
$$

onde

netscape nome do browser

localhost nome da máquina em que está rodando o shttpd - no caso, o nome padrão da máquina local (resolvido como endereço IP 127.0.0.1)

9999 número da porta em que está rodando o shttpd

LstProg código que instrui o shttpd a gerar uma página HTML contendo a lista dos programas disponíveis no banco de dados corrente [seção 5.3.6].

Feito isso, finalmente obtemos a tela seguinte: 


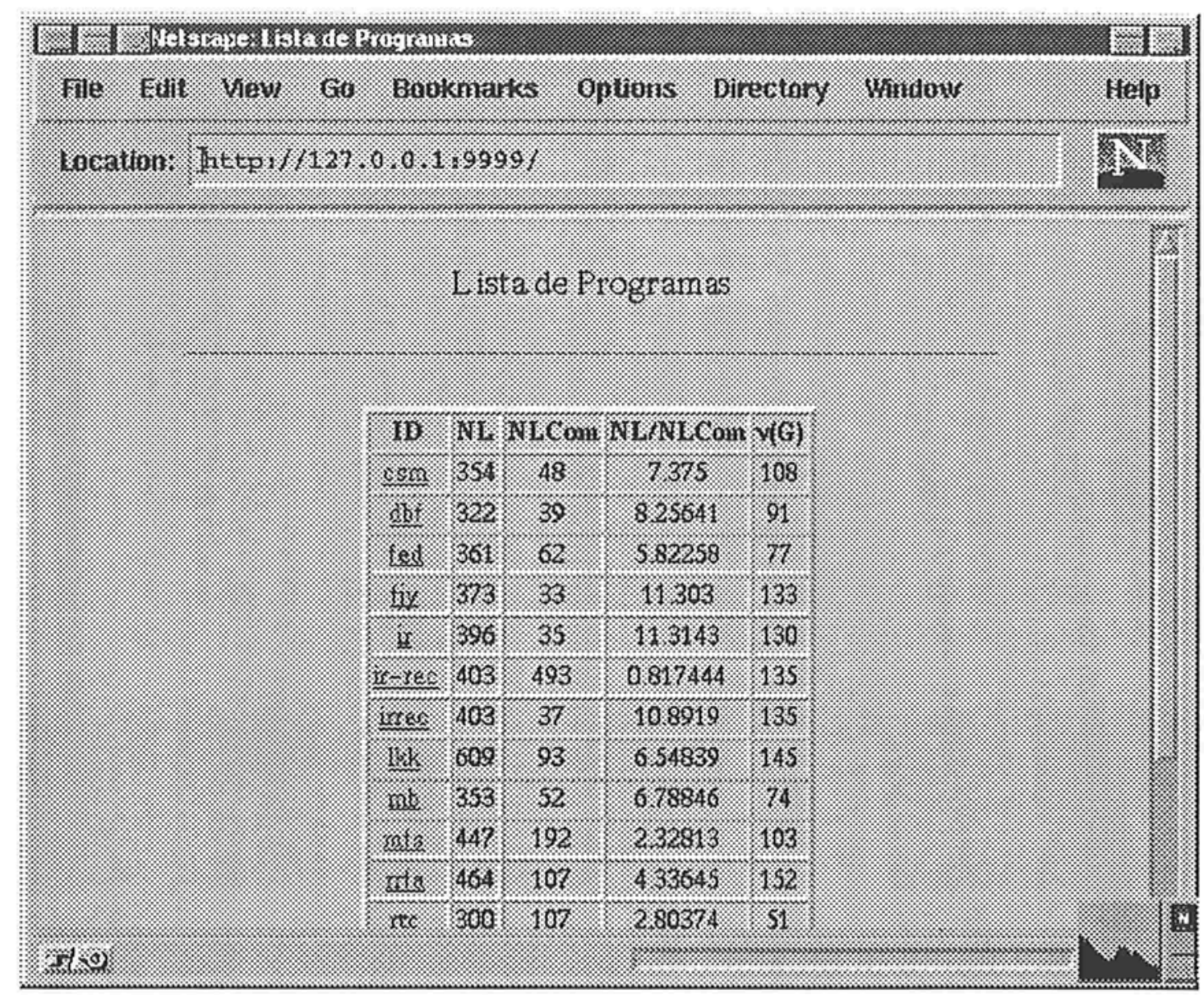

Figura 6-1: Lista de programas

$\mathrm{Na}$ tela, observamos a lista de todos os programas carregados no banco de dados, junto com algumas métricas básicas: número de linhas, número de linhas de comentário, número de linhas de código por número de linhas de comentário e o número ciclomático v(G).

Dentre todos os programas, desejamos analisar primeiro aquele cujo identificador é mfs. Para isso, clicamos sobre esse nome, resultando na tela da figura 6-2. 


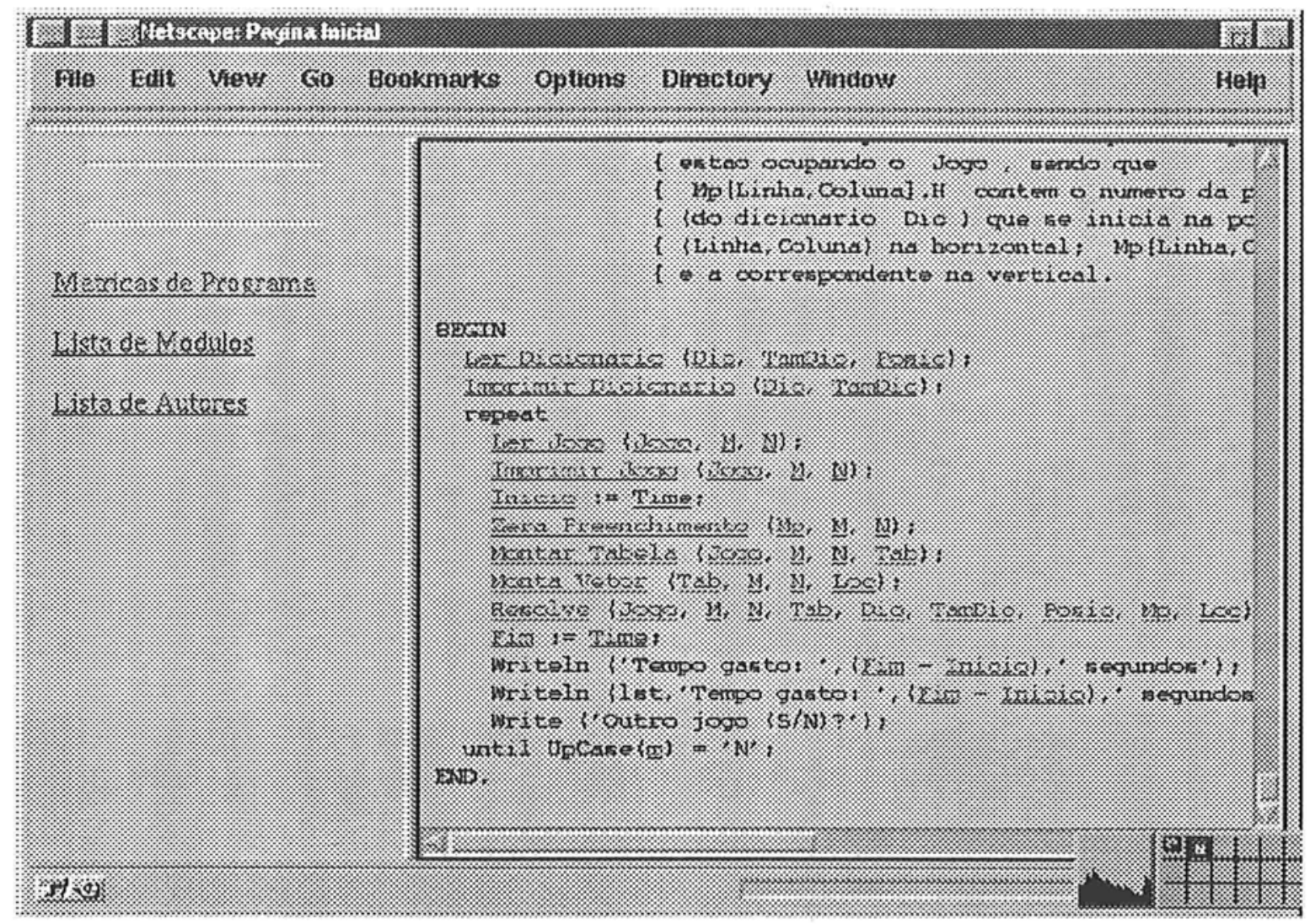

Figura 6-2: Primeira tela da análise do programa (http://localhost:9999/mfs/PagInic)

Ao clicar em mfs na figura 6-1, obtemos a tela da figura 6-2, onde o programa cujo código identificador é mfs começa a ser analisado.

A tela é dividida em dois quadros - o de detalhes, à esquerda, que ocupa, a princípio, um terço da janela (mas que pode ser redimensionado conforme o desejo do usuário), e o principal, onde se mostra um trecho do código fonte.

O quadro de detalhes aponta, inicialmente, para a página InfoProg (seção 5.3.6), contendo hiperlinks para listas de métricas, módulos e autores. O principal, por sua vez, começa mostrando a função principal do programa sendo examinado. Em todo o texto mostrado no quadro principal, todo símbolo não local possui um hiperlink, que leva a informações mais detalhadas sobre ele.

Clicando-se no quadro de detalhes em métricas, obtemos a tela da figura 6-3. 


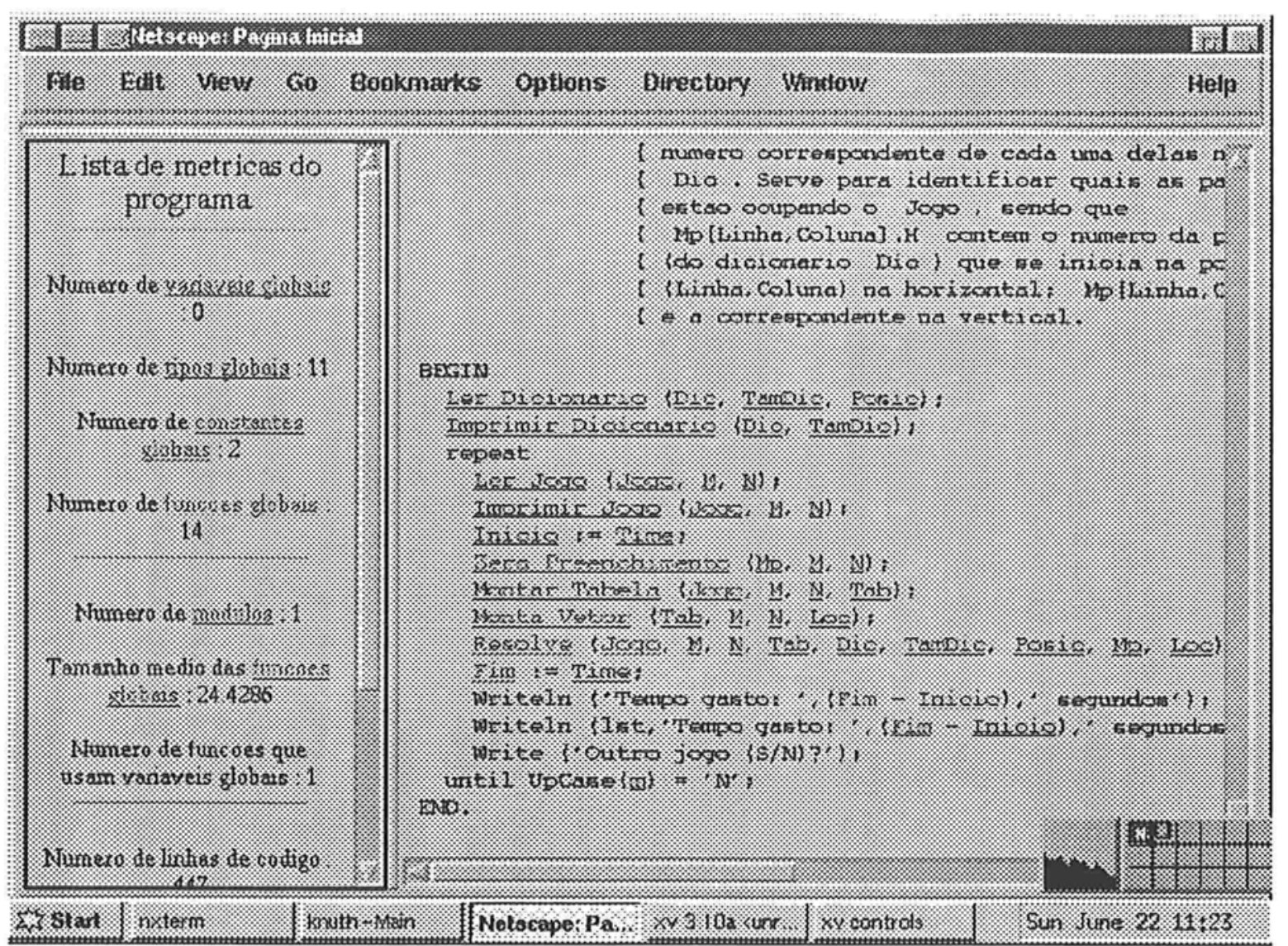

Figura 6-3: Quadro de detalhes mostra lista de métricas (http://localhost:9999/mfs/Met)

Na figura 6-3, vemos parciamente a lista de métricas calculadas sobre o programa. Observe a existência de hiperlinks, que permite o acesso a várias lista de símbolos (por exemplo, clicando-se em funções globais, obtemos a lista de funções globais definidas no programa (figura 6-4). 


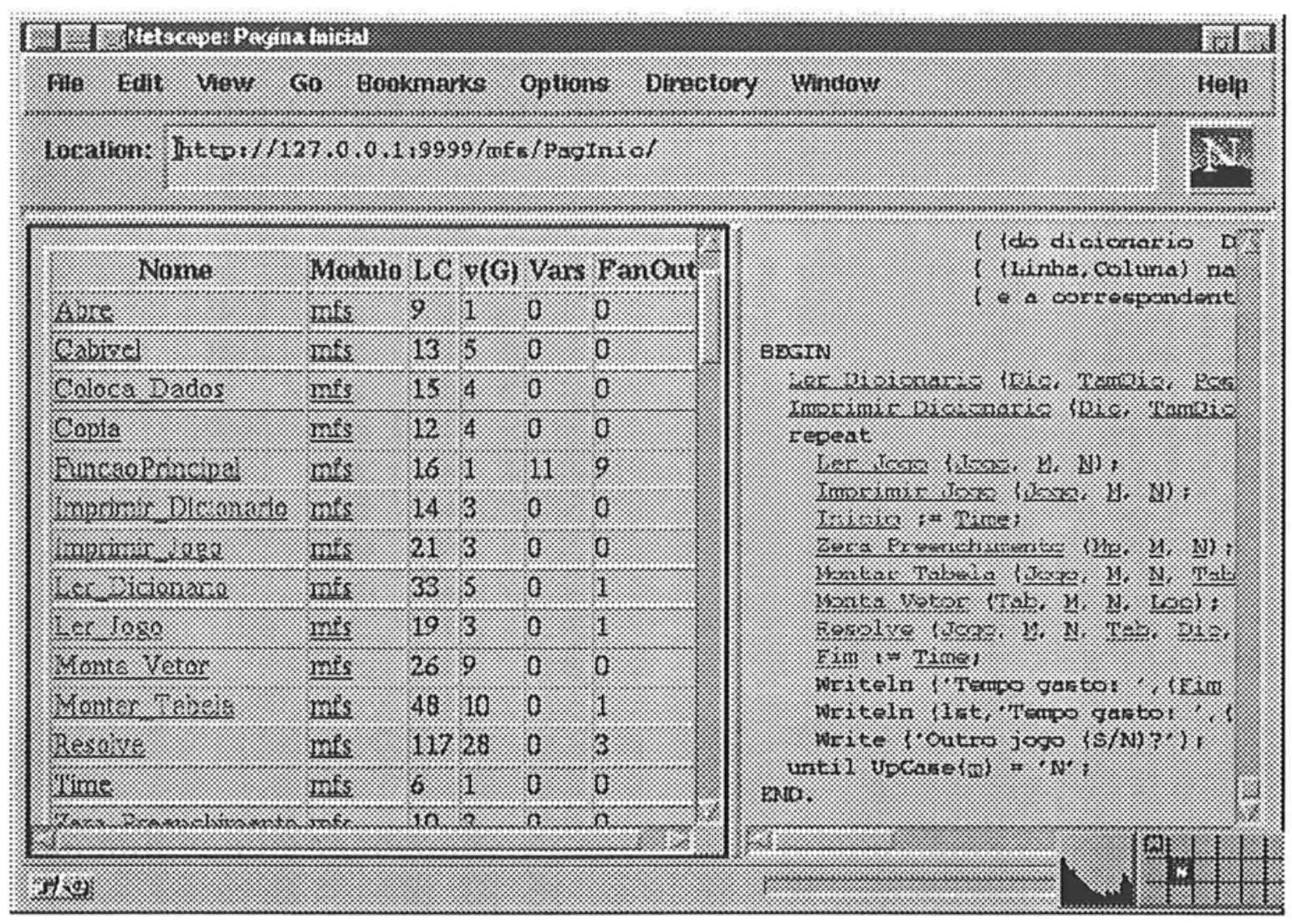

Figura 6-4: O quadro de detalhes apresenta lista de funções globais (http://localhost:9999/mfs/LstSimb/Fc/Programa)

No quadro de detalhes mostrado na figura 6-4 (que foi convenientemente redimensionado), vemos parcialmente a lista de funções globais definidas no programa. Além dos nomes das funções, também são fornecidas algumas métricas importantes como LC (Linhas de código), v(G) (número ciclomático), número de variáveis não locais usadas e o Fan-Out (número de funções chamadas). O uso e interpretação desses valores serão discutidos mais tarde.

Apesar da figura não mostrar, o quadro de detalhes contém, na verdade, 5 tabelas - em cada uma delas, faz-se a ordenação por uma de suas colunas, para facilitar a análise.

Novamente, há a presença de hiperlinks, que levam ao detalhamento de informações sobre o símbolo sublinhado. 


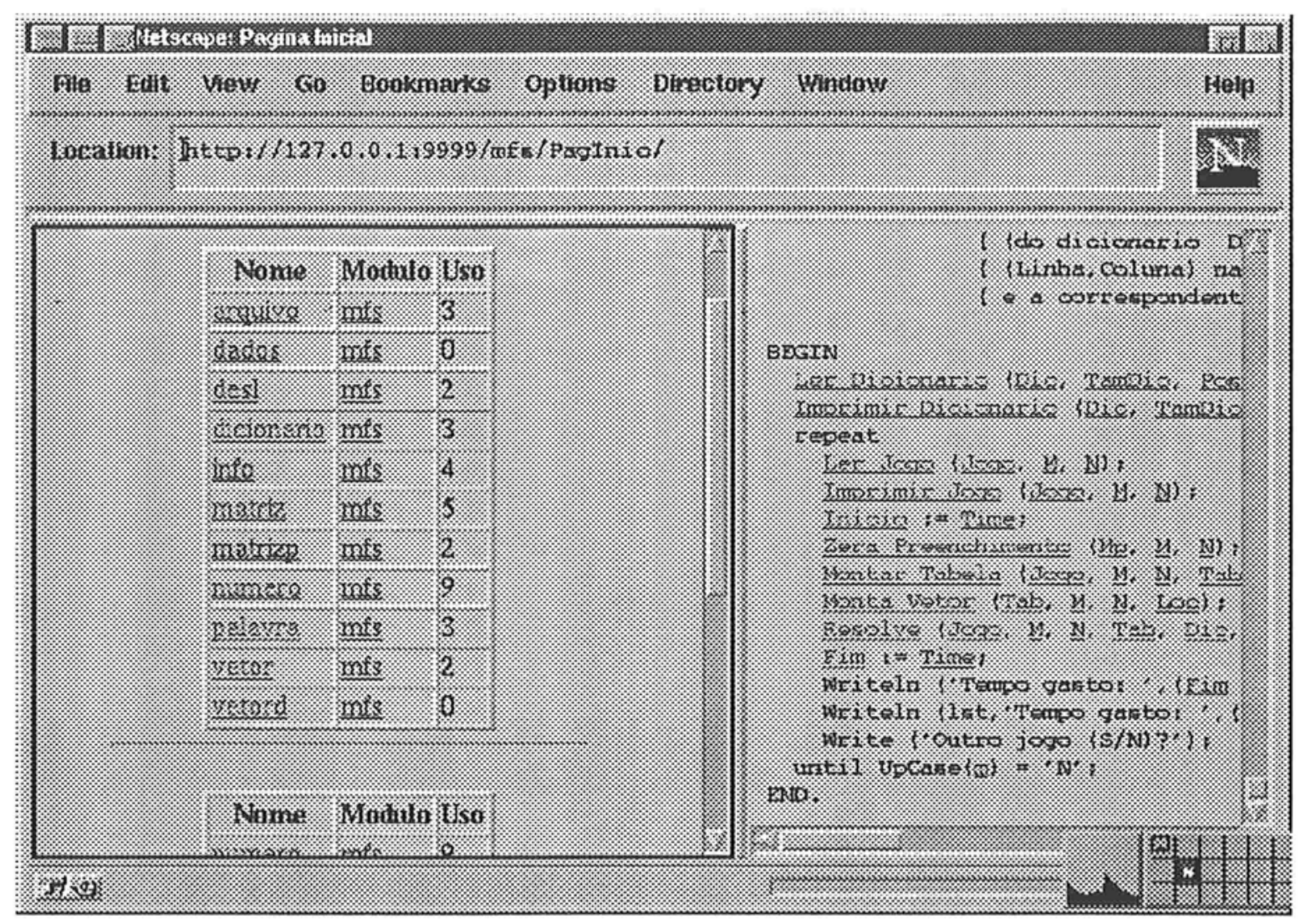

Figura 6-5: Quadro de detalhes exibe lista de tipos globais

Clicando-se, a partir da tela da figura 6-3, o link tipos globais, obtemos o quadro da figura 6-5, onde se exibe a lista dos nomes dos tipos assim como o módulo que exporta o símbolo e o número de funções diferentes por quais cada tipo é usado.

Há 2 tabelas: uma ordenada pelo nome do tipo e outra pelo seu uso.

Pode ser uma boa idéia visitar tipos largamente usados, o que nos ajudaria a entender melhor o programa - no caso, o tipo matriz é bastante usado, por isso clicamos sobre o seu nome, o que nos leva a figura 6-6. 


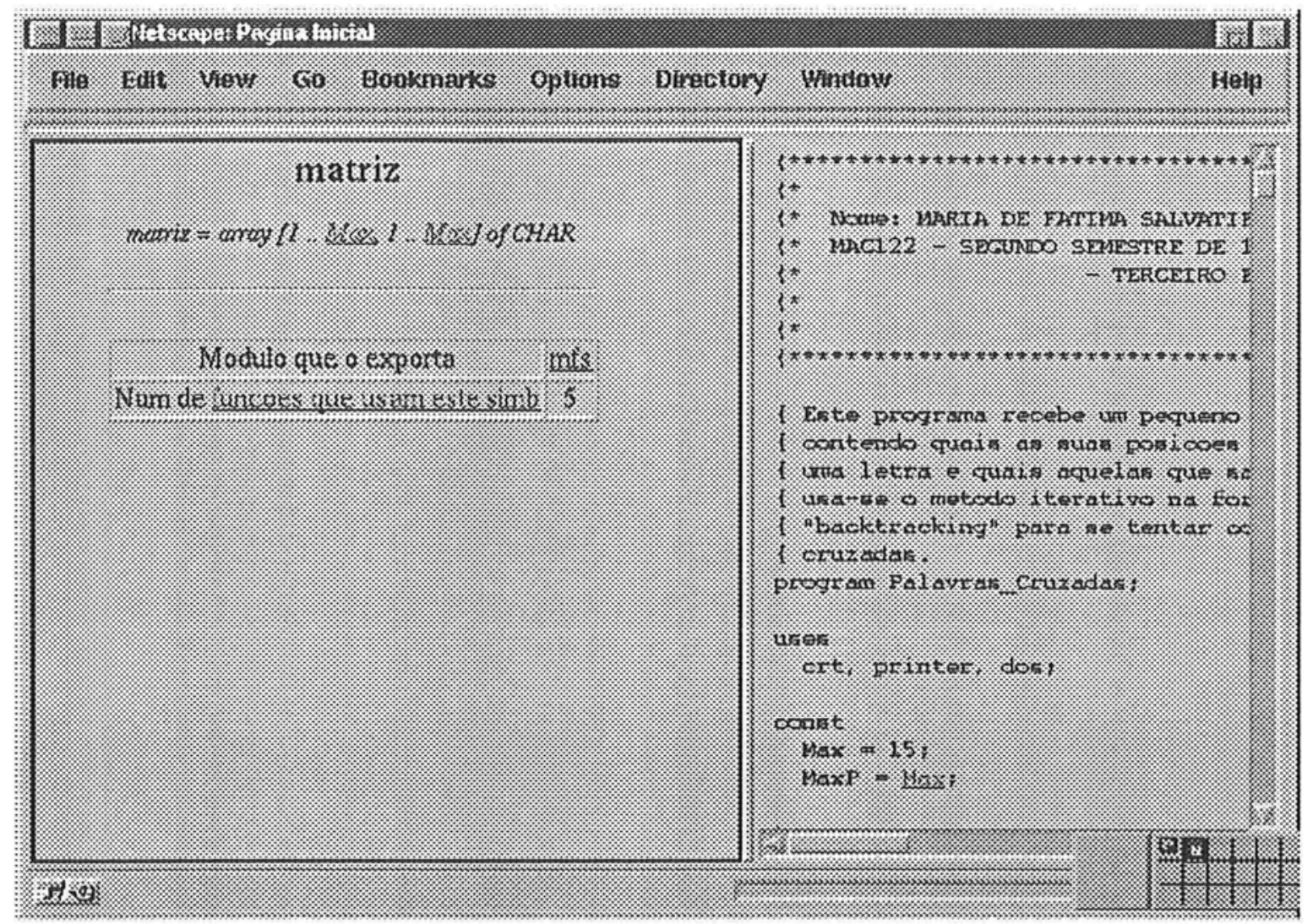

Figura 6-6: Quadro de detalhes apresenta informações sobre o tipo matriz.

Como podemos observar, no quadro de detalhes obtemos a declaração do símbolo (com hiperlinks para outros símbolos, se for o caso). Teríamos também o comentário descritivo associado ao símbolo, se ele tivesse sido recolhido pelo compilador - no exemplo, ou o autor não comentou o tipo ou, se o fez, não seguiu o estilo recomendado. ${ }^{1}$

Neste ponto da análise, o examinador humano já poderia detectar a péssima escolha de nomes feita pelo autor do programa - não só escolheu um nome genérico demais como também o atribuiu a um símbolo importante do programa. Além disso, há a falha em não tê-lo comentado de forma apropriada.

${ }^{1}$ Na verdade, o comentário não foi colocado. 


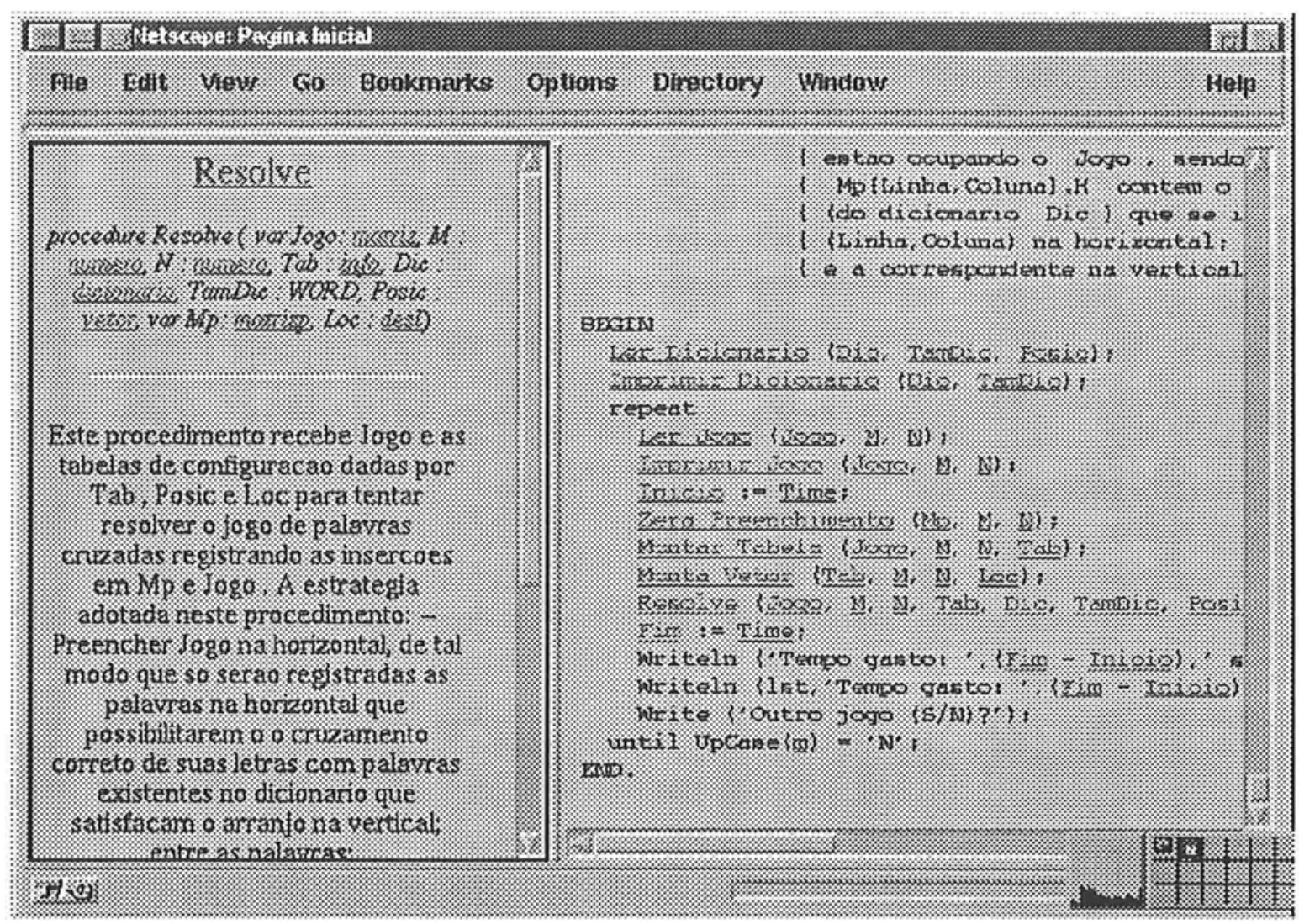

Figura 6-7: No quadro de detalhes há informações sobre a função Resolve

Voltando à figura 6-2, observamos que no texto do código, todos os símbolos não locais têm hiperlinks. Desejando o examinador obter mais detalhes sobre o procedimento Resolve, basta clicar sobre o seu identificador, onde surge a tela da figura 6-7.

No quadro de detalhes, carrega-se uma página contendo a declaração do procedimento, o seu comentário descritivo e algumas métricas que podem ser vistas fazendo-se o rolamento (figura 6-8). 


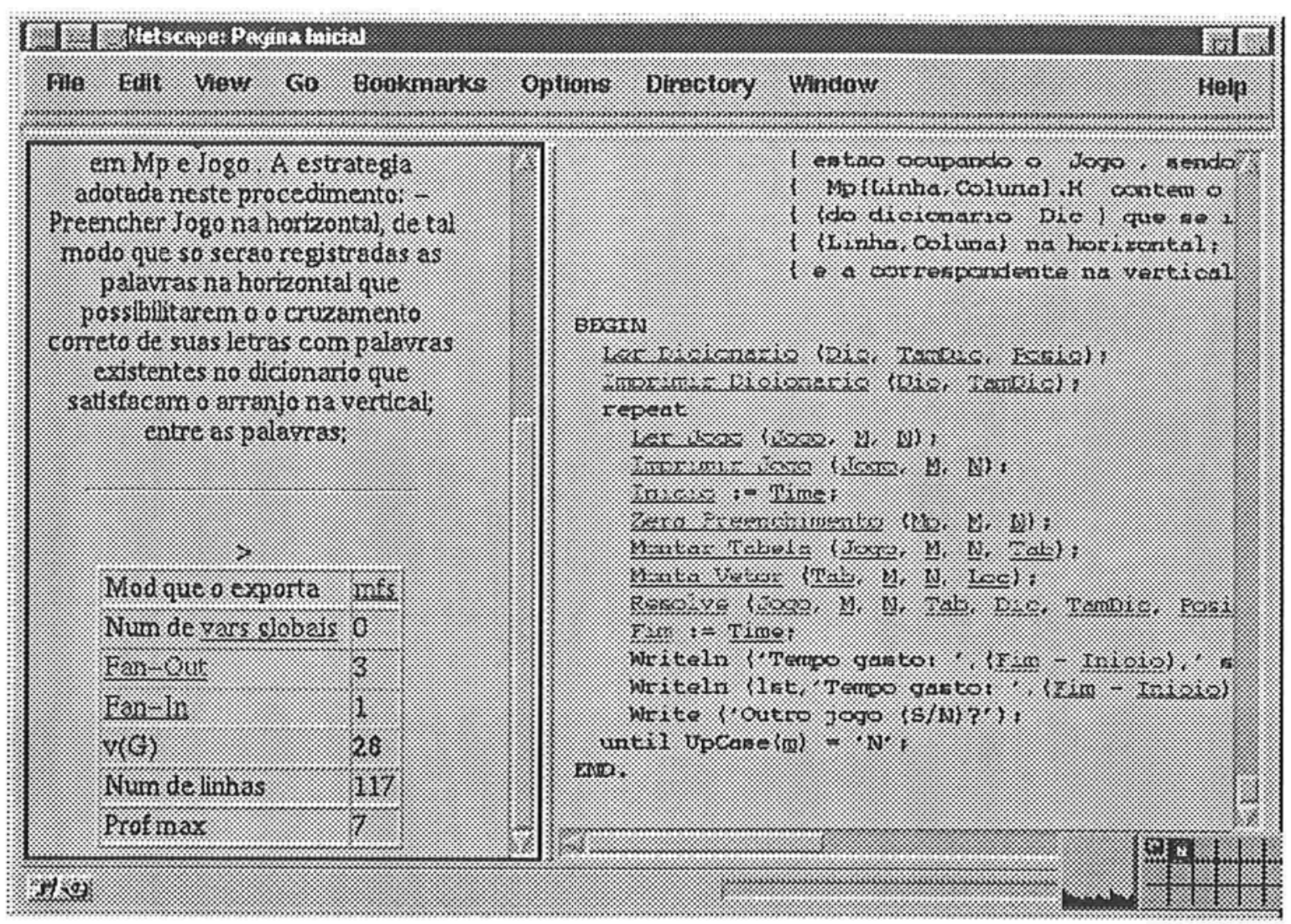

Figura 6-8: Tabela de métricas sobre o procedimento Resolve no quadro de detalhes.

No caso, podemos observar que o procedimento em questão apresenta um v(G) elevado, assim como a profundidade máxima, o que é um prenúncio que estamos diante de um procedimento mais complexo.

A partir dos links de Fan-Out e Fan-In, podemos obter as páginas contendo as listas de funções chamadas pelo procedimento Resolve, além daquelas que o chamam. Por exemplo, clicando-se em Fan-Out, chegamos a figura 6-9. 


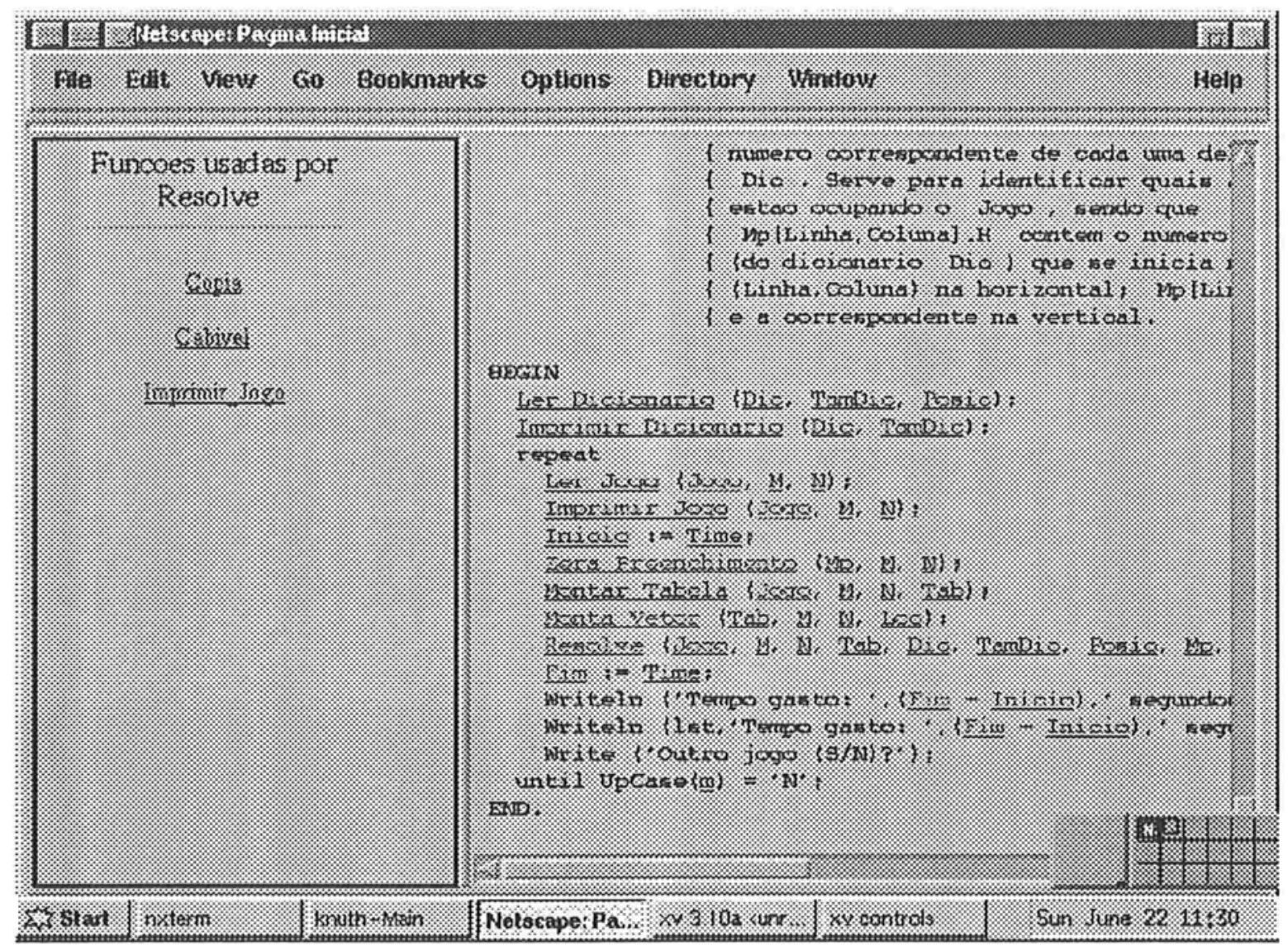

Figura 6-9: No quadro de detalhes lista-se as funções chamadas por Resolve

Chegamos então a informação de quais funções Resolve chama.

Voltando a figura 6-7, se tivéssemos clicado sobre o próprio nome Resolve, surgiria no quadro principal o código correspondente ao procedimento, como mostra a figura 6-10. 


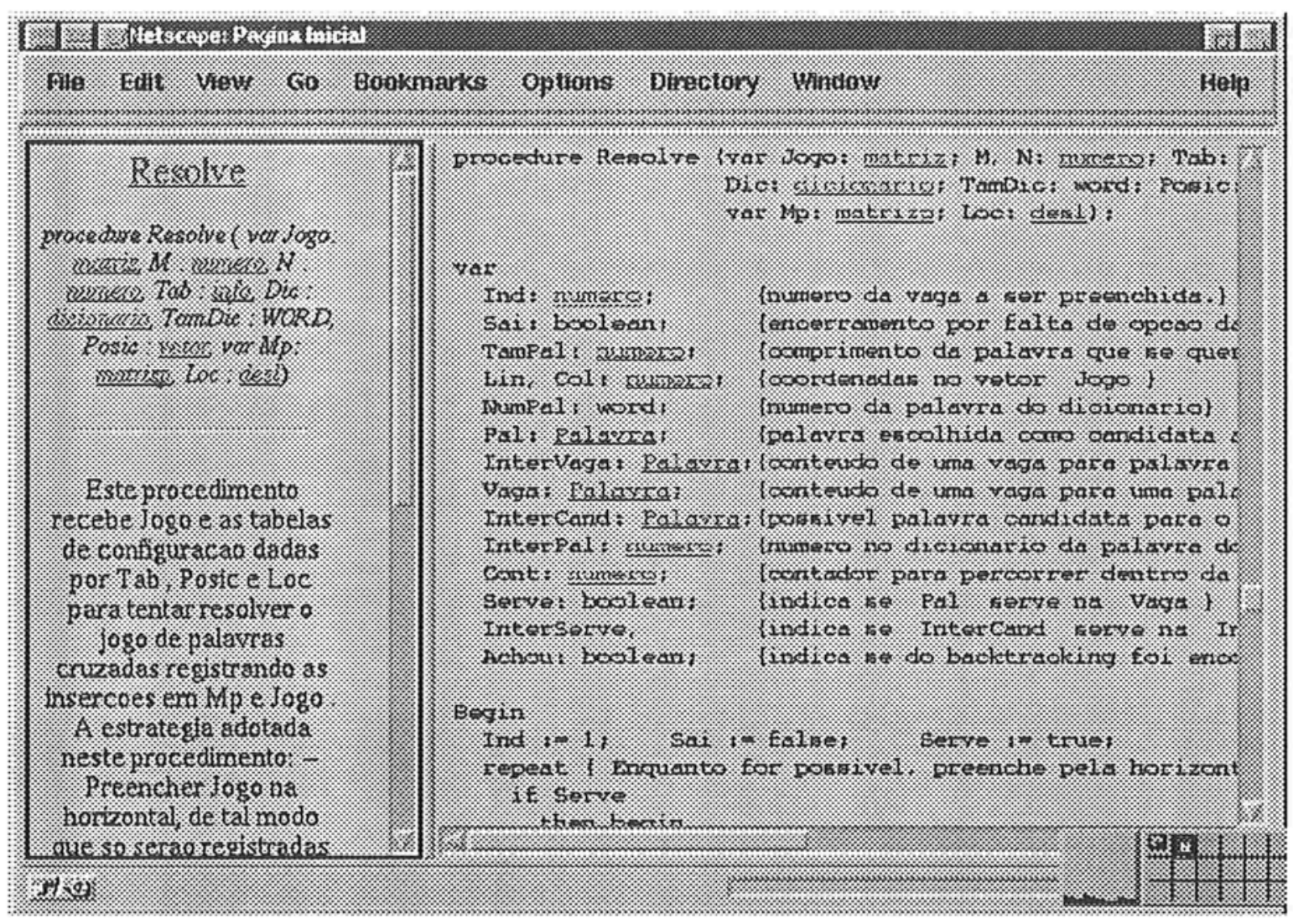

Figura 6-10: No quadro principal surge o código do procedimento Resolve.

Informações sobre as variáveis também estão disponíveis. Por exemplo, se a partir da figura 6-2 tivéssemos clicado na variável Jogo (ou em qualquer outra situação em que o link estivesse disponível), teria surgido a tela da figura 6-11. 


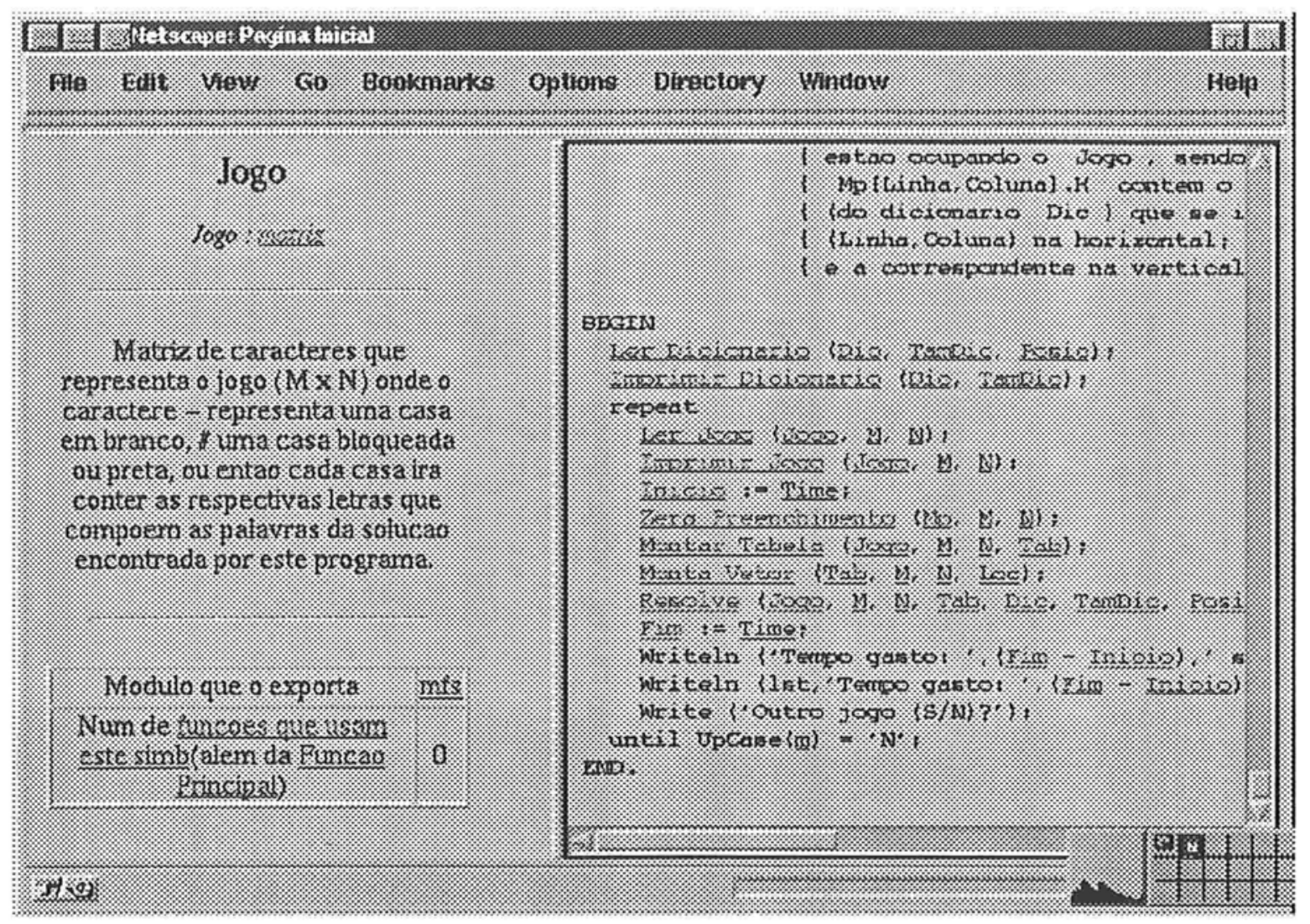

Figura 6-11: Informações sobre a variável Jogo.

Sobre variáveis, mostra-se a forma como o símbolo foi declarado, o seu comentário descritivo, o módulo que o exporta e o número de funções que o usam.

\subsection{Avaliação da Ferramenta}

Neste tópico, descrevemos uma experiência com o uso da ferramenta na avaliação de duas amostras de programas exercícios reais.

\subsubsection{Preliminares}

\section{Os Programas Exercício}

Inicialmente, tomamos dois enunciados de exercícios reais. Um deles, que chamaremos de enunciado 1, é o de resolução de palavras cruzadas, descrito na seção 6.1.1, exigido durante o curso de Princípios de Desenvolvimento de Algoritmos (segunda disciplina de programação ministrada nos cursos de Ciência da Computação e Matemática na USP), onde os alunos já têm um pouco mais de experiência e é dada uma ênfase maior no projeto de algoritmos e estruturas de dados. O outro exercício, que nos referiremos como tendo o enunciado 2, dizia resumidamente o seguinte: 
Este programa consiste em fazer uma variação do conhecido jogo de Batalha Naval. Considera-se um tabuleiro de $15 \times 15$ e as seguintes embarcações: quatro submarinos, três destroyers, dois cruzadores, um porta-avião e cinco hidroaviões.

O programa deve colocar as embarcações no tabuleiro aleatoriamente e em seguida, ler uma sequiencia de tiros. O jogo termina quando os tiros afundarem todas as embarcą̧̃oes.

O programa fornece como saída: o tabuleiro inicial com todas embarcações já dispostas, indicando água (com o número 0) e as embarcações (1 a 15); a seqüência de tiros e as mensagens correspondentes; o tabuleiro final, indicando todas as embarcações afundadas; o número total de tiros dados.

Trata-se de um exercício claramente mais simples que o anterior - mesmo porque, ele foi pedido durante o curso de Introdução à Computação, a primeira disciplina de programação ministrada nos cursos de graduação, em que os alunos são menos experientes.

\section{A Correção}

Escolhemos, aleatoriamente, 30 programas que implementavam o enunciado 1 e 20 do enunciado 2, e os corrigimos da forma tradicional (ou seja, manualmente, sem o auxilio de qualquer ferramenta específica), segundo os critérios descritos no modelo de qualidade da seção 1.1.2.

Em especial, procuramos responder às seguintes perguntas:

- Quais são as funções centrais do programa? Quais são as auxiliares?

- Quais são as principais estruturas de dados?

- O programa está bem dividido em funções?

- Há funções exageradamente/desnecessariamente dependentes de outras ou do contexto geral do programa?

- Há funções fazendo coisas demais?

- Os nomes estão bem escolhidos? Há inconsistências?

- Como está a qualidade dos comentários?

- O programa está legível?

\section{Avaliação com a Ferramenta}

Feito isso, fizemos a análise dos programas usando a ferramenta. No que se segue, fazemos uma discussão sobre os resultados. 


\subsubsection{Sobre o Uso das Métricas}

Na seção 5.2.2, listamos as métricas calculadas pela ferramenta - a nossa idéia seria calculá-las com a intenção de ter uma referência objetiva (no caso, números) que sirva como parâmetro de avaliação (principalmente para a modularidade e complexidade do programa).

\section{Métricas do Programa}

Dentre as métricas de complexidade calculadas, destacamos quatro: número de linhas, número ciclomático, fan-out estrutural e profundidade de aninhamento máximo. As duas primeiras foram calculadas para cada programa, cada módulo e cada função; as duas últimas, apenas para cada função.

Na página que mostra a lista de programas (figura 6-1), o número de linhas e v(G) podem ser comparados entre todos os programas de um mesmo enunciado.

Número de linhas do programa. Nos dois conjuntos de programas exercício analisados, verificamos que a maioria deles têm tamanho parecido - mais de $50 \%$ deles tinham o número de linhas não mais distantes do que o tamanho médio em $15 \%$.

Pelas nossas observações, os programas com o número de linhas muito afastado da média, tanto para baixo como para cima, em geral apresentaram problemas.

Os programas muito pequenos (com número de linhas $<=$ média - desvio padrão) apresentavam problemas de formatação do texto (o autor colocou mais de um comando por linha, por exemplo), funcionalidade (não faz tudo o que o enunciado pedia) ou mesmo de modularidade (programas com poucas funções tendem a ser menores que seus correspondentes com várias delas). Em um dos casos analisados nessa situação, o autor simplesmente declarou apenas 2 funções - uma de uso obrigatório, que o enunciado pedia, e a função principal.

Teoricamente, um programa com um número pequeno de linhas poderia ser mais simples e compacto do que os outros; entretanto, não detectamos nenhum caso desse tipo.

Os programas grandes (com número de linhas >= média + desvio padrão), por outro lado, muito geralmente apresentaram problemas com os algoritmos usados. Nos casos examinados, os programas tinham muito código repetido ou parecido (demonstrando deficiência por parte dos alunos na capacidade de abstrair e generalizar operações e conceitos), que poderia ser abreviado com o uso de funções ou melhor estruturação; estruturas de dados inadequadas para o problema (acarretando algoritmos mais complicados e extensos); ou, simplesmente, os algoritmos usados são pouco elaborados, sendo prolixos e redundantes (fazendo operações desnecessárias) e, portanto, mais extensos. Há ainda os casos em que se implementaram mais coisas do que foi exigido - por exemplo, uma interface mais sofisticada (nesta situação, o examinador já deveria esperar por um código maior se tivesse previamente executado o programa). 
Em relação aos programas cujos tamanhos estão próximos da média, não conseguimos detectar nenhuma relação do número de linhas com alguma característica qualitativa. Neste caso, a métrica se mostrou de pouco uso.

Número Ciclomático $(\mathbf{v}(\mathbf{G}))$ do programa. Observamos que o número ciclomático dos programas examinados é mais disperso do que o número de linhas.

Constatamos que a maioria dos programas com $\mathrm{v}(\mathrm{G})$ relativamente baixo realmente têm algoritmos estruturados de forma relativamente simples, embora não sejam os mais simples (há programas com $\mathrm{v}(\mathrm{G})$ mais alto e que apresentam algoritmos mais elegantes) nem sejam, necessariamente, os mais fáceis de serem entendidos $-v(G)$ não avalia a qualidade dos identificadores ou comentários nem a modularização, por exemplo.

Os programas com $\mathrm{v}(\mathrm{G})$ mais alto, em geral, são os mesmos que apresentam um grande número de linhas - o que explica o fato do $\mathrm{v}(\mathrm{G})$ também ser alto.

\section{Métricas das funções}

Problemas de Modularização. A ferramenta também pode fornecer uma tabela contendo as principais métricas de todas as funções não locais de um programa (figura 6-4).

Verificamos que a maioria das funções examinadas com um número de linhas maior do que 50 têm problemas de modularização (elas poderiam ser quebradas em mais funções, tornando o código mais modular e, portanto, mais claro e reutilizável).

Isto ocorre principalmente quando a função implementa um algoritmo mais elaborado e complexo (uma função contendo 500 linhas apenas com write's não tem, necessariamente, problemas de modularização). Dentre as formas de se tentar detectar essa "riqueza algorítmica", destacamos $\mathrm{v}(\mathrm{G})$ e a profundade máxima.

De fato, quase todas as funções com mais de 50 linhas e com v(G) maior do que 10 e/ou profundade máxima maior do que 3 tinham problemas de modularização.

Sendo assim, nos pareceu que o uso combinado dessas métricas é a melhor alternativa para se apontar as funções mal modularizadas.

Funções Chaves. Conforme o modelo de avaliação de programas que adotamos [seção 1.1.3], o examinador deve identificar quais são as funções chaves do programa.

Verificamos que elas são caracterizadas especialmente por um fan-out elevado (maior ou igual a 5) - em $84 \%$ dos programas examinados, suas funções chaves se incluiam nesse caso.

Como já era de esperar (em razão de suas pequenas dimensões), quase todos os programas examinados tinham uma ou, no máximo, duas funções que podiam ser consideradas chaves. 


\section{Métricas de Uso de Símbolos}

Principais Estruturas de Dados. Também fazia parte do nosso modelo de avaliação detectar quais seriam as principais estruturas de dados do programa.

Começar pelos tipos definidos usados no maior número de funções (figura 6-5) revelou ser uma boa estratégia para se chegar a elas - em $82 \%$ dos casos examinados, ela funcionou.

Infelizmente, houve casos em que as principais estruturas não foram declaradas como tipos (o que é uma prática de programação ruim, aliás).

\section{Sobre as Variáveis Globais}

Variáveis Globais em Programas Pascal. Na contagem de variáveis globais, chegamos a um pequeno problema: se adotarmos a definição de variável global descrita na seção 5.3.3 (ou seja, qualquer variável potencialmente visível pela função principal), a métrica número de variáveis globais fica bastante desviada de seu objetivo inicial.

O que ocorre é que, na linguagem Pascal, uma variável deve ser declarada global em 2 situações: quando se deseja usá-la para fazer a comunicação entre mais de uma função (caso que desejamos contabilizar) ou, simplesmente, quando se deseja usá-la na função principal (ainda que em mais lugar nenhum).

As variáveis globais do segundo caso só são globais por uma imposição da linguagem (a função principal não admite variáveis locais ${ }^{2}$ ) - dessa forma, consideramos injusto contabilizar uma variável global nessa situação junto com as variáveis que promovem comunicação entre funções (estas, sim, que contribuem para o aumento do acoplamento do programa [YC79]).

Assim, contaremos como locais as variáveis globais usadas unicamente na função principal.

Variáveis Globais e Modularidade. O primeiro fato evidente é que os programas de batalha naval apresentam, em média, bem mais variáveis globais que os das palavras cruzadas - provavelmente, porque no estágio em que os alunos se encontram, ainda não foram devidamente educados sobre os efeitos nocivos de variáveis globais sobre a estrutura de um programa.

Consideramos admissível que uma função use variáveis globais em situações onde esses objetos representem dados globais no problema sendo resolvido - em um editor de textos, por exemplo, é razoável que o texto seja acessível globalmente, já que o programa como um todo gira em redor dele. Pelas dimensões do tipo de programa considerado nessa dissertação, espera-se que o número de variáveis que se enquadrem nessa categoria seja pequeno.

\footnotetext{
${ }^{2}$ Mesmo porque a "função" principal não é de fato uma função - vide seção 5.3.3
} 
Funções que usam variáveis globais são facilmente detectáveis (figura 6-4). As que usam um número exagerado de variáveis globais certamente têm problemas de modularidade (no caso, forte dependência do contexto).

Quanto às que usam em menor número, com o auxílio do hipertexto, pode-se rapidamente chegar à uma lista dos nomes das variáveis usadas e checar se elas são globais ao problema.

\section{As Métricas de Comentários}

O que verificamos apos analisar os programas foi que, de um modo geral, os alunos infelizmente não sabem comentar o seu código - ou simplesmente não o comentam ou, quando o fazem, freqüentemente o fazem de um modo impreciso, vago e de pouca utilidade, especialmente quando o papel do símbolo/trecho de código comentado é mais complexo (exatamente o caso em que o comentário seria mais necessário).

Além disso, concluímos também que neste contexto que estamos estudando, programas pouco comentados dificilmente o são porque apresentam um código claro, como alguém poderia esperar - no estágio de aprendizado em que se encontram os alunos, onde mesmo fazer modularização é algo difícil, programas com código auto-documentado são muito raros.

Assim, pode-se ainda tentar fazer algumas interpretações das métricas de comentários: programas com um baixo índice de comentários (mais do que 10 linhas de código para cada uma de comentário) normalmente revela displicência por parte do programador no que concerne à documentação (sobretudo quando os índices de modularidade não são favoráveis).

Além disso, por ser altamente recomendável que para cada função seja feito um comentário no seu cabeçalho explicando o seu funcionamento, um índice baixo de comentários indica que provavelmente isso não foi feito (ou, se foi, fez-se de forma muito superficial ou as funções estão muito grandes, provalmente com problemas de modularidade).

Por outro lado, os programas com os índices mais altos (menos de 5 linhas de código para cada uma de comentário) revelam, no mínimo, uma preocupação do autor com a documentação do código (o que por si só, já é algo positivo, embora não seja suficiente). Verificamos também que os programas com maior índice, embora não estejam necessariamente bem comentados, são os que estão melhor nesse quesito.

\subsubsection{A Interface Hipertexto}

Durante a leitura do código texto, atividade indispensável na avaliação dos programas (seja com ou sem a ferramenta), freqüentemente se deseja obter dados sobre uma função ou variável global referenciada no meio de um trecho de código - a forma como foi declarada, o seu tipo, a sua funcionalidade etc.

O principal apelo da interface hipertexto é, sem dúvida, a facilidade e rapidez com que se pode conseguir obter as informações desejadas - simplesmente clica-se com o mouse sobre o símbolo em questão (ao contrário do que ocorre com o CIA, onde se necessita 
emitir queries). Além disso, ela permite uma rápida checagem das informações indicadas pela análise das métricas, garantindo uma maior segurança no processo de avaliação.

Essa característica da ferramenta se mostrou bastante útil e agradável, já que se perde menos tempo procurando informações e se pode concentrar mais na atividade de entender o código e o algoritmo que ele implementa.

O fato da tela estar dividida em dois quadros se mostrou uma boa idéia, posto que não há perda de contexto - ao mesmo tempo em que se exibe dados sobre um símbolo, pode-se ainda visualizar a situação em que ele foi usado dentro do texto.

\section{O Browser}

Importante observar que o AVASAP acaba herdando algumas das caracterísiticas do browser sendo utilizado. Por exemplo, pode-se tirar vantagem do uso de marcadores de página (bookmarks) para se guardar uma página que contenha informações relevantes; imprimir ou salvar em disco as informações exibidas; há um mecanismo de história, que permite saber ao examinador quais páginas (e em qual ordem) foram visitadas etc.

\section{Comentários Descritivos}

Apesar dos programas analisados não terem sido escritos com a ferramenta em mente (ou seja, os alunos não foram instruídos previamente a usar o estilo de comentário descrito na seção 5.3.5), o AVASAP conseguiu recuperar uma quantidade razoável dos comentários descritivos inseridos nos programas, o que reforça a tese do estilo adotado ser bastante natural e popular.

Observamos que nos casos em que a ferramenta captou os comentários, o processo de entendimento dos programas se tornou bem mais fácil e agradável - no caso, se o examinador clicasse em uma variável, não só se mostraria a sua declaração e dados estatísticos, mas também um comentário, em linguagem natural, do seu papel dentro da implementação.

Assim, sugerimos que a qualidade dos comentários descritivos (no que toca a sua precisão e clareza) seja avaliada de acordo com a sua eficácia em ajudar o entendimento do programa na leitura hipertexto, ou seja, quanto mais os comentários descritivos facilitarem a compreensão do programa com o AVASAP, melhor eles serão considerados.

\subsubsection{Detecção de Plágio}

Provavelmente devido ao pequeno tamanho da amostra, durante a nossa inspeção manual dos programas não detectamos nenhum caso de cola - da mesma forma, as métricas de $\mathrm{v}(\mathrm{G})$ não coincidiram em nenhum dos casos. Os programas que possuíam um $\mathrm{v}(\mathrm{G})$ próximo foram reexaminados, mas não foi identificado um caso de plágio.

De qualquer forma, propositalmente editamos alguns programas e simulamos uma situação de cola e, como era de se esperar, as métricas coincidiram.

Infelizmente, muito pouco pôde se concluir a respeito da eficácia de nosso algoritmo. 


\section{Capítulo 7}

\section{Conclusões}

Neste capítulo, relataremos algumas das conclusões a respeito do trabalho, além de algumas sugestões de continuidade para a pesquisa.

\subsection{Um Novo Modelo de Avaliação}

Na seção 1.1.3, descrevemos um modelo de avaliação de programas sem usar a ferramenta. Aqui, a partir do que foi discutido na seção 6.2, introduzimos um novo modelo, desta vez fazendo uso do AVASAP.

Como antigamente, todos os alunos devem fornecer para serem corrigidos um disquete, contendo o código executável mas também código fonte, e, opcionalmente, uma listagem impressa.

De início, o examinador deve executar a ferramenta sob todos os programas para que ela faça a análise e gere o banco de dados apropriado. Paralelamente, o examinador deve executar cada programa, como antes, para fazer a avaliação externa (o AVASAP só se preocupa com a avaliação interna [seção 1.2]).

Passa-se então à leitura dos códigos fonte dos programas.

Fazendo uma comparação entre os dados de todos os programas (figura 6-1), verifica-se:

- Programas com um número de linhas muito menor ou maior que a média (especialmente esses últimos) devem ser olhados com suspeita (deve-se checar, com o uso do hipertexto, se os algoritmos não estão muito prolixos e/ou código repetido, se há problemas de formatação ou modularização, falta de funcionalidade etc). O mesmo se pode dizer dos programas com um v(G) muito alto.

- Programas com um índice de comentários muito baixo (mais de 50 linhas de código para cada 1 de comentário) possivelmente têm problemas - deve-se checar. 
Para cada programa:

- Se o checador de inconsistências detectou falhas no texto, confirme-as e deixe o aluno avisado sobre isso.

- Funções maiores que 50 linhas, especialmente quando têm $v(G)>=10$ e profundidade máxima de aninhamento maior ou igual a 3 têm problemas de modularização - deve-se identificá-las e checar se isso é verdade.

- Para ajudar na leitura do programa, inicialmente é bom identificar quais são as estruturas de dados principais (e entendê-las); geralmente, elas correspondem aos tipos usados no maior número de funções.

- Passa-se então à fase de leitura do programa, que deve se iniciar na função principal. Para identificar quais são as funções chaves (as que implementam os algoritmos mais importantes), usa-se a heurística de que elas correspondem às que têm o maior fanout. Avalie os algoritmos e estruturas de dados.

- Deve-se também verificar se o uso de variáveis globais foi disciplinado. Pode-se usar as métricas de variáveis globais.

- Comentários descritivos podem ser avaliados conforme a ajuda que eles trazem ao entendimento do programa durante a inspeção hipertexto.

\subsection{Vale a Pena Usar a Ferramenta?}

Antes de responder à pergunta "Vale a pena usar a ferramenta ?", é melhor enumerar as vantagens e desvantagens no seu uso em relação ao método tradicional.

\section{Vantagens}

- A leitura do texto do programa se torna mais rápida e agradável, devido ao hipertexto.

- Pode-se tentar identificar com mais rapidez quais são as funções e estruturas de dados chaves da implementação.

- Se os comentários descritivos estiverem bem feitos, o entendimento do programa pode ser significativamente facilitado.

- Pode-se também tentar identificar as funções com problemas de modularização.

\section{Desvantagens}

- Não se pode fazer comentários diretamente sobre o programa - no papel, costuma-se comentar os erros/virtudes com uma caneta diretamente sobre o código; infelizmente, a ferramenta não dispõe de algo semelhante.

- O uso da ferramenta exige que se faça um processo de análise sobre o programa. Embora o custo disso não seja significativo, para programas muito pequenos (menores do que umas 150 linhas) talvez não compense o esforço. 
- A ferramenta encoraja o examinador a passar mais tempo ainda em frente a um computador, o que pode trazer problemas físicos e psicológicos [Stig95].

\section{Conclusão}

Consideramos o uso válido, apesar dos problemas.

\subsection{Trabalhos Futuros}

Sugerimos as seguintes melhorias na ferramenta, que poderiam ser alvos de trabalhos futuros:

- Possibilidade da ferramenta analisar outras linguagens, especialmente C.

- Permitir que o AVASAP possa registrar comentários do examinador sobre o programa (talvez fazendo uso de formulários (forms) da linguagem HTML).

- Inserir a ferramenta dentro de um mecanismo em que se permita que os programas possam ser submetidos para avaliação por meio de uma rede via correio eletrônico e eles fossem automaticamente compilados pelo AVASAP e colocados a disposição do examinador. A correção do programa também poderia ser enviada ao aluno pelo mesmo meio.

- Data mining para inferência de métricas e características.

- Uso na avaliação e inspeção de código fornecido a empresas por terceiros.

- Uso na reengenharia de programas. 


\section{Bibliografia}

[AM71] E. Ashcroft, Z. Manna, "The Translation of 'goto' Programs to 'while' programs", Proc of the 1971 IFIP Congress, vol 1, pp 250-255.

[Arn93] R. S. Arnold, "A Road Map Guide to Software Reengineering Technology”, Software Reengineering, IEEE Computer Society, 1993, pp 3-22.

[Big89] T. J. Biggerstaff, "Design Recovery for Maintenance and Reuse", Computer, Jul 89, pp 36-49.

[BJ77] J. C. Browne, D. B. Johnson, "FAST: A Second Generation Program Analysis System", Proc. Second Int. Conf. Software Eng., 1977, pp. 142-148.

[BL91] P. T. Breuer, K. Lano, "Creating Specifications From Code: Reverse Engineering Techniques", J. Software Maintenance: Research and Practice, vol 3, 1991, pp 145-162.

[BR87] T. J. Biggerstaff, C. Ricter, "Reusability Framework, Assesment, and Directions”, IEEE Software, Mar 87, pp 41-49.

[CC90] E. J. Chikofsky, J. H. Cross II, "Reverse Engineering and Design Recovery: A Taxonomy", IEEE Software, vol 7, no 1, Jan 90, pp 13-17.

[CHT+90] S. Chen, et al., "A Model for Assembly Program Maintenance”, Journal of Software Maintenance: Research and Practice, John Wiley and Sons, 1990.

[CNR90] Y. Chen, M. Y. Nishimoto, C.V. Ramamoorthy, "The C Information Abstraction System", IEEE Trans. On Software Engineering, vol 16, n.3, Mar 1990, pp 325-334

[Con87] J. Conklin, “A Survey of Hypertext”, Computer, vol 20, no 9, Set 87, pp 17-41.

[Coul83] N. S. Coulter, "Software Science and Cognitive Psychology", IEEE Transactions on Software Engineering, 9(2), Mar 83, pp 166-171.

[DNG89] W. C. Dietrich Jr, L. R. Nackman, F. Gracer, "Saving a Legacy with Objects", Proc OOPSLA, ACM, 1989, pp 77-83.

[Don92] C. Donelly, Bison: The Yacc Compatible Parser Generator, Free Software Foundation Pub, 1992.

[Dow96] K. Kowd, Getting Connected, O’Reilly \& Associates, 1996.

[GNV88] E. R. Gansner, S. C. North, K. P. Vo, "DAG - A Program That Draws Directed Graphs", Software Practice and Experience, 18(11), Nov 1988. 
[Gra94] R. B. Grady, "Successfully Applying Software Metrics", Computer, Sep 1994, pp. 18-25.

[GUR89] “Application Reengineering", Guide Pub. GPP-208, Guide Int'l Corp., Chicago, 1989.

[Hal77] M. H. Halstead, Elements of Software Science, Elsevier Computer Science Library, 1977.

[HB85] D. H. Hutchens, V. R. Basili, "System Structure Analysis: Clustering with Data Bindings", IEEE Trans on Software Eng, 11(8), pp 749-757, Aug 1985.

[HF81] P. G. Hammer, G. D. Frewin, "M. H. Halstead's Software Science - a Critical Examination", Proc of the $6^{\text {th }}$ Intl Conf on SE, IEEE CS Press, New York, 1981.

[HK81] S. Henry, D. Kafura, "Software Structure Metrics Based on Information Flow", IEEE Transactions on Software Engineering, 7(5), pp 510-518, 1981.

[HK84] S. Henry, D. Kafura, "The Evaluation of Software System's Structure Using Quantitative Software Metrics", Software Practice and Experience, 14(6), pp 561-573, 1984.

[HKH81] S. Henry, D. Kafura, K. Harris, "On The Relationship Among the 3 Software Metrics", Proc of the 1981 ACM Workshop, Mar 81.

[How94] J. W. Howatt, "On Criteria for Grading Student Programs", SIGCSE Bulletin 26(3), 1994, pp 3-7.

[HPL+90] P. A. Hausler, et al., "Using Function Abstraction to Understand Program Behavior”, IEEE Software, Jan 90, pp 55-63.

[Hug96] “Mini SQL, A Lightweight Database Engine", Hughes Technologies Pty Ltd, Australia, 1996.

[Jac91] I. Jacobson, "Re-engineering of Old Systems to an Object-Oriented Architecture", Proc OOPSLA, ACM, 1991, pp 340-350.

[JS85] W. L. Johnson, E. Soloway, "Proust: Knowledge-Based Program Understanding", IEEE Transactions on Software Engineering, vol SE11, n.3, Mar 1995.

[JWT/4] K. Jensen, N. Wirth, Pascal User Manual and Report, Springer Verlag, New York, 1974.

[KC85] D. Kafura, J. Canning, "A Validation of Software Metrics and Two Resources", Proc of the $8^{\text {th }}$ Intl Conf on Software Eng, IEEE CS Press, New York, pp 378-385, 1985.

[Kitch86] B. Kitchenham, "Metrics in Practice, Software Reliability", ed. A. Bendell \& P. Mellor, Infotech State of the Art Report, 14:2, 1986. 
[Kitch90] B. Kitchenham, "Software Development Metrics and Models", Software Reliability Handbook (P. Rook, ed), Amisterdan:Elsevier, pp 441-486.

[Kitch90b] B. Kitchenham, "Measuring Software Development", Software Reliability Handbook (P. Rook, ed), Amsterdan:Elsevier, pp 303-331.

[KP74] B. Kernighan, J. Plauger, The Elements of Programming Style, McGrawHill, 1974.

[KPL90] B. Kitchenham, L. M. Pickard, S. J. Linkman, "An Evaluation of Some Design Metrics", IEE/BCS Software Engineering Journal, 5(1), pp 5058, 1990.

[Lea95] R. J. Leach, "Using Metrics to Evaluate Student Programs", SIGCSE Bulletin 27(2), 1995.

[Lev95] S. P. Levy, "Computer Language Usage in CS1: Survey Results", SIGCSE Bulletin, vol 27, n.3, pp 21-26.

[LHG+88] L. D. Landis, et al., "Documentation in a Software Maintenance Environment", Proc. Conference on Software Maintenance, 1988, pp 66-73.

[Lin84] "Implementing Relational Views of Programs", Proc. ACM SIGSOFT/SIGPLAN Software Eng Symp. Practical Software Development Environment, May 1984.

[MB89] T. J. McCabe, C. W. Butler, "Design Complexity Measurement and Testing", Communications of the ACM, 32(12), Dec 89, pp 1415-1424.

[MMNB83] R. J. Miara, J. A. Musselman, J. A. Navarro, B. Shneiderman, "Program Indentation and Comprehensibility", Communications of the ACM, 26(11), 1983, pp 861-867.

[McCab76] T. J. McCabe, "A Complexity Measure", IEEE Transactions on Software Engineering, 2(4), dec 76, pp 308 - 320.

[MK96] C. Musciano, B. Kennedy, HTML: The Definitive Guide, O'Reilly \& Associates, 1996.

[Nick94] J. V. Nickerson, "Visual Programming", PhD Diss, New York University, 1994.

[OC90] P. W. Oman, C. R. Cook, "The Book Paradigm for Improved Maintenance", IEEE Software, Jan 90, pp 39-45.

[Ov80] E. I. Oviedo, "Control Flow, Data Flow and Program Complexity", IEEE COMSPAC, Nov 80, pp 146-152.

[PCM91] S. A. Pereira, M. F. Camêlo, J. A. B. Moura, "Validação de Métricas Para Uso em Modelos Gerenciais de Desenvolvimento de Software nas Linguagens Pascal e C", Anais do V SBES, 1991, p.135-147. 
[Pee81] D. A. Peercy, "A Software Maintainability Evaluation Methodology", IEEE Trans. on Software Engineering, vol SE-7, no 4, Jul 81, pp 343352.

[Pre94] R. S. Pressman, Software Engineering, McGraw Hill, 1994.

[Pri93] R. Prieto-Díaz, "Status Report: Software Reusability", IEEE Software, Mai 93, pp 61-66.

[PRK93] J. Peek, T. O’Reilly, M. Loukides, Unix Power Tools, $1^{\text {st }}$ Ed., O’Reilly \& Associates, 1993.

[Rek85] M. G. Rekoff Jr, "On Reverse Engineering”, IEEE Transactions on Systems, Man and Cybernetics, Mar-Abr 85, pp 244-252.

[RW90] C. Rich, L. Wills, "Recognizing a Program's Design: A Graph-Parsing Approach", IEEE Software, Jan 1990, pp 82-89.

[SCD83] V. Y. Shen, S. Conte, H. Dunsmore, "Software Science Revisited: A Critical Analsysis of the Theory and Its Empirical Support", IEEE Transactions on Software Engineering, 9(2), Mar 83, pp 155-164.

[Sch91] R. W. Schwanke, "An Intelligent Tool for Re-engineering Software Modularity”, Proc. 13 ${ }^{\text {th }}$ Int'l. Conf on Software Eng., IEEE Computer Society Press, May 1991, pp 83-92.

[Schn79] N. F. Schneidewind, "An Experiment in Software Error Data Collection and Analysis", IEEE Transactions on Software Engineering, 5(3), May 79.

[Shep88] M. Shepherd, "A Critique of Cyclomatic Complexity as a Software Metric", IEE/BCS Software Engineering Journal, 3(2), pp 30-36, 1988.

[Shep90] M. Shepherd, "Design Metrics: An Empirical Anaysis", IEE/BCS Software Engineering Journal, 5(1), pp 3-10, 1990.

[SHM86] W. V. Setser, I. S. Homem de Melo, A Construção de um Compilador, 3a edição, Editora Campus, 1986.

[Som96] I. Sommerville, Software Engineering, $5^{\text {th }}$ ed, Addison-Wesley Publishing Company, 1996.

[Stig95] J. Stigliani, The Computer User's Survival Guide, $1^{\text {st }}$ ed, O'Reilly \& Associates, 1995.

[SWKH76] M. Stonebraker, E. Wong, R. Kreps, G. Held, "The Design and Implementation of Ingres", ACM Trans. Database Systems, vol 1(3), pp 189-222, 1976.

[TAR+95] A. Tsukumo, A. L. P. Andrade, C. M. Rêgo et alli, "Avaliação de Produto de Software: Algumas Questões Relevantes e a ISO/IEC 9126”, CTI, Campinas, 1995. 
[TZ81] D. A. Troy, S. H. Zweben, "Measuring the Quality of Software Designs", J. Systems and Software, (2), pp 113-120, 1981.

[Wal79] T. J. Walsh, "Software Reliability Study Using a Complexity Measure", Proc of the National Computer Conf, New York, 1979.

[Wha90] G. Whale, "Identification of Program Similarity in Large Populations", The Computer Journal, 33(2), pp 140-146, 1990.

[Wir76] N. Wirth, Algorithms + Data Structures = Programs, Prentice-Hall, New York, 1976.

[WK95] M. Welsh, L. Kaufman, Running Linux, $1^{\text {st }}$ edition, O'Reilly \& Associates, 1995.

[YC79] E. Yourdon, L. Constantine, Structured Design, Prentice Hall, 1979.

[YK79] G. E. De Young, G. R. Kampen, "Program Factors as Predictors of Program Readability", Proc of COMPSAC, IEEE CS Press, New York, pp 668-673, 1979.

[You89] E. Yourdon, "RE-3, part 1: Re-engineering, Reestructing and Reverse Engineering", American Programmer, vol 2, no 4, abr 89, pp 3-10. 